\title{
Employment and the Collateral Channel of Monetary Policy
}

\author{
Saleem Bahaj Angus Foulis Gabor Pinter Paolo Surico*
}

16th December 2018

\begin{abstract}
This paper uses a detailed firm-level dataset to show that monetary policy propagates via asset prices through corporate debt collateralised on real estate. Our research design exploits the fact that many small and medium sized firms use the homes of the firm's directors as a key source of collateral, and directors' homes are typically not in the same region as their firm. This spatial separation of firms and firms' collateral allows us to separate the propagation of monetary policy via fluctuations in collateral values from that via demand channels. We find that younger and more levered firms who have collateral values that are particularly sensitive to monetary policy show the largest employment response to monetary policy. The collateral channel explains a sizeable share of the aggregate employment response.
\end{abstract}

${ }^{*}$ We are grateful for helpful comments to Andy Blake, Giancarlo Corsetti, V.V. Chari, Simon Gilchrist, Erik Hurst, Sebnem Kalemli-Ozcan, Greg Kaplan, Fred Malherbe, Silvia Miranda-Agripinno, Michael McMahon, Ricardo Reis, Adam Szeidl, Harald Uhlig, Gianluca Violante and Jasmine Xiao. We also thank discussants and seminar participants at the 2018 CEBRA workshop, the 2018 NBER Summer Institute, the Barcelona Graduate School of Economics, the 2018 AEA Meetings, the Sciences Po Workshop on Empirical Monetary Economics, the 2017 RES Conference, the CCBS Chief Economists' Workshop, and the 2017 CCBS-MacCalm Macro-finance Workshop. Bahaj: saleem.bahaj@bankofengland.co.uk; Foulis: angus.foulis@bankofengland.co.uk; Pinter: gabor.pinter@bankofengland.co.uk, Bank of England and Centre for Macroeconomics. Surico: psurico@london.edu, London Business School and CEPR. Surico gratefully acknowledge financial support from the European Research Council (Consolidator Grant Agreement No. 647049). This paper contains the views of the authors and not necessarily those of the Bank of England, the MPC, the FPC or the PRA. 


\section{Introduction}

Conditions in the labour market are a lodestar for assessing the appropriateness of monetary policy. While empirical evidence based on macroeconomic time-series shows that monetary policy can influence aggregate employment (Christiano, Eichenbaum, and Evans, 1999), a more recent literature has emphasised that there is substantial heterogeneity in firm-level employment dynamics that is masked by aggregate data (Davis, Haltiwanger, and Schuh 1996; Fort, Haltiwanger, Jarmin, and Miranda 2013; Dinlersoz, Kalemli-Ozcan, Hyatt, and Penciakova 2018). Yet, the contribution of monetary policy to these heterogenous dynamics and the implications for the transmission mechanism has been less studied. At same time, a separate strand of literature has documented that, at the firm-level, fluctuations in asset and collateral values interact with financial frictions to meaningfully influence firm behaviour and alter the dynamic response of firms to aggregate shocks (Chaney, Sraer, and Thesmar, 2012; Adelino, Schoar, and Severino, 2015; Bahaj, Foulis, and Pinter, 2018). It is well known that monetary policy can influence asset prices (Bernanke and Kuttner, 2005). However, despite the central role asset prices play in key theories (Kiyotaki and Moore, 1997; Bernanke, Gertler, and Gilchrist, 1999), how this interacts with firm-level financial conditions to determine the response to monetary policy has received little attention in the empirical literature.

The goal of this paper is to bring these disparate strands of literature together. Using a variety of different micro-datasets, we document three facts. First, firm-level employment responds heterogeneously to an identified monetary policy shock, with firms who are younger and more levered being particularly sensitive. Second, we present survey evidence to show that these types of firms are particularly reliant on asset based borrowing - and in particular real estate collateral - to finance their activities. Third, we show that monetary policy has a large and spatially heterogeneous effect on the value of this form of collateral. In light of these facts, our key result is that the response of younger, more levered firms is much stronger when collateral values are also sensitive to monetary policy (the same is not true for older, less levered firms that are less reliant on collateralised borrowing). This finding is mirrored by the response of corporate debt to monetary policy shocks.

We argue that these findings are consistent with monetary policy transmitting via asset prices through collateral constraints on specific firms. Furthermore, this interaction between collateral values, monetary policy and firm-level characteristics is of quantitative importance. It is large enough both to explain most of the observed firm level heterogeneity in response to monetary shocks and to explain a sizeable share of the aggregate employment response to monetary policy.

Our firm-level dataset covers the period 1997-2017 and contains annual income statement and balance sheet information on a sample of UK firms, dominated by small and medium 
sized enterprises (SMEs), as documented in Bahaj, Foulis, and Pinter (2018). To identify monetary policy shocks, we use high-frequency variation in the price of UK interest rate futures contracts within a 30-minute window of monetary policy announcements (Gurkaynak, Sack, and Swanson, 2005; Gertler and Karadi, 2015). Following a contractionary monetary policy shock that raises the interest rate by $25 \mathrm{bp}$ on average over the firm's accounting year, the average firm cuts employment by about $1 \%$ two years after the shock hits. Following the literature, we explore heterogeneity along three dimensions: firm size (Gertler and Gilchrist, 1994; Crouzet and Mehrotra, 2017), firm age (Cloyne, Ferreira, Froemel, and Surico, 2018) and firm leverage (Ottonello and Winberry, 2018; Jeenas, 2018). We find that the sensitivity of firms to monetary policy is near monotonically decreasing in age and exhibits a discontinuity of increased sensitivity for more-levered firms. However, the sensitivity is non-monotonic in size and, among the SMEs (with less than 250 employees) that dominate our sample, size seems like a less relevant characteristic. Taken together, we find that the employment response of younger and more levered firms is larger and more significant when compared to any other group.

Using a survey of five major UK banks, we show that younger, more-levered firms are reliant on asset based finance. In particular, as noted by Bahaj, Foulis, and Pinter (2018), the housing wealth owned by firm directors represents an important source of collateral for the corporate sector. Approximately two thirds of loans to younger, more levered firms are guaranteed by their directors' assets. This is crucial as it provides an empirical strategy allows us to separate fluctuations in the collateral values that firms face from other mechanisms by which monetary policy affects firm activity, such as via affecting demand for firms' goods and services. Our dataset contains detailed information on firm directors and we are able to match each firm in our dataset to the regions where the firm's directors live. Approximately $60 \%$ of directors live in a different region from their firm's. We then estimate how sensitive each region's house price index is to exogenous variations in monetary policy and compute the average across directors to measure the sensitivity of real estate collateral to monetary policy. This means we can compare two firms who operate in the same region (and industry) and exhibit similar characteristics, but differ along one key dimension: how sensitive the house value of their directors are to a monetary policy shock.

Further splitting firms along the dimension of collateral value sensitivity, we find the largest employment response is generated by younger, more-levered firms whose real estate collateral values are most sensitive to monetary policy shocks. In contrast, for older, less levered firms the sensitivity of collateral values does not alter the monetary policy response. Consistent with the idea that we are detecting the relevance of monetary policy for relaxing collateral constraints, we also consider the effect on firm debt, and find the same pattern of responses. Taking this idea further, in the next section, we consider a stylised model of firm hiring under short term financial constraints and show that it predicts a pattern of heterogeneous responses in line with 
our empirical exercises.

It is well known that asset values affect demand and through that employment (Mian and Sufi 2011, Mian and Sufi 2014). Key for our results is to disentangle fluctuations in collateral values from changes in local demand faced by the firm. Our strategy based on using director real estate (as directors can live in different regions from their firm), allows us to include region-time fixed effects, thereby controlling for the linear effect of local demand on the firms' behaviour. However, firms may have heterogeneous sensitivity to local demand's response to monetary policy. This may also explain our findings. For example, directors who live close to their firm would have similar house price sensitivities to the region where their firm is located. This, in turn, could generate correlation between the firm's local demand sensitivity and the director's house price sensitivity. We address this in a number of ways.

First, we alter our research design by considering only those firms whose directors live more than 30 miles away from the firm's headquarters, thereby preventing geographical spillovers of local demand in any particular region. Second, we focus only on those firms that should be insensitive to demand conditions in the local region, i.e. those operating in the tradeable goods sector (Mian and Sufi, 2014). Our results are very similar to the baseline. Third, note also that, directors who only have a managerial role have much less incentive than owners to pledge personal assets in order to support their firm. Hence if the collateral channels lies behind the heterogeneous response of monetary policy shocks, we would expect to see an effect only based on the house price sensitivity of those directors who are also shareholders in their firm. We therefore alter our research design by exploiting this variation between shareholder and non-shareholder directors, and find that the heterogeneity is driven entirely by directors who are also shareholders in their firms.

Related Literature Our paper contributes to the empirical monetary economics literature that has studied the role of financing constraints in explaining the monetary policy transmission at the firm-level (Gertler and Gilchrist 1994; Kudlyak and Sanchez 2017; Ottonello and Winberry 2018; Jeenas 2018; Cloyne, Ferreira, Froemel, and Surico 2018 amongst others). Our work differs from these papers in three important ways. First, we use a near-representative sample, covering both the listed and non-listed sectors across all industries in the economy, that is dominated by SMEs - firms that are most likely to be financially constrained. Most existing firm-level studies on the monetary policy transmission use datasets (e.g. Compustat, Worldscope) that contain information only on large publicly listed firms, thereby limiting their focus on a small segment of the size and age distribution of firms. Second, we focus primarily on the effects of monetary policy on employment (rather than on investment as done by the recent literature), as SMEs explain the majority of employment dynamics in the aggregate. Third, we explore multiple proxies for financial constraints (e.g. firm age, size, leverage, credit score, 
price sensitivity of firm collateral) and use multidimensional sorting along these measures to detect not only the presence of, but also possible shifts in, firms' financial constraints.

Our paper is also related to the theoretical literature on the interactions between the macroeconomy and financial markets (Kiyotaki and Moore, 1997; Bernanke, Gertler, and Gilchrist, 1999). Recent quantitative models (Jermann and Quadrini, 2012; Liu, Wang, and Zha, 2013; Christiano, Motto, and Rostagno, 2014; Linde, Smets, and Wouters, 2016) confirmed the importance of financial frictions in explaining business cycle fluctuations. Our firm-level evidence corroborates the importance of financial frictions in the monetary policy transmission mechanism and supports a body of theoretical work that has explored how these frictions shape optimal monetary policy. (Faia and Monacelli, 2007; Gertler, Gilchrist, and Natalucci, 2007; Kolasa and Lombardo, 2014; Curdia and Woodford, 2016).

Our work is also connected to the empirical literature on firm dynamics which studies the sensitivity of various groups of firms to business cycle fluctuations (Davis, Haltiwanger, and Schuh, 1996; Fort, Haltiwanger, Jarmin, and Miranda, 2013; Crouzet and Mehrotra, 2017; Decker, Haltiwanger, Jarmin, and Miranda, 2018). Compared to these papers, our contribution is to study the sensitivity of firms conditional on a monetary policy shock and to propose a research design which can uncover how much of this sensitivity is driven by balance sheet constraints. Moreover, we draw on the recent literature which emphasises that shocks to real estate prices affect firm activity by relaxing financial constraints (Gan, 2007; Chaney, Sraer, and Thesmar, 2012; Catherine, Chaney, Huang, Sraer, and Thesmar, 2018; Bahaj, Foulis, and Pinter, 2018). We use insights from this literature to identify the collateral channel of monetary policy in the present paper. Finally, our results are linked to the recent work on firm finance over the business cycle and the response to credit market disruptions (Chodorow-Reich, 2014; Liam and Ma, 2018; Begenau and Salomao, 2018; Drechsel, 2018). Our paper connects firm finance directly with the monetary policy transmission mechanism.

Structure of the paper The paper is organised as follows: Section 2 presents a simple theoretical framework which guides our research design; Section 3 explains our data sources; Section 4 describes our empirical strategy; Section 5 presents the main results; Section 6 provides further explorations of the mechanism, and Section 7 concludes. Appendix A-H contains further details on the data and a comprehensive list of sensitivity analyses.

\section{Theoretical Motivation}

In this section, we draw on the existing literature and informally lay out the theoretical framework for our empirical analysis. Appendix C provides a formal setting for our arguments by considering a firm that chooses how much labour to hire subject to the need to obtain external 
finance to prepay wages. ${ }^{1}$

An optimising firm will equate the marginal benefit of hiring a worker with the marginal cost of the funds needed to pay the worker (see Figure 1). Monetary policy will shift this optimal choice of employment in a number ways. It will shift the demand for the firm's goods as well as the price of factor inputs thereby altering the marginal benefit of hiring a worker. In general, at least in the short-run, the marginal benefit is decreasing in the level of the interest rate, both due to lower aggregate demand for the firm's goods and services, and second, potentially due to a cost channel if wages are paid in advance of production (Christiano, Eichenbaum, and Evans, 2005). In Figure 1, this is illustrated by a rightward shift in the downward sloping red curve, "MB", in response to an expansionary monetary policy shock. ${ }^{23}$

A number of papers in the macroeconomic literature have focused on the role of firm-level financial constraints in governing the response to aggregate shocks including monetary policy surprises (Bernanke, Gertler, and Gilchrist, 1999; Ippolito, Ozdagli, and Perez-Orive, 2017; Ottonello and Winberry, 2018). Financial constraints in Figure 1 are represented by the convex, upward-sloping blue, "MC", curve. This captures the marginal cost of funds, beyond the risk free interest rate, required to hire additional workers, which would arise in many standard models of financial constraints. How monetary policy affects the equilibrium employment at the intersection of these two curves is ambiguous. There are two competing mechanisms.

First, ceteribus paribus, a firm facing financial constraints should be less sensitive to shocks to the demand for external finance (see Farre-Mensa and Ljungqvist 2016 and Ottonello and Winberry 2018). The intuition being that constrained firms face a steeper (or potentially vertical) supply curve for funding, and hence any given shift in demand results in a smaller change in quantities. This is illustrated by comparing a constrained firm who faces a steeper MC curve (shown by the light blue curve in Figure 1) to an unconstrained firm for whom the marginal cost curve is relatively flat (shown by the dark blue curve in Figure 1). The shift in the MB curve in response to an interest rate shock results in a smaller increase in employment for constrained firms.

Second, key macroeconomic theories have emphasised that monetary policy alters the degree to which firms are financially constrained. Expansionary monetary policy shocks could shift the MC curve rightward and flatten it. This is the heart of the financial accelerator

\footnotetext{
${ }^{1}$ Our reasoning is not reliant on prepaid wages, although our empirical results suggest this mechanism is relevant. If the firm needs to obtain external finance to invest in physical capital and labour is a complement to capital in production then we would obtain similar predictions.

${ }^{2}$ The MB curve is downward sloping due to a production function with decreasing returns to scale in labour.

${ }^{3}$ The sensitivity of firms to these channels, i.e. how much the red curve in Figure 1 shifts, may be heterogenous. Indeed Gorodnichenko and Weber (2016) show that equity value of firms within industries with sticky prices are particularly sensitive to monetary policy shocks. However, to the extent the firms within the same industry face similar demand and input prices, and similarly sensitive to the aggregate price level, controlling for industry should be sufficient to net out the heterogeneity in the response to monetary policy shocks.
} 
mechanism (Bernanke, Gertler, and Gilchrist, 1999). By raising assets prices, the net worth of firms increases thereby increasing their borrowing capacity. If the asset price response is sufficiently large, then financial conditions can improve sufficiently for constrained firms so that they experience a larger employment response than unconstrained firms. This is illustrated by the dashed blue lines in Figure 1b. On the other hand, for unconstrained firms, this asset price response is irrelevant.

Figure 1: Theoretical Employment Responses to an Expansionary Monetary Policy Shock

(a) No Easing of Financial Constraints

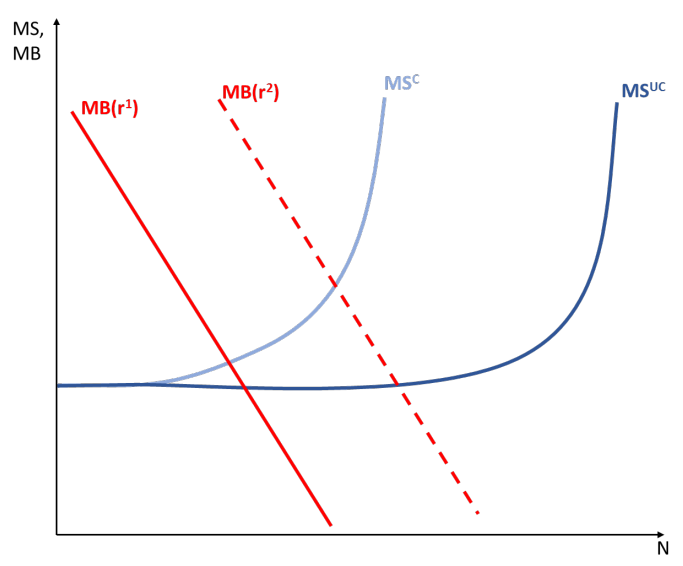

(b) With Easing of Financial Constraints

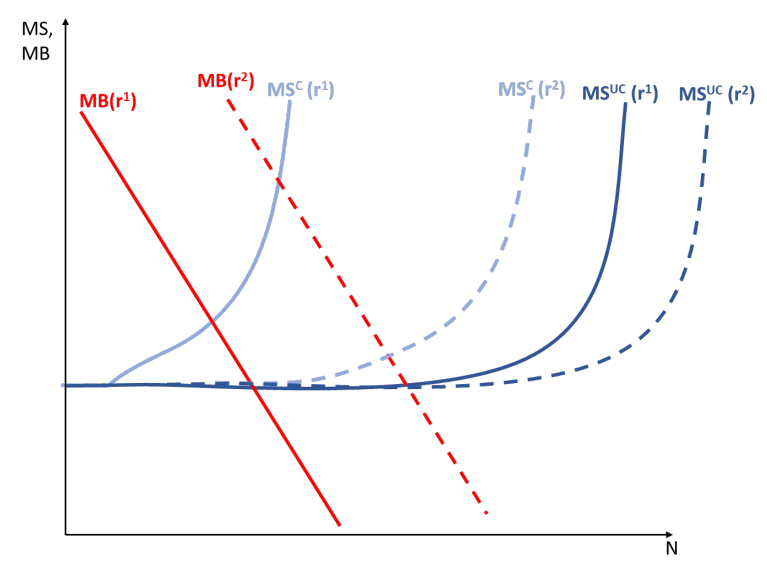

The main contribution of this paper is not only to consider multiple firm-level characteristics as proxies of financial constraints in the data, but also - key for assessing the mechanism - to determine the extent to which those constraints are affected by monetary policy shocks. That is, we are able to proxy at the firm-level the initial steepness of the blue curve as well as how much it shifts in response to a monetary policy shock.

Testable Predictions The analysis above allows us to sharpen our empirical predictions. If financial constraints are relevant for explaining the heterogeneous firm-level response to monetary policy, then we would expect to see the following: (I) Across unconstrained firms, heterogeneity in the sensitivity of collateral values to monetary policy shocks will not generate heterogeneous employment responses. (II) Across constrained firms by contrast, heterogeneous collateral value sensitivity will translate into heterogeneous employment responses. The next section described the data used to test these predictions in our data. ${ }^{4}$

\footnotetext{
${ }^{4}$ Note also that the theory predicts that an expansionary monetary policy shock reduces constrained firm's cost of finance above and beyond the fall in the risk free interest rate. Our analysis is focused on quantities rather than prices but for evidence showing that borrowing costs fall for constrained firms following an expansionary monetary shocks (Anderson and Cesa-Bianchi, 2018).
} 


\section{$3 \quad$ Firm-Level Data and Research Design}

In this section we lay out the construction of our firm-level dataset for private and public firms in the United Kingdom. We also report descriptive statistics for our regression sample, both unconditionally, and when we group firms by age, leverage, and size, which are standard proxies for financial constraints. Finally, we detail our research design and present our source of variation in the sensitivity of firms' collateral values to monetary policy shocks.

\subsection{Sample Construction}

In the UK, under the Companies Acts of 1985 and 2006, all companies must file annual accounts with Companies House, a government agency. We access this data via Bureau van Dijk (BvD), a commercial data provider. This dataset covers around 1.5 million unique company accounts every year, and importantly, covers both public and private firms. Reporting requirements vary by company characteristics such as size. ${ }^{5}$ The dataset has a number of features that make it particularly well-suited for our analysis. First, it contains key variables of interest; Number of Employees and Firm Age (calculated using the date of incorporation). Second, while it also covers large listed firms, the dataset is dominated by small and medium-sized private firms; precisely the firms most likely to be affected by financial frictions (Dinlersoz, KalemliOzcan, Hyatt, and Penciakova, 2018) and heavily dependant on asset-based borrowing (Liam and Ma, 2018). Third, firms from all sectors of the economy are covered, in particular, both manufacturing and non-manufacturing firms. Fourth, it contains detailed financial information on firms including their leverage, credit score, and outstanding secured banking relationships. Finally, it also contains detailed information on who runs the company-the company directorsincluding their name, date of birth, appointment and resignation dates, whether they're a shareholder, and, crucially, their home address. This last piece of information allows us to measure the sensitivity of the director's home values to monetary policy shocks, which is a key source of variation in our empirical design discussed in Section 3.3.

Whilst the BvD dataset has these advantages, a significant limitation is that it's a live database, with many key variables of interest only available for the latest vintage, and not also historically. Most importantly for our purposes, there is no historical information on who company directors are and where they live. Moreover, whilst past accounting variables are available, there is much more missing data historically, in part because firms that die exit the database after five years. To overcome these limitations we use historical vintages of the database, which record company information when it was first published. Through combing 25 different vintages of the database we are able to improve data coverage substantially, observe

\footnotetext{
${ }^{5}$ In Section 3.2 we discuss in detail the sample of firms used in our regressions.
} 
the performance of firms who have since died, and track the identities of company directors and where they lived through time. ${ }^{6}$ In effect, our dataset is annual due to the frequency at which firms file their accounts. However, a key feature of the dataset is that firms file their accounts at different times during the year. Hence, a firm that files in January will have experienced a different sequence of shocks in their accounting window to one that files in July. As shown in Appendix Figure 13, filing months are evenly distributed throughout the year, with two larger nodes at the end of the financial year and the calendar year. However, the sample size is sufficiently large that every month in a year will have many observations.

\subsection{Descriptive Statistics}

Our sample comprises private limited and public quoted firms for whom the UK Companies Acts apply. We exclude firms that operate in the financial, public or non-profit sectors and we also exclude firms that have a parent with an ownership stake greater than $50 \%$ to correctly account for the firm's financial position and avoid double counting. ${ }^{7}$ Our sample period covers firms that file accounts from May 1997 (when the Bank of England was granted operational independence and the Monetary Policy Committee was established) and extends until the end of 2017. Throughout in our employment regressions we consider firms who report employment growth over a five year horizon, from employment in the lagged accounts to four accounts hence. While this implies that our estimates are conditional on survival, it is worth noting that to the extent that a tightening in monetary policy increases the probability of exit by firms more affected by financial frictions, our results may be interpreted as a lower bound for the heterogeneous effects of monetary policy on employment. ${ }^{8}$

In Table 1, we present summary statistics for the full sample used in our firm level regres-

\footnotetext{
${ }^{6}$ For a thorough description of the archival process followed in the construction of our dataset see Section 2 of the Online Appendix of Bahaj, Foulis, and Pinter (2018). See Kalemli-Ozcan, Sorensen, Villegas-Sanchez, Volosovych, and Yesiltas (2015) for a detailed discussion of the importance of using archival information when constructing a panel of firms using BvD data.

${ }^{7}$ Specifically we exclude firms of the following types: "Economic European Interest Grouping", "Guarantee", "Industrial/Provident", "Limited Liability Partnership", "Not firms Act", "Other", "Royal Charter", "Unlimited", "Public Investment Trust", thereby ensuring that our sample contains only limited liability firms to which the firms Act applies. In addition, we exclude from the sample firms operating in utilities (2003-UK Standard Industrial Classification [SIC]: 4011-4100); finance and insurance (2003-SIC: 6511-6720); real estate (2003-SIC: 7011-7032); public administration (2003-SIC: 7511-7530); education, health, and charity (2003-SIC: 8010-8540); and clubs and organisations (2003-SIC: 9100-9199).

${ }^{8}$ The focus on employment eliminates a large number of small entities that are either not required to report employment or have no employees. Nonetheless, our sample provides stable coverage of approximately $30 \%$ of aggregate employment in the industries in question and tracks the business cycle dynamics of aggregate employment well (see Figures 11 and 12 in Appendix A.1). Furthermore, age and leverage are commonly used proxies for financial frictions and, as shown in Appendix Table 3, non-reporting firms tend to be even younger and more levered, suggesting the heterogeneity in monetary policy responses would be even stronger if these firms were included in our analysis. This suggests that selection is unlikely to be a major concern for our analysis.
} 
sions. Our sample contains 188,184 firm level observations on 37,029 unique firms. The upper panel of Table 1 shows that the median firm in our sample has 52 employees, just above the UK small firm threshold of fewer than 50 employees. Furthermore, the lower quartile of firms have 9 or fewer employees, below the UK definition of a micro-entity. By this metric, it is clear that our sample is dominated by small firms. However, the right skew of the size distribution reflects an upper tail of relatively large firms, whose average asset value is $£ 92.9$ million compared to $£ 3.8$ million for the median firm. In contrast, the age distribution is more evenly distributed: the median firm is 15 years old and the lower (upper) quartile of firms have been incorporated less than 7 (more than 29) years before the monetary policy shock hits. There is also even dispersion of firm leverage (measured as the ratio of total liabilities to total assets), with a median leverage ratio of $61 \%$ and an interquartile range running from $40 \%$ to $80 \%$. The table also highlight the geographical dispersion between directors and their firms with $60 \%$ of directors living in a different region to their firm and the average director living over 25 miles away. As discussed in Section 3.3, this geographical dispersion is useful for our research design.

A number of earlier and concurrent contributions have proposed several proxies for financial constraints, including size (Gertler and Gilchrist, 1994; Haltiwanger, Jarmin, and Miranda, 2013; Crouzet and Mehrotra, 2017; Dinlersoz, Kalemli-Ozcan, Hyatt, and Penciakova, 2018), age (Cooley and Quadrini 2001; Hadlock and Pierce 2010; Cloyne, Ferreira, Froemel, and Surico 2018) and leverage (Ottonello and Winberry, 2018; Jeenas, 2018), with the latter directly mapping into firm net-worth - a key state variable governing access to external finance in models of financial frictions (Bernanke, Gertler, and Gilchrist, 1999; Kiyotaki and Moore, 1997). As shown by Figure 2, however, these proxies are correlated, with firms tending to reduce their leverage and increase their size as they age (conditional on survival). This highlights the importance of conditioning on firm age when assessing how firm size and leverage affect a firm's behaviour; a point made by Fort, Haltiwanger, Jarmin, and Miranda (2013) in relation to firm size and age. In Section 5.1 we show that being younger and more levered are the best (combined) predictor of a larger employment response to monetary policy shocks.

\subsection{Exposure to Collateral Value Fluctuations}

Whilst, in keeping with previous literature, we focus on a number of traditional proxies for financial frictions such as age and leverage, we also proxy for the extent to which monetary policy affects financial constraints, by analysing the sensitivity of firms' collateral values to monetary policy shocks. ${ }^{9}$ We do this by focusing on real estate, for four reasons. First, real estate is a major source of collateral, particularly for smaller companies, serving as security

\footnotetext{
${ }^{9}$ Interestingly, using a sample of U.S. publicly listed firms, Liam and Ma (2018) show that while, on average, borrowing is mainly secured on cash-flows, smaller firms rely disproportionally more on collateral-based borrowing. Collateral-based borrowing is also highly prevalent among SMEs, which dominate our sample.
} 
Table 1: Regression Sample Summary Statistics

\begin{tabular}{|c|c|c|c|c|c|c|}
\hline \multicolumn{7}{|l|}{ Full Sample Summary Statistics } \\
\hline Variable & Mean & Median & $25 \%$ tile & $75 \%$ tile & & \\
\hline Number of Employees & 517 & 52 & 9 & 122 & & \\
\hline Total Assets (£'000s) & 92,893 & 3,765 & 834 & 9,056 & & \\
\hline 2-year Real Asset Growth (\%) & 2.1 & 1.5 & -2.3 & 6.2 & & \\
\hline 2-year Employment Growth (\%) & 1.5 & 0.0 & -1.0 & 3.9 & & \\
\hline Age (years) & 22 & 15 & 6.9 & 29 & & \\
\hline Leverage ( $\%$ assets) & 78 & 61 & 40 & 80 & & \\
\hline Director living in different region (\%) & 60 & 100 & 0 & 100 & & \\
\hline Director average distance (miles) & 26 & 10 & 4.1 & 26 & & \\
\hline \multicolumn{7}{|c|}{ 188,184 Firm-Year Observations on 37,029 Firms } \\
\hline \multicolumn{7}{|c|}{ Median/Mean values by Age, Leverage, Size } \\
\hline & \multicolumn{2}{|c|}{ Age } & \multicolumn{2}{|c|}{ Leverage } & \multicolumn{2}{|c|}{ Size (Employees) } \\
\hline & 0-15 & $15+$ & Below & Above & $1-250$ & $250+$ \\
\hline Variable & & & Median & Median & & \\
\hline Number of Employees ${ }^{a}$ & 28 & 68 & 57 & 47 & 40 & 551 \\
\hline Total Assets $(£ ' 000 \mathrm{~s})^{a}$ & 2,485 & 4,794 & 4342 & 3234 & 3149 & 35362 \\
\hline 2-year Real Asset Growth $(\%)^{a}$ & 1.9 & 1.2 & 1.5 & 1.4 & 1.5 & 1.4 \\
\hline 2-year Employment Growth $(\%)^{b}$ & 2.2 & 0.8 & 1.2 & 1.8 & 1.6 & 1.1 \\
\hline Age $(\text { years })^{a}$ & 6.8 & 29 & 21 & 11 & 15 & 20 \\
\hline Leverage $(\%$ & 70 & 54 & 41 & 79 & .61 & .61 \\
\hline Director living in different region ( & 61 & 58 & 59 & 61 & 58 & 71 \\
\hline Director average distance (miles) ${ }^{b}$ & 27 & 25 & 27 & 26 & 24 & 39 \\
\hline
\end{tabular}

$a=$ median, $b=$ mean

Notes: Age is defined as the number of years elapsed from the date of incorporation. Leverage is measured as the ratio of the balance sheet items "Total Liabilities" to "Total Assets". Size is measured as the "Number of Employees". The upper panel shows the statistics based on the regression sample. The lower panel splits the statistics into two groups for each of age, leverage and size.

for more than $75 \%$ of loans to UK SMEs (Bahaj, Foulis, and Pinter, 2018). Second, monetary policy has a significant effect on real estate prices. Third, as we show below, monetary policy has a heterogeneous regional impact on real estate prices, providing a key source of variation in collateral values. Finally, the UK has high-quality monthly regional real estate price indices, allowing for the measurement of this heterogeneity.

The ideal experiment would exploit variation in the value of a firm's collateral that is independent of its business opportunities. Whilst an increase in local real estate prices leads to an increase in firm activity by relaxing financial constraints (Gan 2007 and Chaney, Sraer, and Thesmar 2012), this is likely to be correlated with local demand. To circumvent this identification issue we instead focus on the residential real estate of company directors, who frequently borrow against their own homes to finance their firms, typically by issuing a personal 
Figure 2: Firm Leverage and Size Over the Life-Cycle

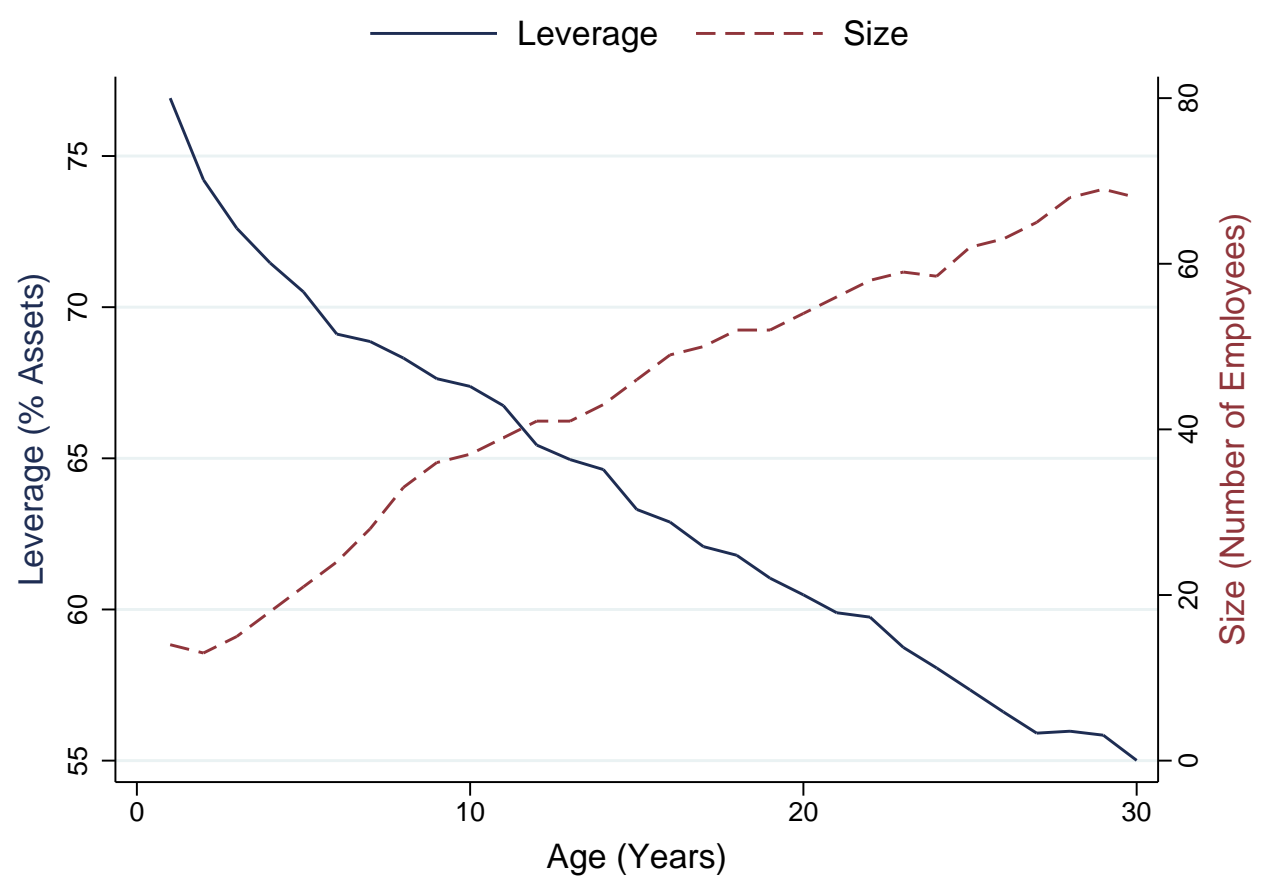

Notes: the figure shows the median leverage (measured as the ratio of total liabilities to total assets) and the median firm size (measured as number of employees) for firms of each age group from 1 to 30. Age is measured as number of years since incorporation.

guarantee. ${ }^{10}$ This residential collateral is a significant source of financing for firms, being worth around $80 \%$ of GDP, around four times more than the buildings owned by firms. It also generates a source of transmission from real estate prices to firm employment: every $£ 1.1 \mathrm{~m}$ increase in the combined home values of a firm's director causes the average firm to add one job (Bahaj, Foulis, and Pinter, 2018). Crucially, over half of the directors in our sample live in a different region to their firm, reducing the correlation between collateral values and local demand. Accordingly, we can compare the employment responses of two firms in the same location, with similar characteristics, one of which has its director living in a region where house prices have higher sensitivity to monetary policy and the other whose director lives in a lower sensitivity region.

We provide evidence on this type of borrowing in Table 2, which summarises evidence from the Bank of England's 2015 Survey of Bank Lending to SMEs and Mid-Corporates. ${ }^{11}$ There

\footnotetext{
${ }^{10}$ A personal guarantee is legal commitment given by the firm's director to back the firm's debt that typically involves a fixed charge on the director's home. Should the firm fail to repay the amount owed, the bank can seize the assets of any and all directors of the firm. For further details on personal guarantees, including their international prevalence, see Bahaj, Foulis, and Pinter (2018).

${ }^{11}$ The survey covers outstanding loans at the five major UK banks to firms borrowing at least $£ 250,000$ and whose annual revenue is less than half a billion pounds.
} 
are two key takeaways from the table. First, borrowing against personal guarantees is very prevalent, being used as security by $50 \%$ of firms. Second, there is significant heterogeneity across firms. In Section 5.1, we show that the employment of younger, more levered firms is the most responsive to monetary policy shocks. So for brevity, we focus here (across rows) on four firm groups splitting based on the joint age-leverage distribution. In column (1) of Table 2, we show that almost two-thirds of borrowing by younger firms (less than 15 years old) with higher leverage (above the median) is secured by personal guarantees, being charged an average interest rate of $3.80 \%$. These figures are significantly lower for the remaining groups, particularly for older and less levered firms. This latter groups secures only one third of their loans by personal guarantees and for that are charged an interest rate which is about 60 basis points lower. More generally, the relationship between age/leverage and access to credit appears monotonic. $^{12}$

Table 2: Personal Guarantees and Interest Rate by Firm Age and Leverage

\begin{tabular}{lcc}
\hline & $\begin{array}{c}\text { Lending Secured by } \\
\text { Personal Guarantee }\end{array}$ & $\begin{array}{c}\text { Interest Rate } \\
(2)\end{array}$ \\
\hline Younger, Higher Leverage & $63 \%$ & $3.80 \%$ \\
Younger, Lower Leverage & $52 \%$ & $3.06 \%$ \\
Older, Higher Leverage & $49 \%$ & $3.27 \%$ \\
Older, Lower Leverage & $33 \%$ & $3.24 \%$ \\
\hline All Firms & $50 \%$ & $3.41 \%$ \\
\hline
\end{tabular}

Notes: The table presents the results of the Bank of England's 2015 survey of UK SME and Mid-Corporate Lending by the five major UK banks. We merge this with BvD data on firms to measure firm leverage. The survey covered lending from the five major UK banks to businesses borrowing at least $£ 250 \mathrm{k}$, and whose annual revenue was no more than $£ 500$ million. To facilitate comparison with our regression results, we exclude lending to businesses in Human Health, Education, Financial and Insurance Activities, and Commercial Real Estate. We further exclude businesses with 0-1 employees and limit to limited liability firms firms that not subsidiaries in Scotland, England, and Wales. Column (1) shows the fraction of business lending (weighted by number) that was secured by a personal guarantee, broken down by the leverage of business being lent to (with higher/lower leverage being above/below median firm leverage in the baseline regression sample and younger/older being firm age below/above 15 years old). Column (2) shows the interest rate on the bank's largest exposure to the business, averaged within each firm leverage group and weighted by number.

To measure the regional sensitivity of house prices to monetary policy we run a simple projection of local house prices on monetary policy shocks for each of the 172 regions in England and Wales, using the Land Registry's monthly repeat sales house price index from 1995-2016. ${ }^{13}$ The regional variation in this measure is illustrated by a heat map in Figure 15, confirming

\footnotetext{
${ }^{12}$ Cutting the sample behind Table 2 by age only or by leverage only reveals that younger firms and more levered firms are also more reliant on personal guarantees and so are more exposed to variations in the value of their directors' homes. But the heterogeneity is further amplified by considering the two dimensions jointly, which motivates the focus in Table 2.

${ }^{13}$ Appendix A.3 describes the estimation procedure in detail. The one area omitted in England and Wales is the Square Mile financial district in London, in which there is very little residential property and no house price index is calculated. For further details on the Land Registry's repeat sales house price index see http://pro.landmarkanalytics.co.uk/Land-Registry-House-Price-Index-Methodology-1995.pdf. The house price sensitivities are not calculated for Scotland as the regional house price indicies do not exist prior to 2004.
} 
substantial spatial heterogeneity in the sensitivity of house prices to monetary policy shocks. To compute a firm-level measure of house price sensitivity to monetary policy we average the estimated sensitivities across the regions where each of the firm's directors live. In Figure 17 we report the correlation between the sensitivity of a firm's region with the average sensitivity of its director's regions, broken down by the average distance between the firm and its director's houses. ${ }^{14}$ Across all firms, (first bar on the left) the correlation is $75 \%$ but it falls substantially as the average distance increases. For a quarter of firms, their directors live an average of at least 30 miles away (see Table 1), and the correlation is below 40\%. We exploit this low correlation in a robustness test.

We consider two alternatives to this baseline approach. First, we calculate a measure of housing exposure, which interacts the house price sensitivity of a director's region with the value of their house, before summing across all directors at a firm. ${ }^{15}$ This adds an additional source of variation: within a region, a director with a more expensive house will experience a greater change in the value of their house, for a given monetary policy shock. Second, as an alternative to these model-based estimates of house price sensitivities, we use a regulation-based measure: the regional refusal rates of planning applications for residential projects, taken from Hilber and Vermeulen (2016). The idea is that the increase in housing demand associated with an expansionary monetary policy shock will be translated into a greater increase in housing prices in regions with a greater refusal rate, as the housing supply response will be weaker. Appendix A.3 describes the data on refusal rates in greater detail; Figure 16 demonstrates substantial regional variation in refusal rates. ${ }^{16}$

\section{Empirical Framework}

In this section we describe the identification strategy used to isolate monetary policy shocks, lay out the empirical model we use for firm-level estimation, and present the estimated average effect of monetary policy on employment over our full sample.

\footnotetext{
${ }^{14}$ We calculate this distance for each firm-director pair using the full postcode (an area of around 17 properties) of the firm's headquarters and the house of each director. The Office for National Statistics calculate the center of each postcode to the nearest meter; using data from the Ordinance Survey we then convert this to latitude and longitude coordinates and calculate the distance. We then average this distance at the firm level across all of its directors. Note that if all directors lived in the same region as their firm this correlation would be $100 \%$.

${ }^{15}$ To estimate the value of a director's house we match their residential address to the Land Registry's Price Paid dataset, which records all property transactions in England and Wales since 1995; and the FCA's Product Sales Database (PSD), which records the universe of mortgage originations in the UK. For a detailed discussion of this matching procedure see Online Appendix 4 of Bahaj, Foulis, and Pinter (2018). The Product Sales Data include regulated mortgage contracts only, and therefore exclude other regulated home finance products such as home purchase plans and home reversions, and unregulated products such as second charge lending and buy-to-let mortgages.

${ }^{16}$ Note that the refusal data is only available for England, and not also Wales.
} 


\subsection{Identification of Monetary Policy Shocks}

Our strategy for measuring exogenous fluctuations in UK monetary policy builds on the series of Gerko and Rey (2017). This series, making use of a high frequency identification strategy, essentially serves as an instrument for monetary policy in our empirical analysis that follows. It is constructed by measuring the reaction in the sterling rate futures market during the window from 10 minutes before to 20 minutes after the release of two UK monetary policy releases: (i) the publication of the minutes of the Bank of England's MPC meeting and (ii) the publication of the Bank of England's Inflation Report. ${ }^{17}$ To convert the surprises to a monthly variable, they sum all the surprises within the same month. The monthly series is plotted in Figure 18 of Appendix B and covers the period January 2000 to January 2015.

Having obtained a source of exogenous variation in monetary policy, we use the series as an external instrument in a structural vector autoregression (proxy-SVAR) model covering UK aggregate data. The methodology for proxy-SVARs is now relatively standard and we refer readers to Stock and Watson (2012) and Mertens and Ravn (2013) for further information about implementation.

We use the identified monetary policy shock series from the VAR in our firm-level regressions. This is advantageous as we can use the patterns of correlation between the reduced form residuals and the instrument to extend the identified policy shock series back to periods before the Gerko and Rey (2017) series was available hence extending our firm-level sample. ${ }^{18}$

Our VAR specification is almost identical to Gerko and Rey (2017): we specify a monthly VAR(12) covering the period January 1981 to March 2015. We include the following time series in the VAR: the UK index of manufacturing production (in logs), five year gilt yields (in percentage points), the UK retail price index (in logs) and the unemployment rate. We modify their specification in one dimension by additionally including aggregate employment (in logs) for the same industries covered by our firm level data. This is to obtain a comparable aggregate benchmark for the employment response to a monetary policy shock.

The F-statistic from the regression of the VAR residuals on the proxy is 12.2. This is, in effect, the first stage regression of our empirical model and the F-statistic represents the most conservative measure of instrument relevance. The firm-level regressions below cover a longer time period and, as one would expect, the extracted shock is more closely correlated with interest rate changes than the Gerko and Rey (2017) series.

Figure 20 in Appendix B presents the impulse response functions to the contractionary

\footnotetext{
${ }^{17}$ See Appendix B of Gerko and Rey (2017) for further details of the construction of the series.

${ }^{18}$ This is a common approach in the proxy SVAR literature (Gertler and Karadi 2015). Specifically, this methodology identifies the contemporaneous coefficients on the reduced form residuals that can be combined to produce the identified shock. Since our reduced form specification extends back beyond 2000, we can use the estimated residuals for the pre-2000 sample, along with the identified coefficients, to extend our shock series prior to 2000.
} 
monetary policy shock that emerges from the VAR. To enable comparability with the firm-level results, the monetary policy shock is scaled so that the average increase of the 5-year yield over the first year is 25bps. The pattern of responses is in line with the monetary policy literature. The 5-year yield increases on impact and then decreases and returns to zero after around 2.5 years. Aggregate employment does not respond on impact, but thereafter decreases with a peak response after 3 years, before returning to zero at the end of the horizon. At its peak, the monetary policy shock results in around a $0.5 \%$ decrease in employment. These findings align with the results of Christiano, Eichenbaum, and Evans (1999) on the effects of monetary policy on employment.

\subsection{A Panel LPIV model}

Let $E M P_{i, t}$ be firm $i$ 's number of employees for accounting period $t$. Here it is necessary to introduce a brief remark on notation: as described, our firm level data is effectively annual so $t$ refers to the firm's accounting year and we use the index $m \in\{1, \ldots, 12\}$ to denote months within that year. To ensure no ambiguity, $m=12$ is the month in which the firm files its accounts within that year, not December. We use the index $s$ to denote months in the time domain, which are common to all firms.

Our baseline linear specification is specified as a local projection (Jorda 2005) and is an extension of the model discussed in Ramey (2016) into a panel instrumental variable setting:

$$
\ln \left(E M P_{t+h, i}\right)-\ln \left(E M P_{t-1, i}\right)=\sum_{g=1}^{G} \alpha_{g}^{h} \times D g_{i, t-1}+\sum_{g=1}^{G} \beta_{g}^{h} \times D g_{i, t-1} \times \Delta r_{t}+v_{i, t}^{h}
$$

where $h \in\{0, \ldots, 4\}$ indexes a set of regressions at different horizons, running from 0 to 4 years. The term $\Delta r_{t}$ is the change in the average 5-year interest rate over the firm's accounting year. ${ }^{19}$ We instrument the interest rate changes with the series $\sum_{m=1}^{12} e_{m, t}$, where the term $e_{m, t}$ denotes the monetary policy shock for month $m$ of accounting year $t$ as extracted from the VAR described in Section 4.1. ${ }^{20}$

To allow for heterogeneous responses, the term $D g_{i, t-1}$ is a dummy variable that takes a value of 1 when firm $i$ is part of a particular group of firms (e.g. firms less than 15 years old) in period $t-1$, and 0 otherwise. The impulse response to an interest rate change for a particular group is then given by the vector of coefficient estimates $\left\{\beta_{g}^{h}\right\}_{h=0}^{4}$. We re-scale all

\footnotetext{
${ }^{19}$ Precisely, $\Delta r_{t}=1 / 12\left(\sum_{m}\left(r_{m, t}-r_{m, t-1}\right)\right.$, where $r_{m, t}$ is the average of daily observations of the 5 year gilt yield in month $m$ of firm accounting period $t$.

${ }^{20}$ We can also estimate an over-identified model using the 12 shocks that occur over the firms accounting year as separate instrument. However, this is computationally intensive and the results, available upon request, for our main specification are near identical.
} 
impulse responses so they can be interpreted as a shock that raises the interest rate by $25 \mathrm{bp}$ on average over the firm's accounting year (i.e. $\Delta r_{t}=25 b p$ ), allowing direct comparison with the aggregate employment results in Figure 20.

By including time fixed effects, we can also compute relative impulse responses:

$$
\ln \left(E M P_{t+h, i}\right)-\ln \left(E M P_{t-1, i}\right)=\delta_{j, s}^{h}+\gamma_{l, s}^{h}+\sum_{g=1}^{G} \tilde{\alpha}_{g}^{h} \times D g_{i, t-1}+\sum_{g=1}^{G-1} \tilde{\beta}_{g}^{h} \times D g_{i, t-1} \times \Delta r_{t}+v_{i, t}^{h} .
$$

In this context, $\delta_{j, s}^{h}$ is a dummy that takes a value of 1 for firms operating in (SIC-1) industry $j$ that file their accounts in month $s$, and 0 otherwise. This means we are comparing firms within industry and thus eliminating the role of industry-specific sensitivities to monetary policy. Similarly, $\gamma_{l, s}^{h}$ is a dummy that takes a value of 1 for firms that operate in (NUTS-1) region $l$ and file their accounts in month $s$, and 0 otherwise. Hence, we are comparing two firms in the same region subject to the same local economic conditions.

We focus on the specification in Equation (2) when conducting inference over differences between groups both because estimation uncertainty over the linear effect of the shock is absorbed and because the fixed effects enable tighter identification of the mechanism of interest. Since the linear effect of $\Delta r_{t}$ is absorbed by the time fixed effects, the term $\tilde{\beta}_{g}^{h}$ captures the response of group $g$ relative to the $G$ th group. The statistical significance of the difference in responses between groups $g_{1}$ and $g_{2}$ can be assessed by a formal hypothesis test that $\tilde{\beta}_{g_{1}}^{h}=\tilde{\beta}_{g_{2}}^{h}$.

When constructing cumulative growth rates, $\log \left(E M P_{i, t+h}\right)-\log \left(E M P_{i, t-1}\right)$, we (i) omit observations in the 99th and 1st percentiles of observations in order to prevent outliers distorting the results, (ii) omit observations where any accounting period in the window between $t-1$ and $t+h$ is not one year, (iii) rectangularise the sample such that for any observation to be included $\ln \left(E M P_{t+4, i}\right)-\ln \left(E M P_{t-1, i}\right)$ must be reported, and (iv) when using alternative left hand side variables from employment, recast all nominal variables in real terms by dividing through by the seasonally adjusted UK consumer price index for the month when the account was filed.

We compute standard errors using the methodology from Driscoll and Kraay (1998). This accounts for the serial correlation at the firm level that is standard in local projections as well as arbitrary cross-sectional dependence between firms both contemporaneously and through time. The orthogonality of $e_{m, t}$ means that it is unnecessary to control for additional firmlevel or aggregate variables for the purposes of reducing omitted variable bias. Adding controls neither affects the coefficient estimate nor the error bands (see Figure 23 in the Appendix). For the same reason it is not necessary to include firm level fixed effects. Adding a firm fixed effect is equivalent to estimating a firm specific trend in employment growth. However, the time dimension of any given firm in the panel is relatively small, between five to ten years on 
average. Hence, adding firm fixed effects is demanding of the data, particularly at long horizons where there may only be a couple of observations per firm. We do report results including firm fixed effects in Figure 24 in the Appendix, which shows a similar if slightly larger employment impact, though the effect of monetary policy on firm level employment is more persistent.

\subsection{Average Firm-Level Effect of Monetary Policy}

Figure 3 shows the average firm-level employment response to a contractionary monetary policy shock that raises the interest rate by 25bp on average over the firm's accounting year, together with $90 \%$ confidence intervals. ${ }^{21}$ Our results suggest that the contractionary shock brings about a $0.3 \%$ decline in firm-level employment on impact ${ }^{22}$, although this effect is not statistically different from 0 . The fall in employment continues with the mean response reaching a trough of about - $1 \%$ after 2 years before the recovery starts. Importantly, we can compare these firmlevel employment responses to the aggregate responses in Figure 20. The aggregate response displays a very similar hump shaped pattern but the size of the effect is diminished. The simple explanation for this discrepancy is that the aggregate response is effectively equivalent to the employment weighted average response rather than the simple average across firms. Indeed, if we run the employment-weighted firm-level response, the peak impact on employment is $0.6 \%$, which is very similar to the aggregate response. The next sections turns to heterogeneous characteristics that affect the firm-level response to monetary policy shocks.

Figure 3: The Linear Effect of Monetary Policy on Firms

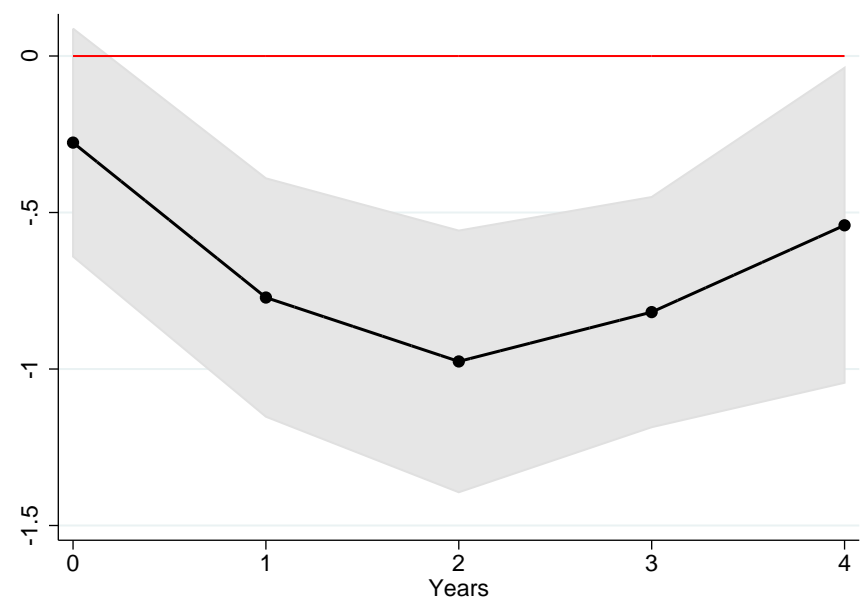

Notes: Firm level responses to a 25bp contractionary monetary policy shock. Black lines are point estimates. Grey shaded area is $90 \%$ confidence interval. The dependent variable is the cumulative growth rate in log points of employment from $t-1$ to $t+h$ where $t$ is the date of the monetary policy shock and $h$ is the x-axis.

\footnotetext{
${ }^{21}$ This regression showing the average affect across all firms is equivalent to $G=1$ in Equation 1.

${ }^{22}$ To reiterate, as the firm-level data is annual, this impact response is the annual employment response to monetary policy shocks over the firm's accounting year.
} 


\section{The Heterogeneous Effects of Monetary Policy on Em- ployment}

In this section we explore heterogeneity in the responses of firm-level employment to monetary policy shocks along our three proxies for financial constraints-age, leverage, and size-showing that employment responses are particularly large for younger, more levered firms. We then exploit geographical variation in house price sensitivity to monetary policy shocks to show that the employment response of the younger, more levered firms is materially larger when their directors live in more house price sensitive regions. Section 6 then examines the response of several firm balance sheet variables, including net worth and borrowing, to shed further light on the transmission mechanism of monetary policy to firm employment, through collateral value fluctuations and borrowing constraints.

\subsection{Heterogeneity by Firm Characteristics}

Figure 4 shows the two year employment response cut by alternative firm age, leverage, and size groups (for the full dynamic responses see Figures 25, 26, and 27 in Appendix E). Starting with age on the top row, we find that firms established less than five years prior to the monetary policy shock clearly respond the most whereas the oldest firms (more than 30 years old) respond the least. In between these two extremes, the effect of monetary policy on employment decreases near monotonically in firm age. Turning to leverage, Figure 4 shows that the upper three quintiles of firms by leverage (approximately those with a ratio of total liabilities to total assets greater than 50\%) respond in a relatively homogeneous fashion but the difference relative to the lower two quintiles is very sharp, with only the latter characterised by far smaller and, for the lowest quintile, insignificant, effects.

The estimates based on a size split in the last row, in contrast, are non-monotonic and thus less clear cut. For instance, the largest response is recorded for firms with between 500 and 2000 employees, whereas the two smallest adjustments are associated with the groups at either tail of the size distribution, namely firms with the smallest (below 50) and the largest (above 10,000) number of employees. This implies that using the sample cut ${ }^{23}$ in Crouzet and Mehrotra (2017) one would find that smaller firms react more to monetary policy shocks; using instead 500 employees as the threshold above which firms are classified as large, the differences across

\footnotetext{
${ }^{23}$ Crouzet and Mehrotra, 2017 don't categories firms by employment, but by assets, with small firms the bottom $99.5 \%$ and large firms the top $0.5 \%$ by assets. In our sample, cutting at these thresholds, a large firm is one with over $£ 2$ bn in assets. Such large firms have a median of 32,000 employees in our sample.
} 
Figure 4: Employment Responses to a Contractionary Monetary Shock by Age, Leverage, Size Groups - 2 year horizon
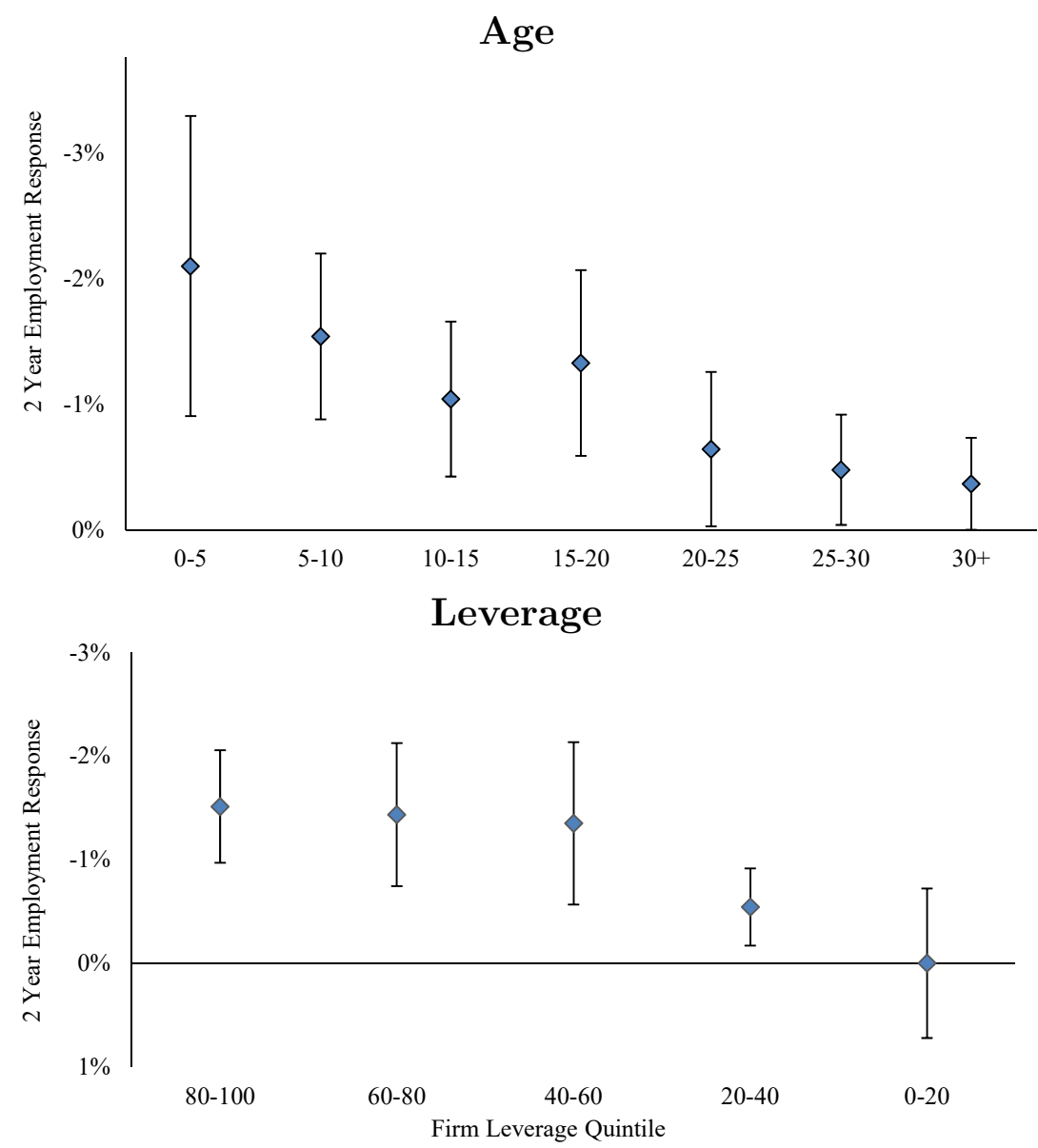

Size

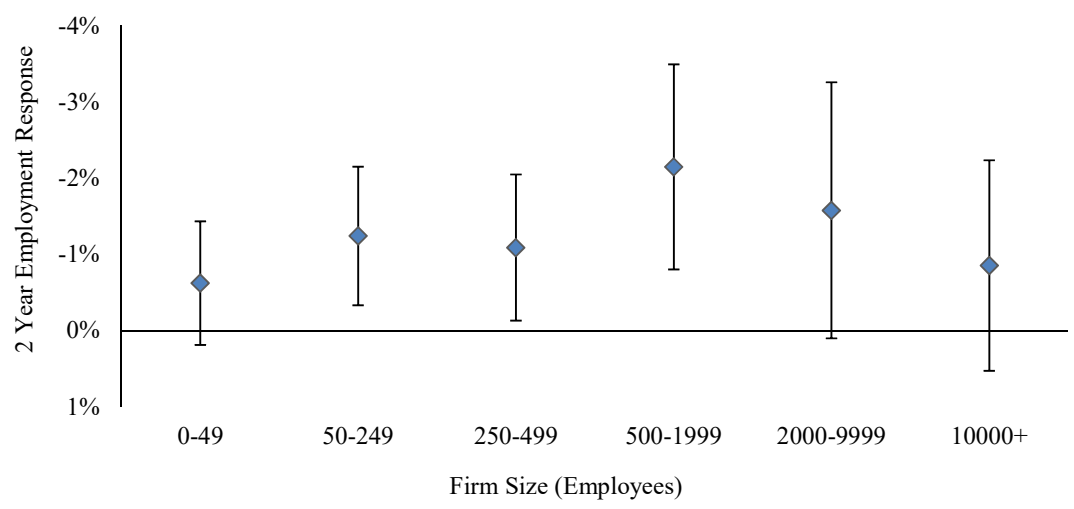

Notes: The candle chart summarises the point estimates (together with the $90 \%$ confidence interval) corresponding to the effect of a 25bp contractionary monetary policy shock for different groups of firms, sorted by age (top panel), leverage (middle panel) and size (bottom panel), as estimated by Equation 1.

groups would become far less stark; using 250 employees, the European Union upper limit for the definition SMEs, larger firms would now adjust their employment more than smaller 
firms. Indeed, the recent academic literature is mixed on whether smaller or larger firms are more responsive over the business cycle. ${ }^{24}$ Moreover, Figure 4 shows that among among SMEs the employment response is fairly homogeneous across firms of different sizes. Indeed, our key results that follow are based on our SME-dominated sample, where there is less heterogeneity in firm-level employment responses by size.

In summary, the employment of younger or more-levered firms appears significantly more sensitive to monetary policy shocks than the employment of older or less-levered firms, in a way that is not dependent on the specific threshold used. While younger and more levered firms also tend to be smaller (see Table 1), not all small firms are young and highly levered. Accordingly, the heterogeneity in the employment responses by size appears less marked and often insignificant.

In an effort to identify sharply the dimensions most closely related to the unobserved characteristics driving a greater firm-level response, we build on the estimates in Figure 4 to further decompose the distribution of firms into higher-levered (above the median in a given year) and lower-levered (below the median in a given year) firms. In a balancing act between exploring the full extent of heterogeneity in the employment responses across firms and maximizing the number of observations per group-time cell, we focus on two age categories: less than 15 years (younger), and above 15 years (older) since incorporation, which cuts almost exactly around the median firm age in our sample.

The result of the double cut by age and leverage is reported in the four panels of Figure 5a. The top (bottom) row refers to the younger (older) group whereas the most left (right) column represents higher-levered (lower-levered) firms. A comparison of the IRFs across columns highlights the marginal contribution of leverage for any given age level. A comparison across rows reveals the marginal contribution of age within a given leverage group. In Figure 5b, we report the relative effect version of the specification behind Figure 5a, in which we have also added (industry by time, region by time) fixed effects and chosen the older, lower-levered firms as the baseline group. Figure 5 delivers three main takeaways. First, being younger makes a significant contribution to the heterogeneity in employment responses, over and above having higher leverage. This is visible in the first columns of Figures 5a and 5b, which compare younger and older higher-leveraged firms. Second, being highly leveraged makes a significant contribution over and above being a younger firm, as can be seen from the first row of Figures $5 \mathrm{a}$ and $5 \mathrm{~b}$. Third, the most sensitive group, with a peak employment contraction of almost

\footnotetext{
${ }^{24}$ Kudlyak and Sanchez (2017) find that, following the financial crisis of 2008, the sales and short-term debt of large firms contracted much more than for small firms. Updating the dataset of Gertler and Gilchrist (1994), Chari, Christiano, and Kehoe (2013) find that the response of small and large firms are similar following recessions. Moscarini and Postel-Vinay (2012) find that large firms contract employment by more when unemployment is high. Whilst Crouzet and Mehrotra, 2017 do find that the sales of small firms respond more following a fall in GDP or tight periods of monetary policy, the effect does not materially affect the aggregate and cannot be attributed to financial frictions.
} 
Figure 5: The Effects of Monetary Policy on Employment by Age and Leverage, Double Sorted

(a) Level Effects
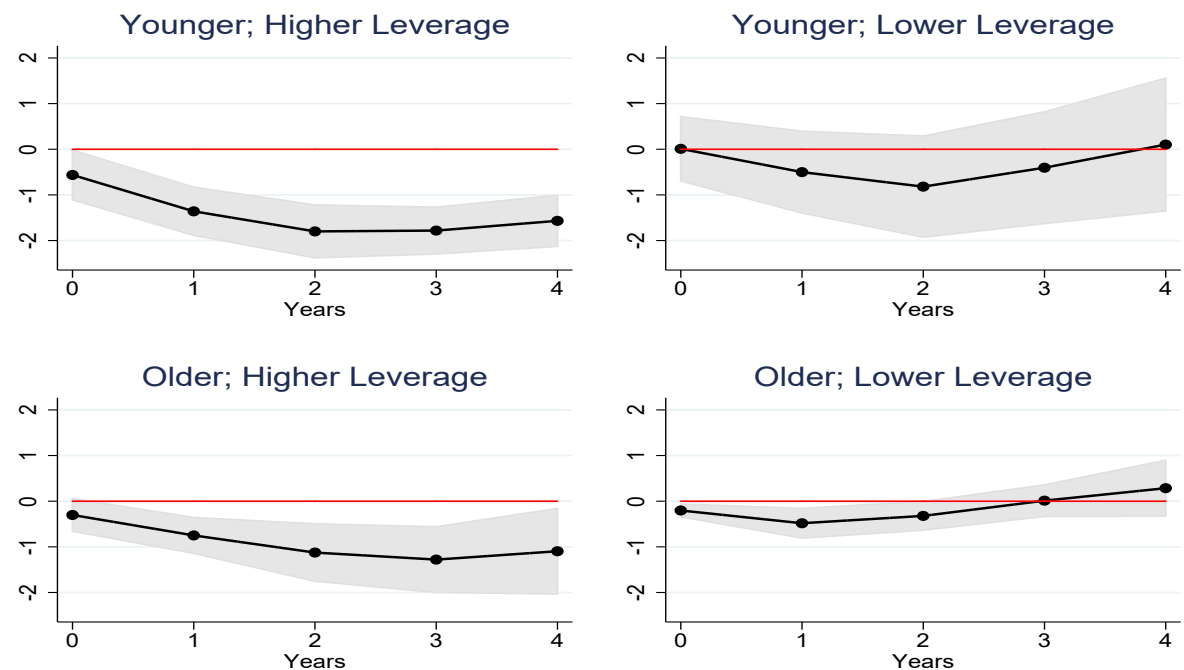

(b) Relative Effects
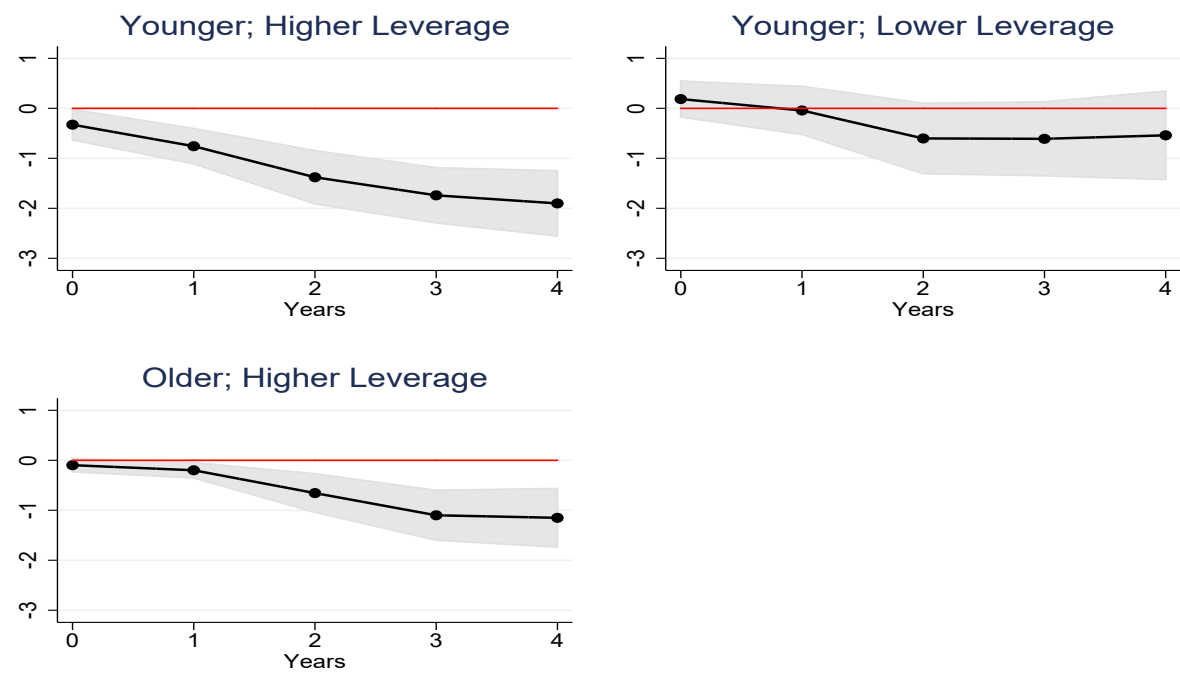

Notes: The figure shows firm-level responses to a $25 \mathrm{bp}$ contractionary monetary policy shock. Black lines are point estimates. Grey shaded area is $90 \%$ confidence interval. The dependent variable is the cumulative growth rate in log points of Employment from $t-1$ to $t+h$ where $t$ is the date of the monetary policy shock and $h$ is the x-axis. Panel $a$ and $b$ shows the results for specification 1 and 2, respectively. All the responses in Panel $b$ are relative to the group of older and more levered firms (omitted given the inclusion of industry-month and NUTS1-month fixed effects). Younger is defined as less than 15 years old, and higher leverage is defined as above the median leverage by year.

$2 \%$, is younger, more levered firms: exactly the firms more likely to be financially constrained. This is consistent with the results in Table 2 showing that younger, more levered firms face higher interest rates and are more likely to have their loans secured on the personal assets of the company directors.

The heterogeneity identified here has macroeconomic significance. Using the employment 
shares of each of the four groups in Figure 5a we can calculate the contribution of each group to the average firm-level employment response. The group of younger, higher leverage firms account for over a quarter of total employment in our sample. Combined with their materially larger employment response, this group are then responsible for $50 \%$ of the peak employent response to monetary policy shocks. By contrast, whilst the older, lower leverage firms account for over $30 \%$ of employment, they contribute less than $10 \%$ of the peak employment response.

\subsection{Heterogeneity by Firm Characteristics and Regional House Prices Sensitivity}

As described in Section 2, if financially constrained firms respond more to monetary shocks this implies a key role for collateral constraints and asset price fluctuations. In this section, we exploit regional heterogeneity in the sensitivity of real estate values to monetary policy shocks and ask: is the employment response of younger/more levered firms more pronounced when their company directors live in regions with a higher sensitivity of house prices to monetary policy?

For ease of exposition, in Figure 6a, we focus on the groups on the main diagonal of Figures 5a-5b, namely younger firms with higher leverage (Figure 6a: top row) and older firms with lower leverage (Figure 6a: bottom row), as these two groups are distinguished by the two key characteristics that drive the heterogeneity in the employment responses. In Figure 6a, we further split these two groups depending on whether the firm directors live in a region with high (top tertile, left column) or low (bottom tertile, right column) house price sensitivity to monetary policy shocks. In Figure 6b, we report estimates from the relative effects specification with time fixed effects (Equation 2), using the older, lower levered firms with directors living in low house price sensitive regions as the baseline group.

Three main findings emerge from Figure 6. First, our key result: among younger, higherlevered firms (the top row in Figures 6a--6b), the employment of firms with directors living in high sensitivity regions (left column) contracts more than the employment of similar firms whose directors are located in low sensitivity regions (right column). This is consistent with the notion that while younger, more-levered firms are more likely to be financially constrained, the constraints tighten more in regions where real estate collateral values are more sensitive to monetary policy. This effect is economically and statistically significant. Firms with directors in more sensitive regions experience a employment response approximately 1.5 percentage points greater than firms with directors in less house price sensitive regions. Formal hypothesis tests based on the coefficients in the top row of Figure $6 \mathrm{~b}$ yield p-values of less than $1 \%$ at 2- and 3year horizons. This finding is consistent with the prediction that monetary policy transmission partly works through altering the collateral value of financially constrained firms. 
Figure 6: The Effects of Monetary Policy on Employment by Age, Leverage and Director Beta, Triple Sorted

(a) Level Effects
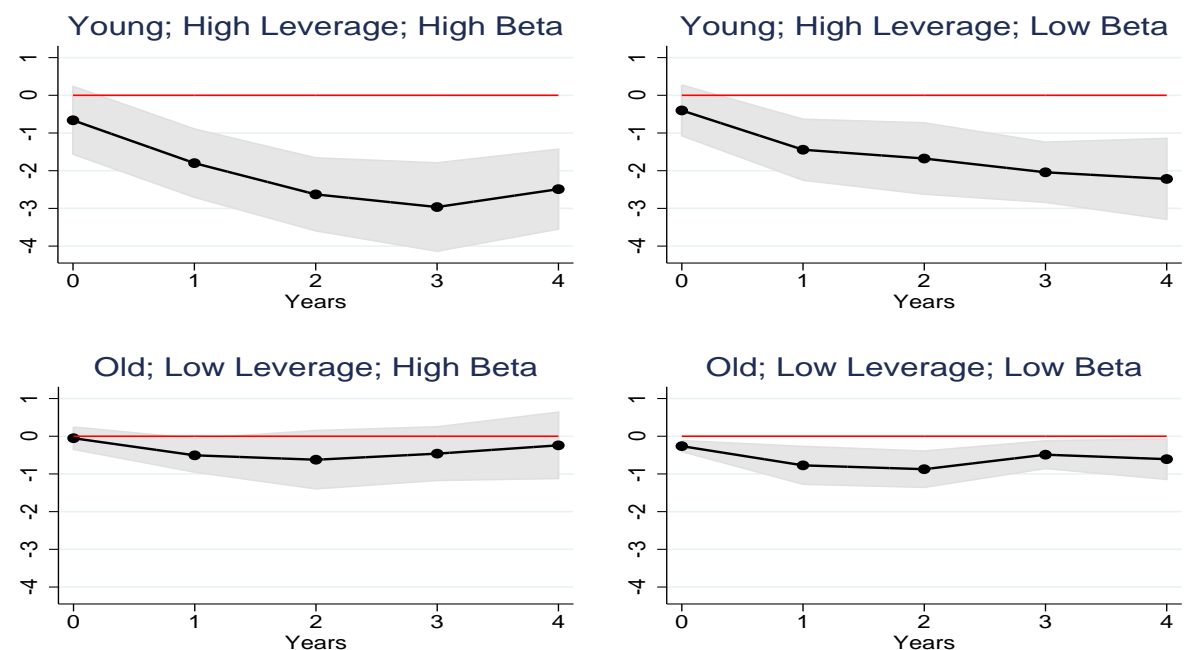

(b) Relative Effects
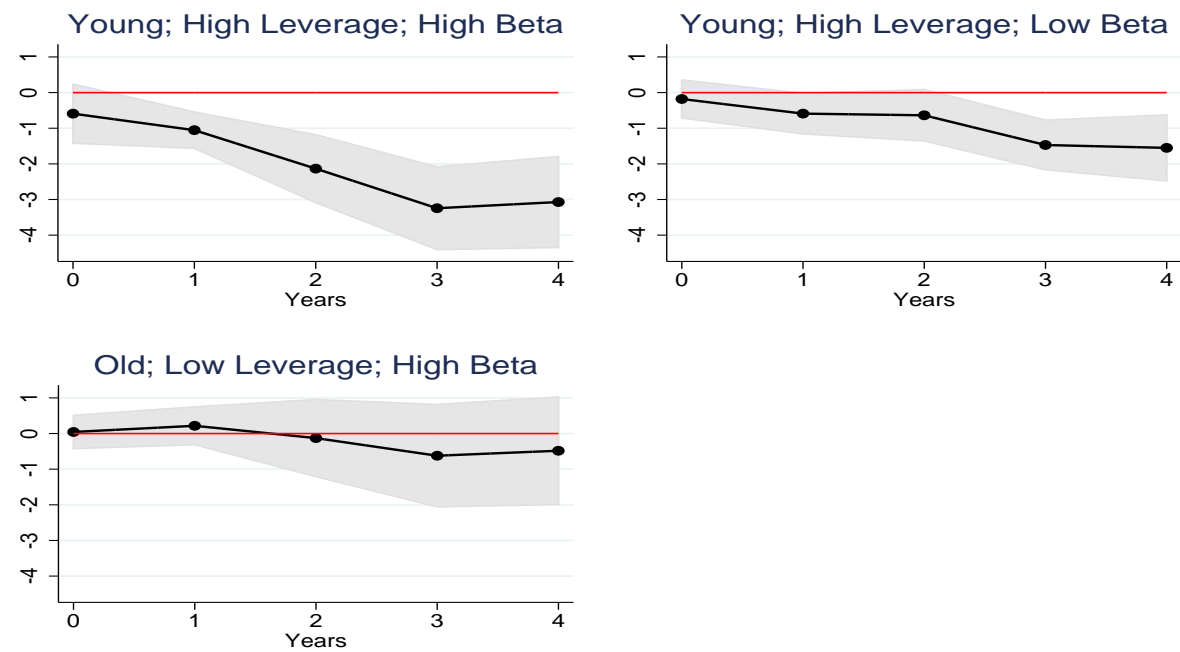

Notes: The figure shows firm-level responses to a $25 \mathrm{bp}$ contractionary monetary policy shock. Black lines are point estimates. Grey shaded area is $90 \%$ confidence interval. The dependent variable is the cumulative growth rate in log points of Employment from $t-1$ to $t+h$ where $t$ is the date of the monetary policy shock and $h$ is the x-axis. Panel $a$ and $b$ shows the results for specification 1 and 2 , respectively. All the responses in Panel $b$ are relative to the group of older and more levered firms in low- $\beta$ regions (omitted given the inclusion of industry-month and NUTS1-month fixed effects). Younger is defined as less than 15 years old, and higher leverage is defined as above the median leverage by year.

Second, among the group of older less-levered firms, house price sensitivity is irrelevant: the bottom left and bottom right panels in Figure 6a exhibit very similar dynamics (the bottom left chart in Figure $6 \mathrm{~b}$ formally shows no statistical difference). This is consistent with heterogeneity in collateral value changes, induced by a monetary policy shock, having no impact on unconstrained firms. 
Third, even within the group of firms whose directors live in higher house price sensitivity regions (left column), the employment response of younger, high levered firms is large and very significant whereas the response of older, less-levered firms is small and insignificant, consistent with the notion that older, less-levered firms are less likely to be financial constrained.

This regional heterogeneity within younger, higher leverage firms also has macroeconomic significance. Using the employment shares of firms in first row of Figure 6a, we can calculate the contribution to the aggregate employment response for younger, higher leverage firms, which have directors living in higher vs lower house price sensitive regions. The contribution to the peak employment response of younger, higher leverage firms is around four times higher when their directors live in a higher rather than a lower sensitivity region. This reflects the fact they tend to be larger, employing over 2.5 times as many workers, and are themselves more responsive to monetary policy shocks (with, for example, an employment response 1.5 times larger after 2 years). By contrast, this regional heterogeneity makes no difference for older, lower leverage firms (bottom row of Figure 6a), which both make an equal, small, contribution to the aggregate response.

\subsection{Robustness}

In Appendices $\mathrm{F}$ and $\mathrm{G}$ we subject our main result from Section 5.2 to an extensive range of robustness analysis. To preview the results, no alternative cut of the data overturns our findings. In what follows, we comment briefly on the list of sensitivity exercises detailed in Appendices F and G.

\subsubsection{Identification}

For identification, a key challenge is to disentangle fluctuations in collateral values from changes in local demand faced by the firm. The latter is also potentially related to how sensitive real estates prices are to monetary policy shocks in the firm's region. Our strategy based on using director real estate (as directors can live in different regions from their firm), allows us in our relative effect specification to control for region-time fixed effects. By doing so, we are comparing two firms operating in the same region that file accounts in the same month, thereby being exposed to the same local economic conditions. This strategy controls for the linear effect of local demand on the firms' behaviour.

In our baseline regressions, the definition of the region is at the NUTS-1 level, which is relatively coarse. In Figure 28 of the Appendix, we add region-year fixed effects, where regions correspond to the same smaller areas that are used when computing the house price sensitivities. At such disaggregated regional level we lack a sufficient number of observations to include monthly fixed effects, instead we use annual fixed effects, thereby comparing two firms in the 
same region that file accounts in the same calendar year. These results are very similar.

The region-time fixed effects only capture the average responsiveness of firms to local demand. Firms may have heterogeneous responsiveness to shocks to local demand generated by monetary policy. This may also explain our results. For example, directors that live close to their firms would have similar house price sensitivities to the firm's which in turn could correlate with how sensitive demand in the region is to monetary policy shocks. To address this, in Figures 29-30 of Appendix F.2.1, we re-run the specifications corresponding to Figure 6 but only for firms whose directors live more than 30 miles away from the firm's headquarters on average. In Figure 17, we plot the average correlation between the house price sensitivity in the firm's region and in the firm's director's region, based on the average distance between the director and the firm. At 30 miles, the correlation is just 0.4. Using this cut, we find that younger and more levered firms still have a greater employment response to monetary policy shocks when their directors live in more house price sensitive regions.

To reinforce our interpretation that the heterogeneity induced by house price sensitivity is due to the use of housing as collateral, we exploit the fact that directors who are only managers, and not also owners, have much less incentive to pledge personal assets in order to support the firm. Hence if the collateral channel lies behind the heterogeneous response of monetary policy shocks, we would expect to see an effect only based on the house price sensitivity of those directors who are also shareholders in their firm. To avoid the house price sensitivity of non-shareholder director regions's being correlated with the house price sensitivity of the firm's region, for this sub-sample analysis we limit to firms where directors live 30 miles from the firm on average. In Figures 31-32 of Appendix F.2.2 (for shareholder directors) and Figures 33-34 of Appendix F.2.3 (for non-shareholder directors) we show that the differential responses induced by the house price sensitivity of director regions is entirely due to shareholders. For non-shareholders there is no statistically significant difference in the responses for the younger more levered firms based on the house price sensitivity of the directors' region. ${ }^{25}$

Even accounting for directors that live relatively far away from their firm and their shareholder status, there may be some correlation left between demand in the firm's region and house price sensitivities in the director's region if the relative locations of the director and the firm reflects local patterns of commuting. ${ }^{26}$ To further ensure that local demand is not driving our results, in Figures 35-36 of Appendix F.3, we focus on firms that should be insensitive to demand conditions in the local region, namely those operating in the tradeable goods sector (Mian and Sufi, 2014). ${ }^{27}$ Our results are very similar to the baseline. At this point, it is worth

\footnotetext{
${ }^{25}$ To run these specifications we separately calculate at the firm level the average house price sensitivity across directors that are shareholders and across directors that are not shareholders.

${ }^{26}$ We thank Erik Hurst for raising this point.

${ }^{27}$ We proxy this with firms in the manufacturing sector. Specifically, in this specification, we restrict to firms with 2003 UK SIC Codes between 1511 and 3720.
} 
re-emphasising that industry-specific sensitivities to monetary policy shocks are also not driving our results: they are absorbed by industry-time fixed effects.

As with the linear model, adding firm controls has little effect on either the point estimates or the error bands (Figures 39 and 40). As discussed in Section 4, it is not necessary to add firm fixed effects due to the orthogonality of the monetary policy shock. It is also demanding of the data as it involves estimating firm-specific trends in employment growth for each horizon. Nevertheless, in Figures 37 and 38, we estimate the level and relative models also including firm fixed effects, resulting in very similar estimates to the baseline model and a clear economic and statistical difference between the employment response of younger, higher leverage firms whose directors live in more and less house price sensitive regions.

An additional plausible concern is that directors that are located in London are, or run firms that are, systematically different from those in other parts of the UK. For example, London based directors may have better access to financial or political networks. The estimates in Figures 41 and 42 show that excluding directors living in London has no effect on our results.

Finally, our results may be driven by the behaviour of banks. Certain banks may have business models that are based on lending to firms of different types, and their credit provision may be heterogeneous with respect to monetary policy shocks. Similarly, banks that operate in specific regions may be sensitive to house prices in the given region through the value of their mortgage book, for instance. Thus the sensitivity of bank credit supply to monetary policy shocks could be correlated with either the house price sensitivity of director regions or the employment sensitivity of firms along firm characteristics. For firms that have secured debt, we also observe the name of the bank that holds the loan (although not its quantity). This allows us to match firms to their creditor banks and include bank-year fixed effects in the regression to control for any effects that may be due to bank credit supply. ${ }^{28}$ The results shown in Figure 43 of Appendix F.7 are similar to the baseline.

\subsubsection{Measurement and Selection}

Our results so far are based on a model-dependent estimate of the house price sensitivity of the firm's directors. As an alternative, we use the average refusal rate of planning applications for residential projects to split director regions into high and low sensitivity, splitting around an average refusal rate of $25 \%$. Using this measure we find results that are are very similar to our baseline (Figures 44 and 45 in Appendix G.1). Specifically, the formal hypothesis testing of Figure 45 reveals that the employment response of younger, higher levered firms, is statistically and economically significantly different when their directors are living in a high rather than a low refusal rate region.

\footnotetext{
${ }^{28}$ See Anderson, Bahaj, Chavaz, Foulis, and Pinter (2018) for further details on the construction of the bank-year fixed effects.
} 
By looking at house price sensitivity, we are abstracting from the fact that directors live in houses of different values, and are therefore differentially exposed to fluctuations in house prices. To address this, we use the methodology described in Section 3.3, whereby we use information on the value of the house of directors to compute a measure of housing exposure to monetary policy shocks. When using this measure to proxy house price sensitivity at the firm-level, the results are, if anything, even stronger than our baseline, as shown by Figures 46-47 in Appendix G.2.

Firms also borrow using their own commercial real estate as collateral (Chaney, Sraer, and Thesmar, 2012), hence we can consider heterogeneity in the house price sensitivity of the firm's region. This is less well-identified and we can not use region-time fixed effects. However, cutting the data on this dimension (rather than on our baseline specification using the directors' region), and restricting to firms in the tradables sector to mitigate local demand concerns, gives similar results (see Figures 48 and 49 in Appendix G.3).

One may be concerned that our results are driven by the period where interest rates were stuck against the zero lower bound. In Figures 50-51 of Appendix G.4, we therefore end our sample in 2008 and still find a very similar heterogeneity relative to the one estimated over the full sample in Section 5.2.

We can also consider alternative proxies for financial frictions. First, we check whether our results are robust to replacing leverage with credit score as an alternative measure of balance sheet strength. ${ }^{29}$ Figures 52-53 in Appendix G.5 confirm that the pattern of heterogeneity along the dimension of collateral price sensitivity continues to resemble our baseline when using credit score in place of leverage. Second, we show that our results are not specific to our particular choice of age. Other studies have defined young firms at a lower age, e.g. age of 5 . We cut at 15 trading off maximising heterogeneity whilst maintaining a reasonable number of firms in each each group. Nevertheless, we explore changing our age threshold, and the results are similar to our baseline when we instead chose 5 years of age as the threshold, as shown by $54-55$ in Appendix G.6.

Finally, we check whether the patterns of heterogeneity along the dimensions of age, leverage and house price sensitivity are masking heterogeneity in size. We therefore focus on smaller firms with less than 250 employees and find similar results to our full sample, as shown by Figures 56 and 57 in Appendix G.7.

\footnotetext{
${ }^{29}$ We measure the Credit Score of a given firm in a given year using the "QuiScore", which is reported in the FAME dataset. The QuiScore is produced by CRIF Decision Solutions Limited and is designed to reflect the likelihood that the company will fail in the following 12 months. Each firm is assigned a value between 0 and 100, with a larger value indicating a lower probability of failure. We split firms into two categories: lower credit score, for firms with a QuiScore below 60 (a rating below "Stable"); and higher credit score, for firms with a QuiScore of 60 or above (those who are "Stable" or "Secure".)
} 


\section{Further Exploration of the Mechanism}

In this section, we dig deeper into the data and consider alternative left-hand-side variables at the firm-level, which allows us to sharpen our understanding of the mechanism generating the heterogeneity in our baseline results. We consider four different accounting variables: the firm's indebtedness, the value of its current assets, the value of its fixed assets, and its turnover.

Debt As laid out in Section 2, the heart of the collateral channel runs through external borrowing. Therefore the heterogeneity in the employment responses to monetary policy shocks observed in the previous section should be mirrored in the response of firm's debt stocks. Moreover, for unconstrained firms we would not expect collateral values to play a role in governing the dynamics of their debt position. In Figure 7, we show the equivalent to Figure 6a after replacing employment as a left-hand-size variable with logarithmic growth of the firm's total debt stock, measured from its balance sheet. As can be seen, the patterns of heterogeneity are similar when using debt compared to when using employment. If anything, the difference between the impulses shown in the top row of Figure 7 is larger than in our baseline: debt falls by 5 percentage points more for younger and more levered firms whose directors live in high sensitivity region compared to similar firms whose directors live in low sensitivity regions. Figure 58 in the Appendix shows the same model with the time fixed effects.

Figure 7: Level Effects on Total Debt by Age, Leverage and Director Beta, Triple Sorted
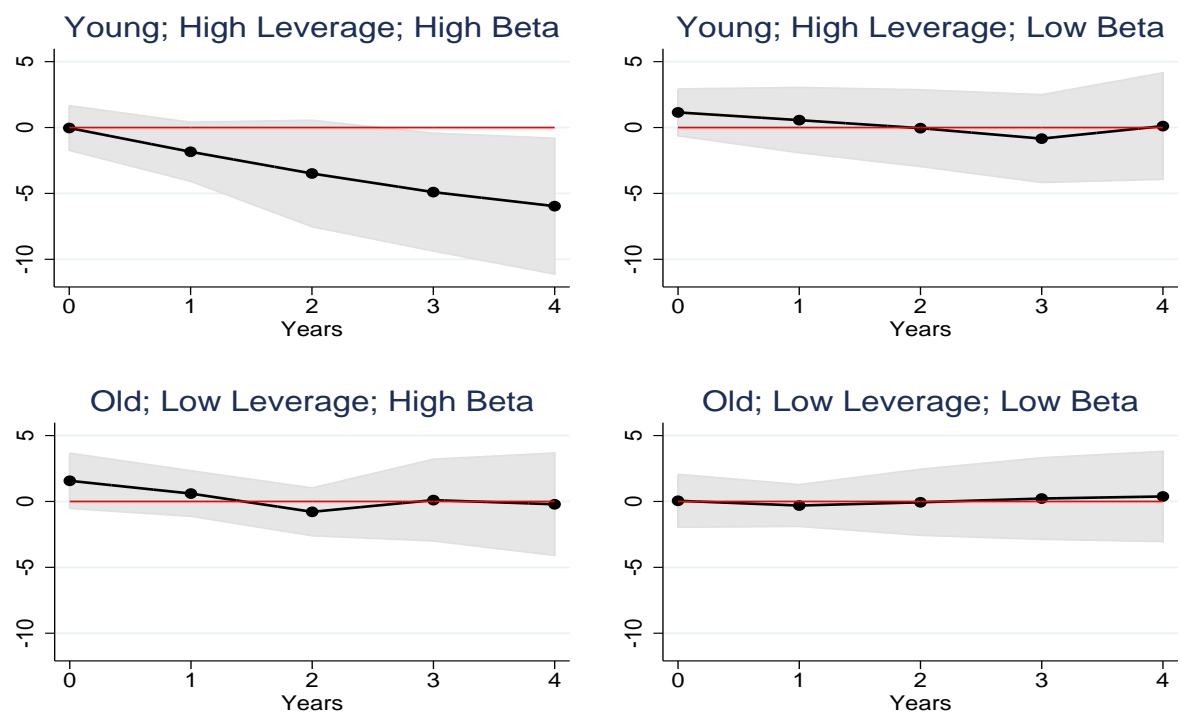

Notes: Firm level responses to a 25bp contractionary monetary policy shock. Black lines are point estimates. Grey shaded area is $90 \%$ confidence interval. The dependent variable is the cumulative growth rate in log points of Total Debt from $t-1$ to $t+h$ where $t$ is the date of the monetary policy shock and $h$ is the $\mathrm{x}$-axis - see specification 1 . All the responses are \%-deviations. 
Current Assets In many theoretical models, the firm's cost of borrowing interacts with employment decisions via a working capital channel. The firm must pay workers in advance of production and therefore requires external financing to employ workers (Christiano, Eichenbaum, and Evans, 2005; Mendoza, 2010). The prepayment of wages and other inputs is recorded as current assets in the firms' accounts. If our results partially reflect a collateral driven working capital constraint, we would expect that firms whose employment is particularly responsive to monetary policy shocks should have particularly responsive current assets. In Figure 8, we explore this by altering our left-hand-size variable, replacing employment growth with current asset growth (with the relative effects shown in Figure 59 in the Appendix). The results again confirm that current assets of younger more levered firms, whose directors live in high house price sensitivity regions, respond the most.

Figure 8: Level Effects on Current Assets by Age, Leverage and Director Beta, Triple Sorted
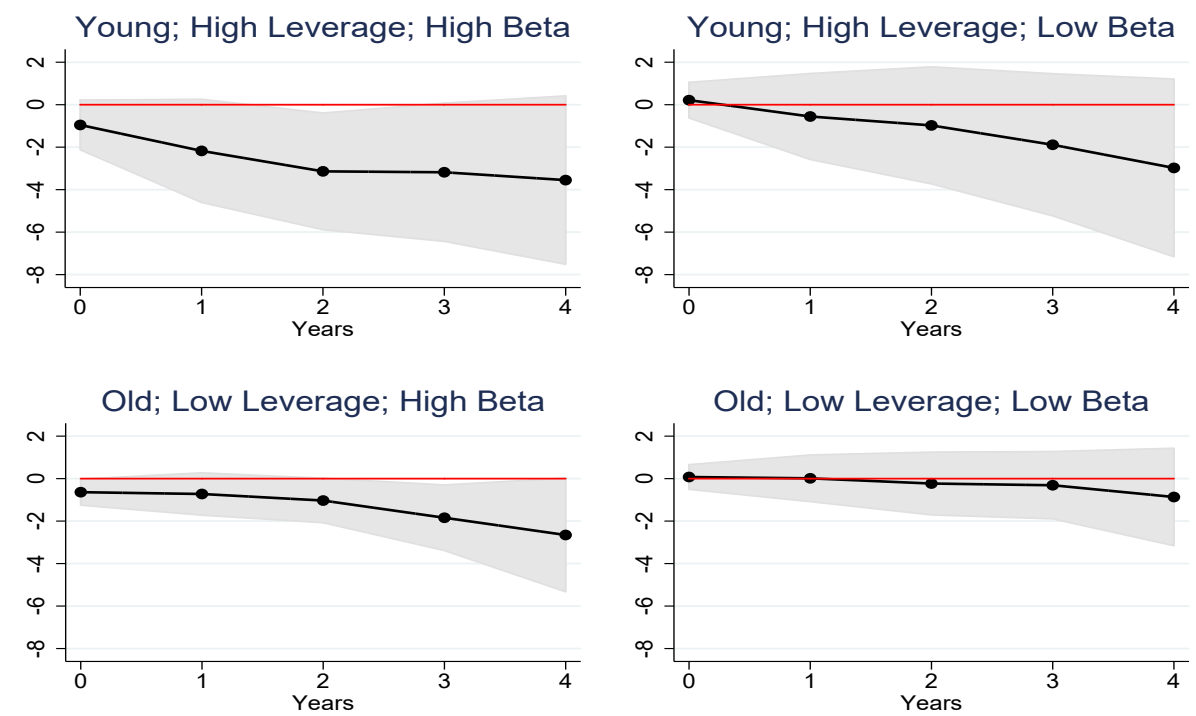

Notes: Firm level responses to a 25bp contractionary monetary policy shock. Black lines are point estimates. Grey shaded area is $90 \%$ confidence interval. The dependent variable is the cumulative growth rate in log points of Current Assets from $t-1$ to $t+h$ where $t$ is the date of the monetary policy shock and $h$ is the x-axis - see specification 1 . All the responses are \%-deviations.

Fixed Assets However, the employment response may be explained not just by a working capital channel. As many recent papers (Ippolito, Ozdagli, and Perez-Orive, 2017; Ottonello and Winberry, 2018; Jeenas, 2018) show, financial constraints are also relevant to how firm investment responds to monetary policy shocks. To the extent that capital and labour are complements in production, a reduction in investment may also reduce firms' hiring. In this paper, we focus on employment, because we have a sample dominated by SMEs, and these 
firms are particularly important for driving aggregate employment dynamics. However, we can assess the heterogeneity in the impact of monetary policy shocks on investment as well. To proxy investment, or more precisely the firm's capital stock, in Figure 9 we use the cumulative growth of fixed assets as a left-hand-side variable (with the relative effects shown in Figure 60 in the Appendix). Again, we find that the patterns of heterogeneity in the investment response maps that of our baseline employment response.

Figure 9: Level Effect on Fixed Assets by Age, Leverage and Director Beta, Triple Sorted
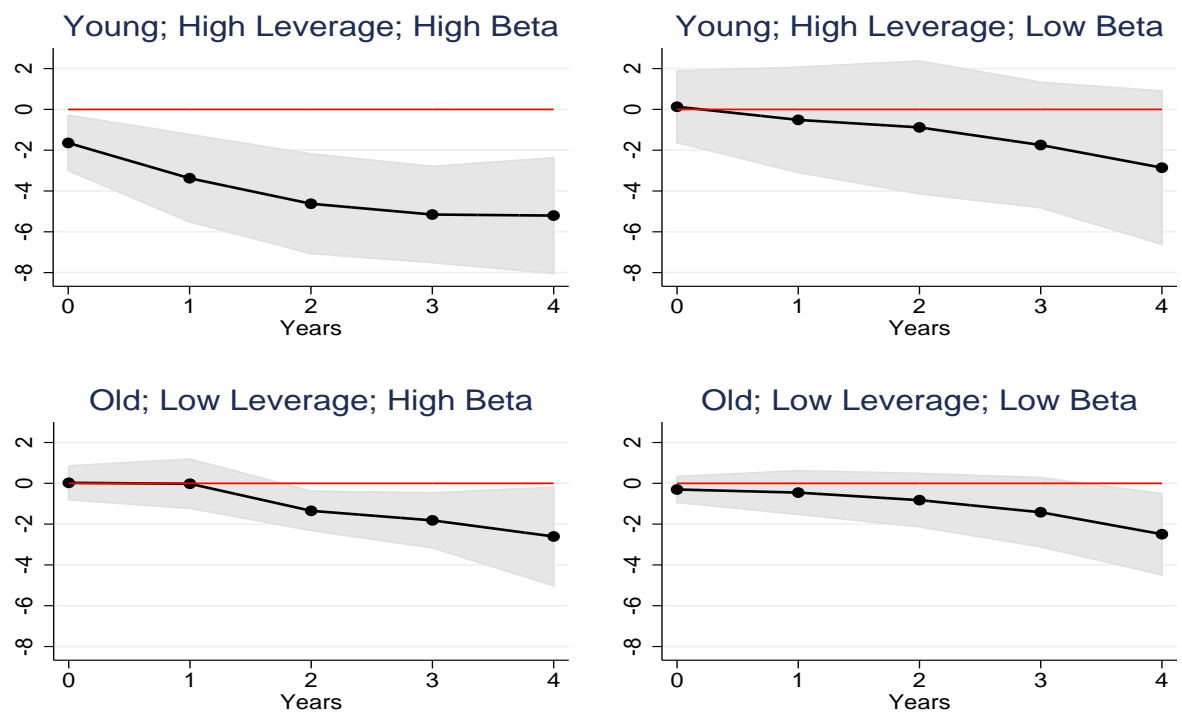

Notes: Firm level responses to a 25bp contractionary monetary policy shock. Black lines are point estimates. Grey shaded area is $90 \%$ confidence interval. The dependent variable is the cumulative growth rate in log points of Fixed Assets from $t-1$ to $t+h$ where $t$ is the date of the monetary policy shock and $h$ is the x-axis - see specification 1 . All the responses are \%-deviations.

Turnover Last, we argued in Section 5.3.1 that our results are not driven by heterogeneity in demand conditions. To further reinforce this finding, we use turnover as a proxy for demand at the firm-level and use it as an alternative left-hand-size variable in our regression. Figure 10 shows that monetary policy shocks have a significant effect on turnover across all firm groups (relative effects shown in Figure 61 in the Appendix), consistent with a decline in aggregate demand. Yet, there is no obvious heterogeneity in the responses of turnover across these firm groups, suggesting that our baseline responses are not a result of these firms experiencing heterogeneous demand following monetary policy shocks. 
Figure 10: Level Effects on Turnover by Age, Leverage and Director Beta, Triple Sorted
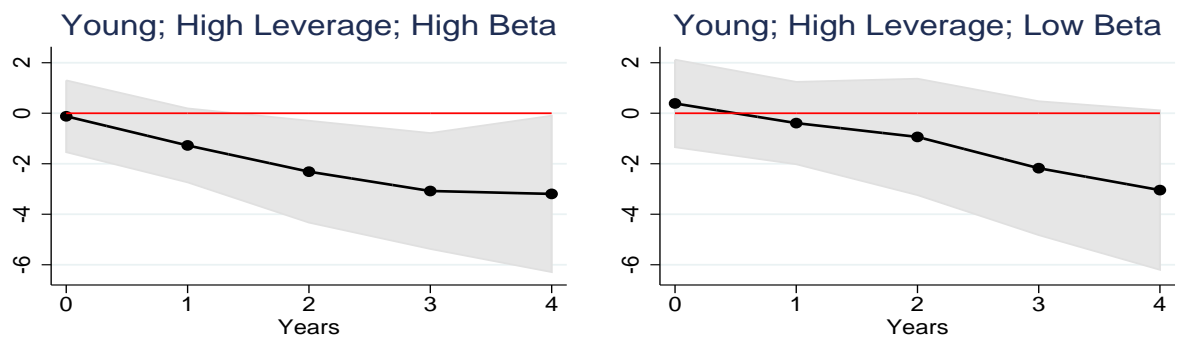

Old; Low Leverage; High Beta
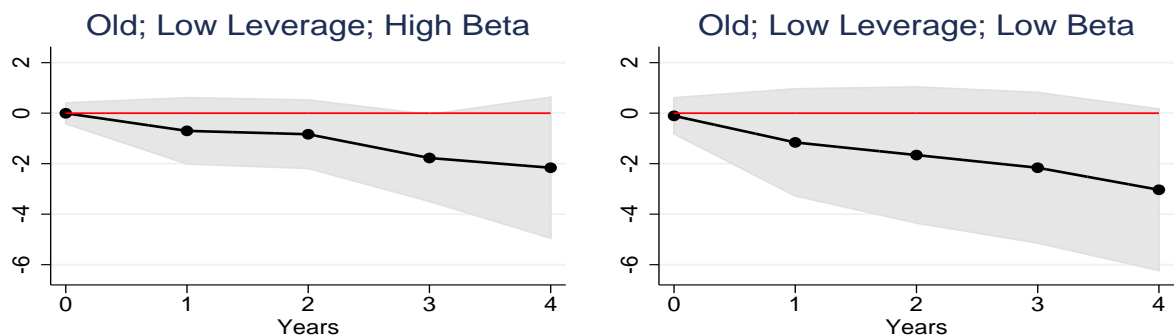

Notes: Firm level responses to a 25bp contractionary monetary policy shock. Black lines are point estimates. Grey shaded area is $90 \%$ confidence interval. The dependent variable is the cumulative growth rate in log points of Turnover from $t-1$ to $t+h$ where $t$ is the date of the monetary policy shock and $h$ is the $\mathrm{x}$-axis - see specification 1 . All the responses are \%-deviations.

\section{Conclusion}

This paper finds that the employment adjustment to monetary policy is large and significant for younger and more levered firms but is small and statistically negligible for older and less levered firms. This heterogeneity becomes even more pronounced when we look at regions with a higher sensitivity of local house prices to monetary policy shocks (or a higher housing supply elasticity). This finding is mirrored by the response of corporate debt to monetary policy shocks.

Our results are consistent with monetary policy transmitting via asset prices through collateral constraints on firms. To arrive at this conclusion, our research design employed various strategies to ensure that we are not simply picking up monetary policy effects via demand channels. Furthermore, this interaction between collateral values, monetary policy and firmlevel characteristics is of quantitative importance. It is large enough both to explain most of the observed firm level heterogeneity in response to monetary shocks and to explain a sizeable share of the aggregate employment response to monetary policy. 


\section{References}

Adelino, M., A. Schoar, And F. Severino (2015): "House Prices, Collateral and SelfEmployment," Journal of Financial Economics, 117(2), 288 - 306.

Anderson, G., S. Bahaj, M. Chavaz, A. Foulis, and G. Pinter (2018): "Lending Relationships and the Collateral Channel," Bank of England Staff Working Paper Series No. 768.

Anderson, G., And A. Cesa-Bianchi (2018): "Firm Heterogeneity, Credit Spreads, and Monetary Policy," Mimeo, Bank of England.

Bahaj, S., A. Foulis, And G. Pinter (2018): "Home Values and Firm Behaviour," Discussion Papers 1724, Centre for Macroeconomics (CFM).

Begenau, J., And J. Salomao (2018): "Firm Financing Over the Business Cycle," Review of Financial Studies, forthcoming.

Bernanke, B. S., M. Gertler, and S. Gilchrist (1999): "The financial accelerator in a quantitative business cycle framework," in Handbook of Macroeconomics, ed. by J. B. Taylor, and M. Woodford, vol. 1, chap. 21, pp. 1341-1393. Elsevier.

Bernanke, B. S., And K. N. Kuttner (2005): "What Explains the Stock Market's Reaction to Federal Reserve Policy?," Journal of Finance, 60(3), 1221-1257.

Catherine, S., T. Chaney, Z. Huang, D. Sraer, and D. Thesmar (2018): "Quantifying Reduced-Form Evidence on Collateral Constraints," .

Chaney, T., D. Sraer, and D. Thesmar (2012): "The Collateral Channel: How Real Estate Shocks Affect Corporate Investment," American Economic Review, 102(6), 2381-2409.

Chari, V. V., L. J. Christiano, and P. J. Kehoe (2013): "The Gertler-Gilchrist Evidence on Small and Large Firm Sales," mimeo, Northwestern University.

Chodorow-Reich, G. (2014): "The Employment Effects of Credit Market Disruptions: Firm-level Evidence from the 2008-09 Financial Crisis," Quarterly Journal of Economics, 129(1), 1-59.

Christiano, L., M. Eichenbaum, and C. Evans (2005): "Nominal Rigidities and the Dynamic Effects of a Shock to Monetary Policy," Journal of Political Economy, 113, No.1.

Christiano, L. J., M. Eichenbaum, and C. L. Evans (1999): "Monetary policy shocks: What have we learned and to what end?," in Handbook of Macroeconomics, ed. by J. B. Taylor, and M. Woodford, vol. 1, chap. 2, pp. 65-148. Elsevier.

Christiano, L. J., R. Motto, And M. Rostagno (2014): "Risk Shocks," American Economic Review, 104(1), 27-65. 
Cloyne, J., C. Ferreira, M. Froemel, and P. Surico (2018): "Monetary Policy, Corporate Finance and Investment," mimeo, University of California at Davis, Bank of Spain and London Business School.

Cooley, T. F., And V. Quadrini (2001): "Financial Markets and Firm Dynamics," American Economic Review, 91(5), 1286-1310.

Crouzet, N., And N. Mehrotra (2017): "Small and Large Firms over the Business Cycle," FRB Minneapolis Working Paper.

Curdia, V., And M. Woodford (2016): "Credit Frictions and Optimal Monetary Policy," Journal of Monetary Economics, 84(C), 30-65.

Davis, S., J. C. Haltiwanger, And S. Schuh (1996): "Job creation and destruction," Mit Press.

Decker, R. A., J. C. Haltiwanger, R. S. Jarmin, and J. Miranda (2018): "Changing Business Dynamism and Productivity: Shocks vs. Responsiveness," NBER Working Papers 24236, National Bureau of Economic Research, Inc.

Dinlersoz, E., S. Kalemli-Ozcan, H. Hyatt, and V. Penciakova (2018): "Leverage over the Life Cycle and Implications for Firm Growth and Shock Responsiveness," Nber conference paper, NBER.

Drechsel, T. (2018): "Earning-based borrowing constraints and macroeconomic fluctuations," Mimeo,, London School of Economics.

Driscoll, J. C., And A. C. KraAy (1998): "Consistent Covariance Matrix Estimation With Spatially Dependent Panel Data," The Review of Economics and Statistics, 80(4), 549-560.

FAiA, E., And T. Monacelli (2007): "Optimal interest rate rules, asset prices, and credit frictions," Journal of Economic Dynamics and Control, 31(10), 3228-3254.

Farre-Mensa, J., AND A. Ljungqvist (2016): "Do Measures of Financial Constraints Measure Financial Constraints?," The Review of Financial Studies, 29(2), 271-308.

Fort, T. C., J. Haltiwanger, R. S. Jarmin, and J. Miranda (2013): "How Firms Respond to Business Cycles: The Role of Firm Age and Firm Size," IMF Economic Review, 61(3), 520-559.

Gan, J. (2007): "Collateral, debt capacity, and corporate investment: Evidence from a natural experiment," Journal of Financial Economics, 85(3), 709-734.

Gerko, E., And H. Rey (2017): "Monetary Policy in the Capitals of Capital," Journal of the European Economic Association, 15(4), 721-745.

Gertler, M., And S. Gilchrist (1994): "Monetary Policy, Business Cycles, and the Behavior of Small Manufacturing Firms," The Quarterly Journal of Economics, 109(2), 309-40. 
Gertler, M., S. Gilchrist, And F. M. Natalucci (2007): "External Constraints on Monetary Policy and the Financial Accelerator," Journal of Money, Credit and Banking, 39(2-3), 295-330.

Gertler, M., And P. Karadi (2015): "Monetary Policy Surprises, Credit Costs, and Economic Activity," American Economic Journal: Macroeconomics, 7(1), 44-76.

Gorodnichenko, Y., And M. Weber (2016): "Are Sticky Prices Costly? Evidence from the Stock Market," American Economic Review, 106(1), 165-199.

Gurkaynak, R., B. Sack, and E. Swanson (2005): "Do Actions Speak Louder Than Words? The Response of Asset Prices to Monetary Policy Actions and Statements," International Journal of Central Banking, 1(1).

Hadlock, C., And J. Pierce (2010): "New Evidence on Measuring Financial Constraints: Moving Beyond the KZ Index," The Review of Financial Studies.

Haltiwanger, J., R. S. Jarmin, and J. Miranda (2013): "Who Creates Jobs? Small versus Large versus Young," The Review of Economics and Statistics, 95(2), 347-361.

Hilber, C. A. L., And W. Vermeulen (2016): "The Impact of Supply Constraints on House Prices in England," The Economic Journal, 126(591), 358-405.

Ippolito, F., A. K. Ozdagli, And A. Perez-Orive (2017): "The Transmission of Monetary Policy through Bank Lending: The Floating Rate Channel," Finance and Economics Discussion Series 2017-026, Board of Governors of the Federal Reserve System (U.S.).

Jeenas, P. (2018): "Monetary Policy Shocks, Financial Structure, and Firm Activity: A Panel Approach," mimeo, New York University.

Jermann, U., And V. Quadrini (2012): "Macroeconomic Effects of Financial Shocks," American Economic Review, 102(1), 238-71.

JordA, O. (2005): "Estimation and Inference of Impulse Responses by Local Projections," American Economic Review, 95(1), 161-182.

Kalemli-Ozcan, S., B. Sorensen, C. Villegas-Sanchez, V. Volosovych, and S. Yesiltas (2015): "How to Construct Nationally Representative Firm Level data from the ORBIS Global Database," NBER Working Papers 21558, National Bureau of Economic Research, Inc.

Kiyotaki, N., And J. Moore (1997): "Credit Cycles," Journal of Political Economy, 105(2), 211-48.

Kolasa, M., And G. Lombardo (2014): "Financial Frictions and Optimal Monetary Policy in an Open Economy," International Journal of Central Banking, 10(1), 43-94.

Kudlyak, M., And J. M. Sanchez (2017): "Revisiting the behavior of small and large firms during the 2008 financial crisis," Journal of Economic Dynamics and Control, 77, 48 - 69. 
Liam, C., AND Y. MA (2018): "Anatomy of Corporate Borrowing Constraints," mimeo, MIT and Chicago Booth.

Linde, J., F. Smets, And R. Wouters (2016): "Chapter 28 - Challenges for Central Banksâ Macro Models," vol. 2 of Handbook of Macroeconomics, pp. 2185 - 2262. Elsevier.

Liu, Z., P. Wang, and T. Zha (2013): "Land-Price Dynamics and Macroeconomic Fluctuations," Econometrica, 81(3), 1147-1184.

MendozA, E. G. (2010): "Sudden Stops, Financial Crises, and Leverage," American Economic Review, 100(5), 1941-66.

Mertens, K., and M. O. Ravn (2013): "The Dynamic Effects of Personal and Corporate Income Tax Changes in the United States," American Economic Review, 103(4), 1212-47.

Mian, A., And A. Sufi (2011): "House Prices, Home Equity-Based Borrowing, and the US Household Leverage Crisis," American Economic Review, 101(5), 2132-56.

\section{3}

(2014): "What Explains the 20072009 Drop in Employment?," Econometrica, 82(6), 2197-

Moscarini, G., And F. Postel-Vinay (2012): "The Contribution of Large and Small Employers to Job Creation in Times of High and Low Unemployment," American Economic Review, 102(6), 2509-2539.

Ottonello, P., And T. Winberry (2018): "Financial Heterogeneity and the Investment Channel of Monetary Policy," NBER Working Paper, (24221).

Ramey, V. A. (2016): "Macroeconomic Shocks and Their Propagation," vol. 2 of Handbook of Macroeconomics, pp. 71 - 162. Elsevier.

Stock, J. H., And M. W. Watson (2012): "Disentangling the Channels of the 2007-2009 Recession," NBER Working Papers 18094, National Bureau of Economic Research, Inc.

Townsend, R. M. (1979): "Optimal contracts and competitive markets with costly state verification," Journal of Economic Theory, 21(2), 265-293. 


\section{Appendix}

\section{A Data Construction and Sample Selection}

\section{A.1 Sample Selection}

Figure 11: Sample Coverage of Total Employment

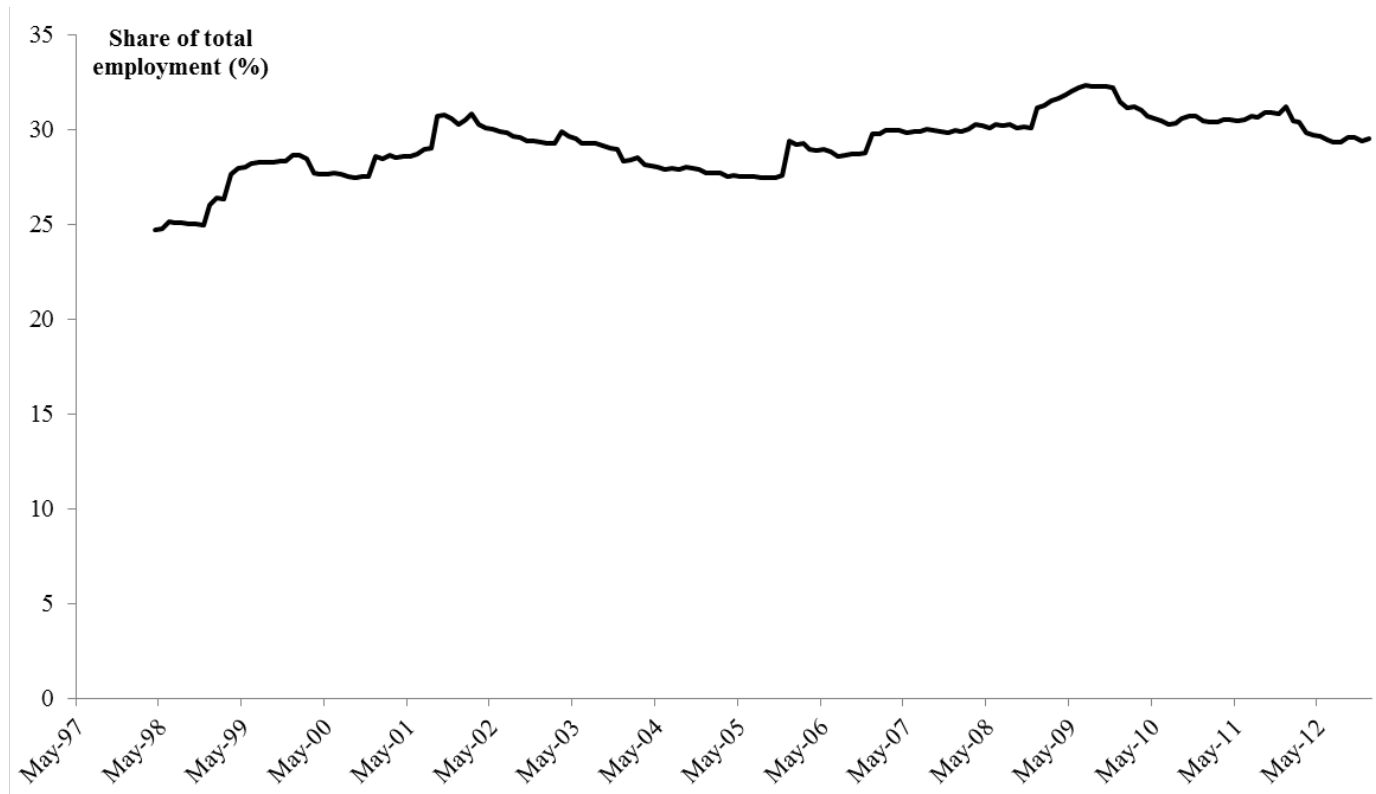

Notes: The figure presents the share of aggregate employment (from the same industries, sourced from the ONS) from the firms in our regression sample. The exact calculation is the rolling sum of employment who filed accounts in the past 12 months over aggregate employment in the month. 
Figure 12: Employment Growth at the Firm and Aggregate Level

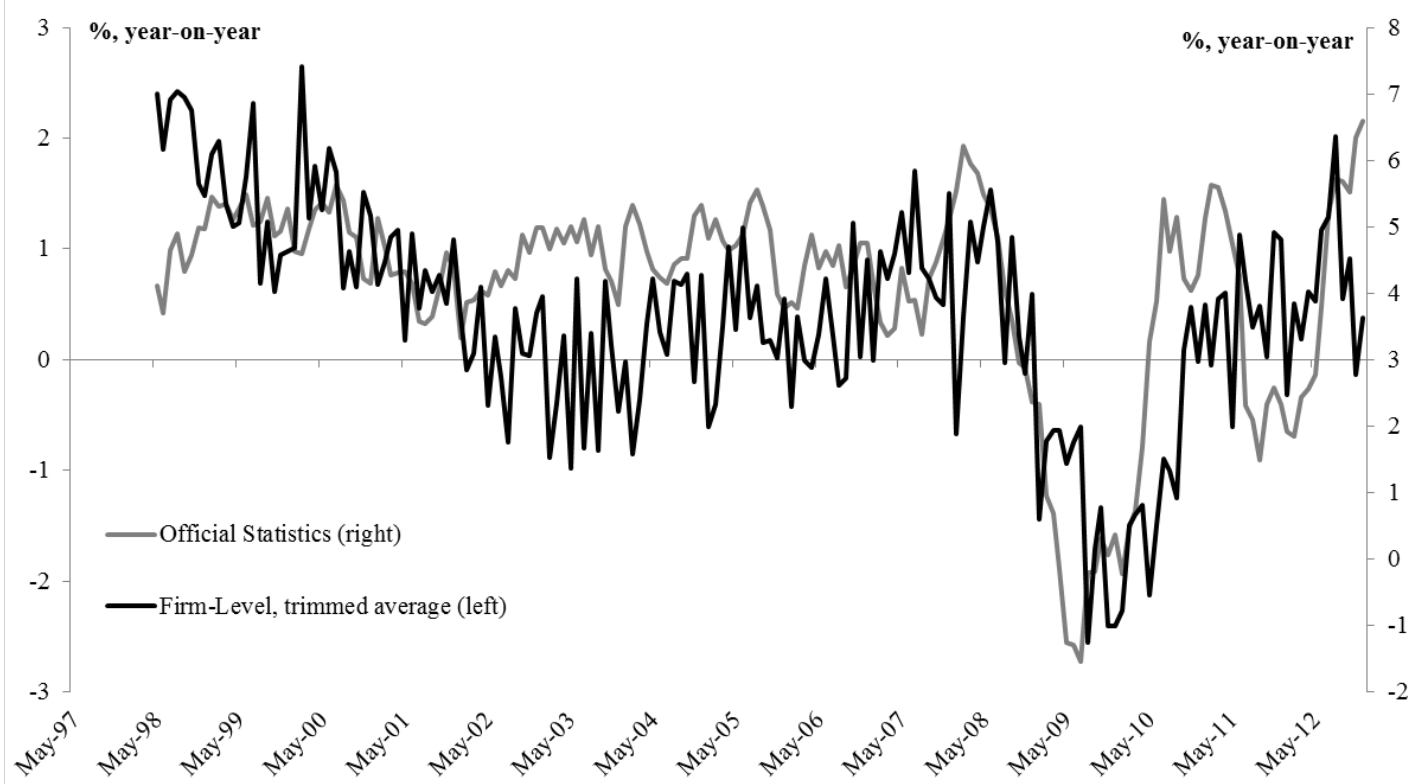

Notes: The figure presents the aggregate employment growth (year-on-year, from the same industries, sourced from the ONS, grey line right) against the unweighted average (trimmed at 1/99\%) employment growth of firms in the regression sample that file in the same aggregate month (black line, right).

Table 3: Summary Statistics of Firms That Do and Do Not Report Employment

\begin{tabular}{|c|c|c|c|c|}
\hline \multicolumn{5}{|c|}{ Summary Statistics } \\
\hline & \multicolumn{2}{|c|}{ Age (Years) } & \multicolumn{2}{|c|}{ Leverage (\% Assets) } \\
\hline & Mean & Median & Mean & Median \\
\hline All Firms & 7 & 4 & 93 & 77 \\
\hline Regression Sample & 22 & 15 & 78 & 61 \\
\hline
\end{tabular}

Notes: Age is defined as the number of years elapsed from the date of incorporation date. Leverage is measured as the ratio of the balance sheet items "Total Liabilities" to "Total Assets". The first row presents summary statistics for all firms that satisfy the company type and industry codes described in Section 3.2. This sample does not limit to firms that report employment. The second row presents summary statistics for the firms in our baseline regression sample. This includes the additional restriction that firms report employment growth over a four year horizon. 


\section{A.2 Filing Months}

Figure 13: Distribution of Filing Dates by Month

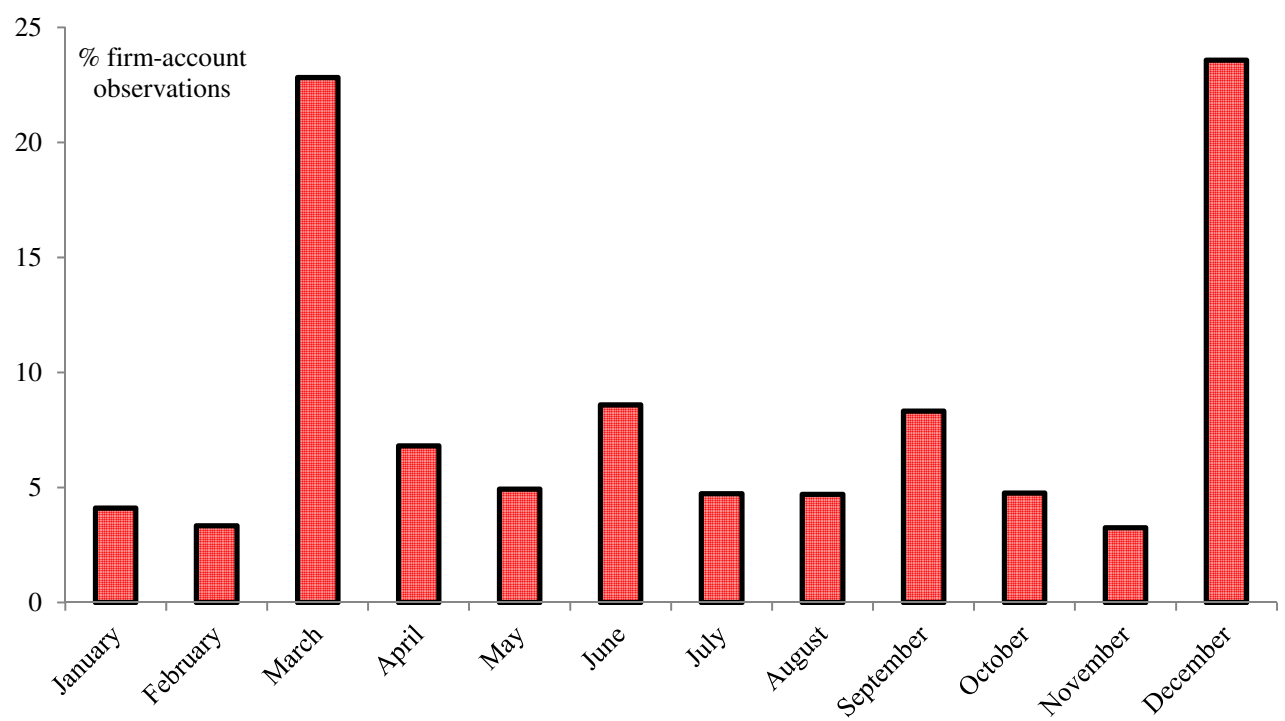

Notes: The Figure presents the distribution across months in which firms file their accounts.

\section{A.3 Regional Variation in House Price Sensitivities}

To estimate spatial variation in the sensitivity of real estate prices to monetary policy shocks, we proceed as follows. First, we apply local projection methods and estimate region-by-region the following house price regression:

$$
\log \left(P_{t+h}\right)-\log \left(P_{t-1}\right)=a+\beta^{h} \times M P_{t}+\text { controls } s_{t}+\varepsilon_{t}^{h},
$$

where $h$ is the horizon (in months) over which the local projection model is estimated, and $P_{t}$ is a monthly repeat sales real estate price index, obtained from the Land Registry's Price Paid dataset, covering 172 regions in England and Wales. ${ }^{30}$ As controls, we include a linear and a quadratic time trend. For each region $j$, we estimate 3 up to horizon $h=24$, and sum the estimated $\beta$ s to obtain a region-specific measure of house price sensitivity:

$$
B_{j}=\sum_{i=1}^{h} \beta^{i} .
$$

To illustrate how much more sensitive house prices in the high-sensitivity regions are to monetary policy shocks, we estimate the following monthly regression:

\footnotetext{
${ }^{30}$ As mentioned in the main text the one area omitted is the Square Mile financial district in London, in which there is very little residential property and no house price index is calculated.
} 
Figure 14: The Relative Response of House Prices to Monetary Policy in High-Sensitivity Regions

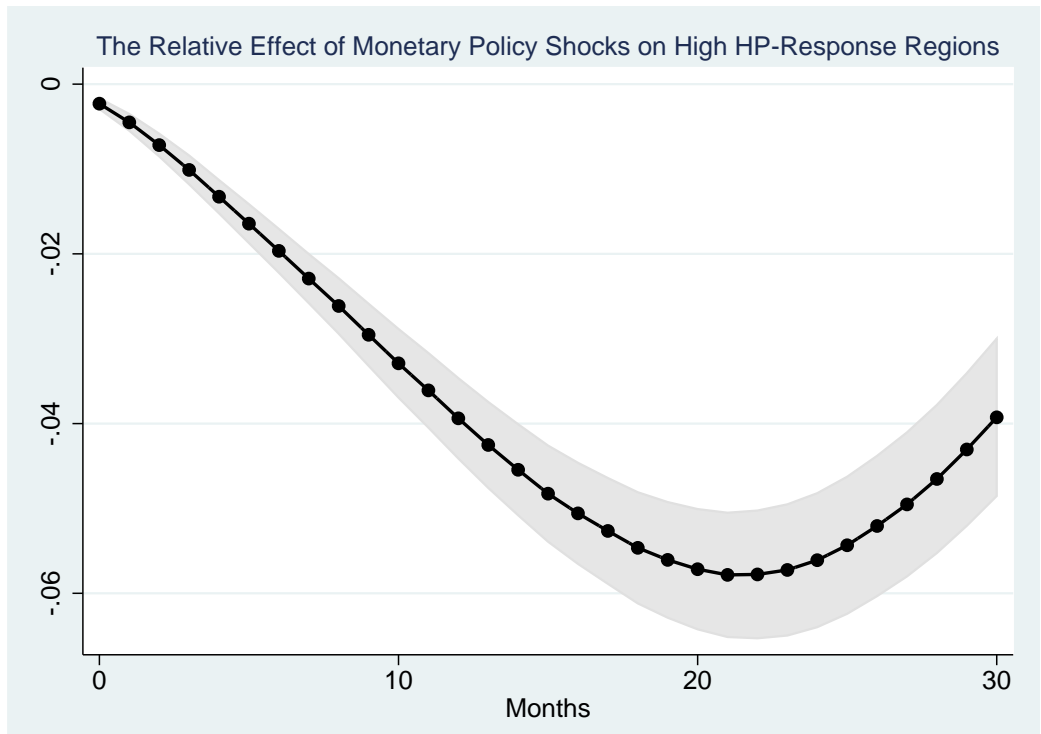

Notes: Regional house prices responses to a 100bp standard deviation contractionary monetary policy shock. Black lines are point estimates. Grey shaded area is $90 \%$ confidence interval. The dependent variable is the cumulative growth rate in log points of house prices from $t-1$ to $t+h$ where $t$ is the date of the monetary policy shock and $h$ is the x-axis.

$$
\log \left(P_{j, t+h}\right)-\log \left(P_{j, t-1}\right)=a_{j}+\mu_{t}+\beta^{h} \times D_{j}^{H P} \times M P_{t}+\varepsilon_{t}^{h},
$$

where the subscript $j$ denotes the region $(j=1,2, \ldots, 173), a_{j}$ is a region fixed effect, $\mu_{t}$ is a time fixed effect, and $D_{j}^{H P}$ is a dummy variable taking value 1 if the given region has a high (above the median) value of $B_{j}(4)$. Figure 14 shows that a $100 \mathrm{bp}$ contractionary monetary policy shock has an average 6pp larger peak effect in regions whose house price sensitivity is above the median. This confirms the quantitatively large regional heterogeneity in the sensitivity of real estate prices to monetary policy shocks, which is a major source of variation allowing us to test the financial accelerator mechanism.

As an alternative measure of regional house price sensitivities, we use the refusal rate of planning applications on residential projects consisting of 10 or more dwellings, as constructed in Hilber and Vermeulen, 2016. The primary source is the Department of Communities and Local Government, and the measure aims to capture the regulatory restrictiveness of local governments on housing supply. Although the measure is based on new construction projects, it also proxies the regulatory stance on improvements of the existing housing stock. Given the endogenous and cyclical nature of refusal rates (i.e. number applications is high/low during economic booms/busts), we use for each region the average refusal rates between 1979 and 2008.

Figures 15 and 16 illustrate the regional variation in our estimated $\beta$ measure and the refusal 
Figure 15: Regional Variation in House Price Sensitivity to Monetary Policy Shocks: 24 month horizon

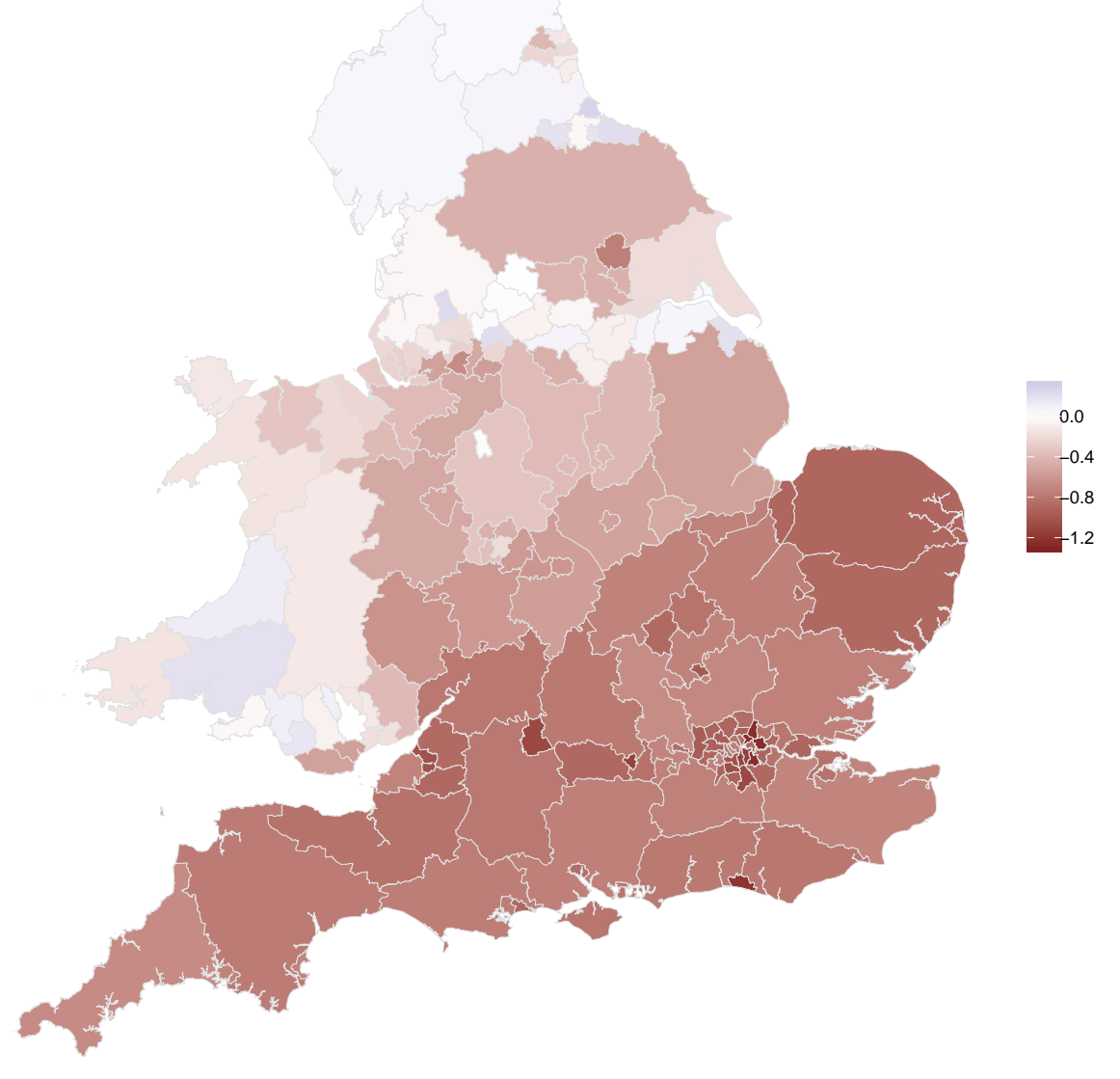

rates. House price sensitivities are typically higher in the South than in the North. 
Figure 16: Regional Variation in Average (1979-2008) Refusal Rates of Residential Planning Applications

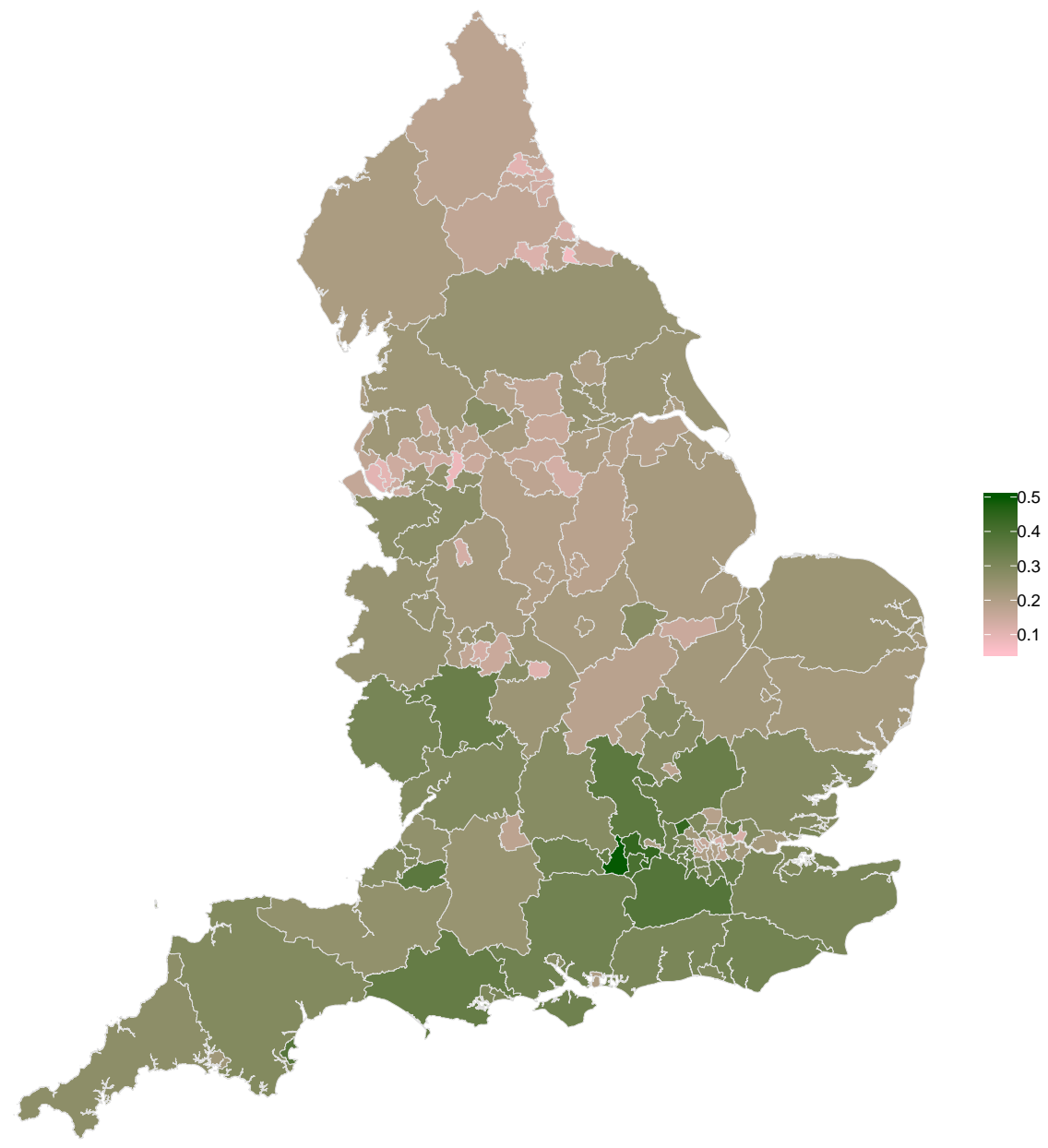

Figure 17: Correlation between Firm and Director Betas

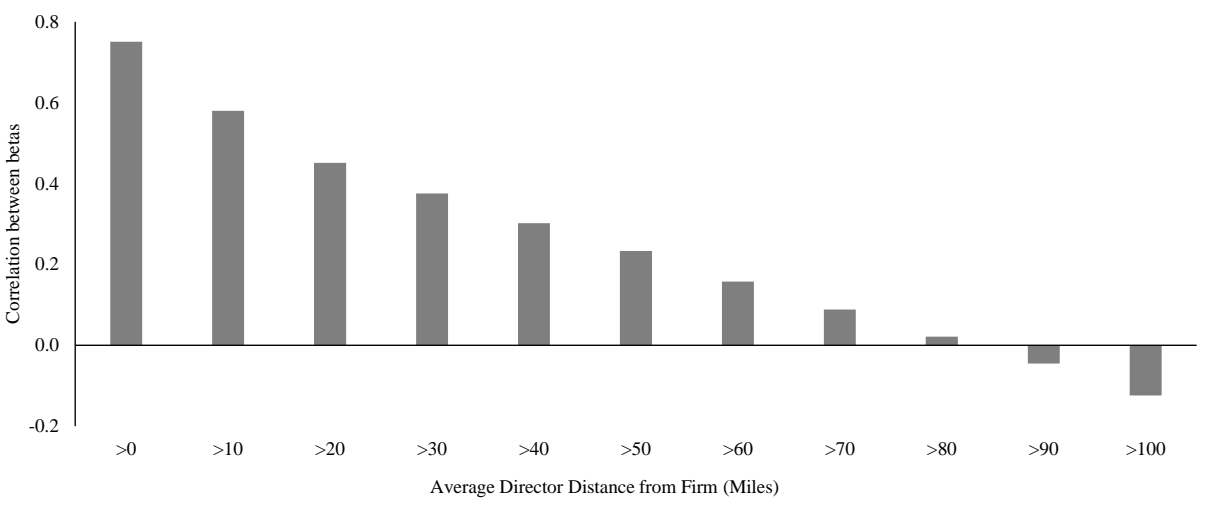




\section{B Monetary Policy Surprises and VAR Macro Evidence}

Figure 18: The Gerko-Rey instrument for UK monetary policy shocks

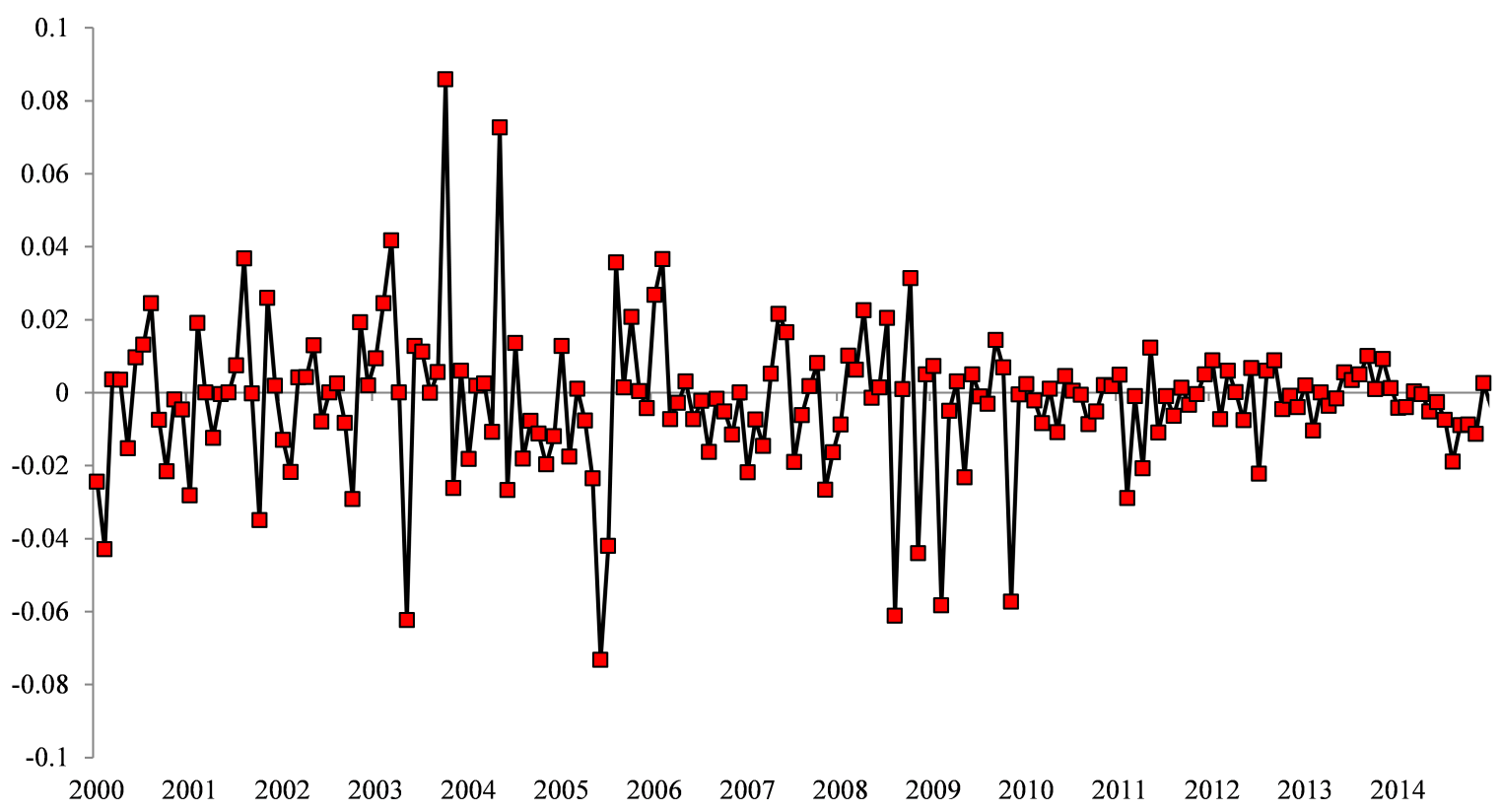

Notes: Instrument for monetary policy shocks from Gerko-Rey (January 2001 to March 2015). The time series is the raw market surprises to monetary policy announcements. The y-axis can be interpreted as changes in an interest rate.

Figure 19: Monetary Policy Shock Series Extracted From the VAR

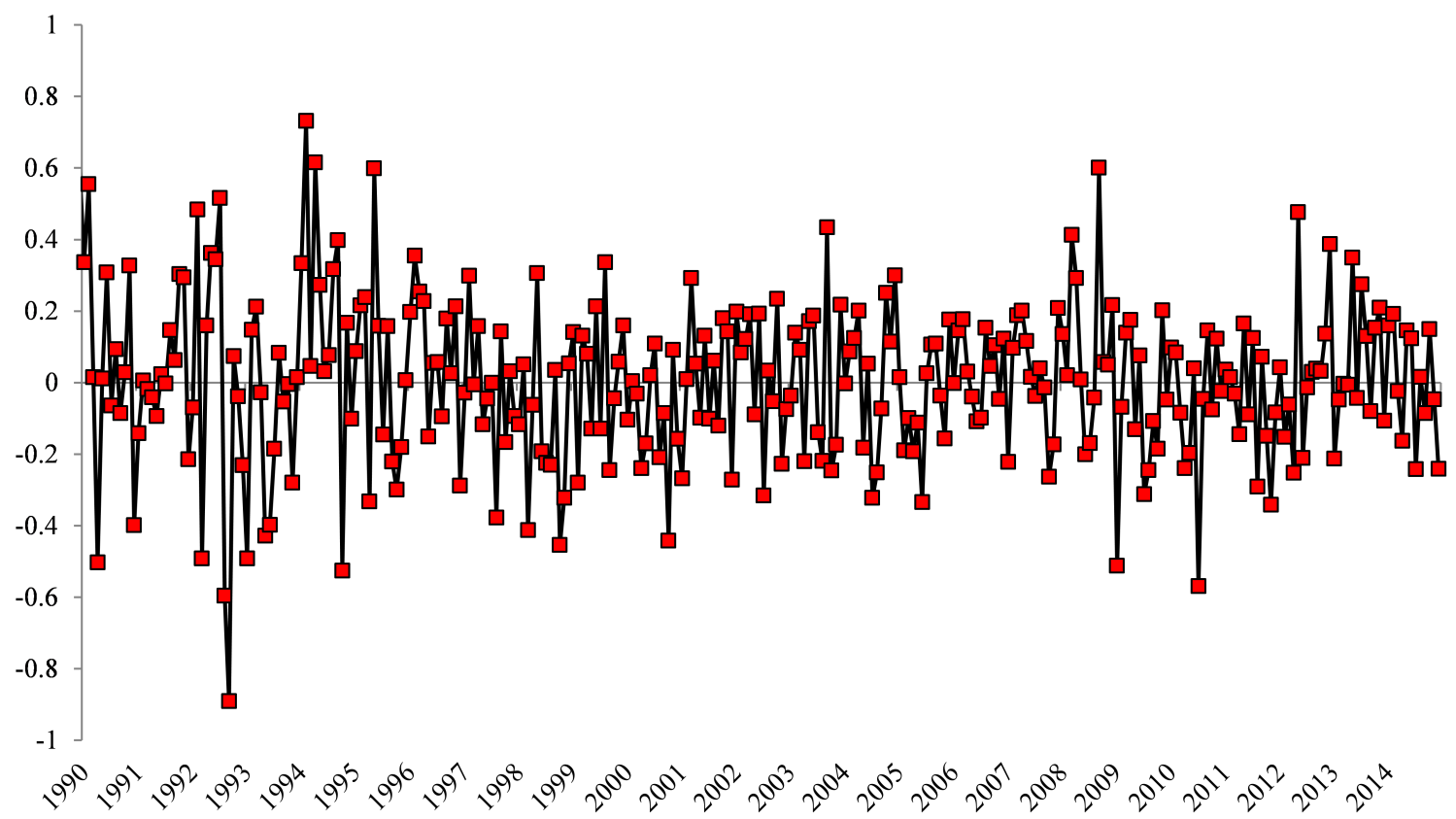

Notes: Monetary monetary policy shock series extracted from the VAR. The y-axis is in stand a can be interpreted as changes in an interest rate. 
Figure 20: Aggregate Impulse Responses to a Monetary Policy Shock
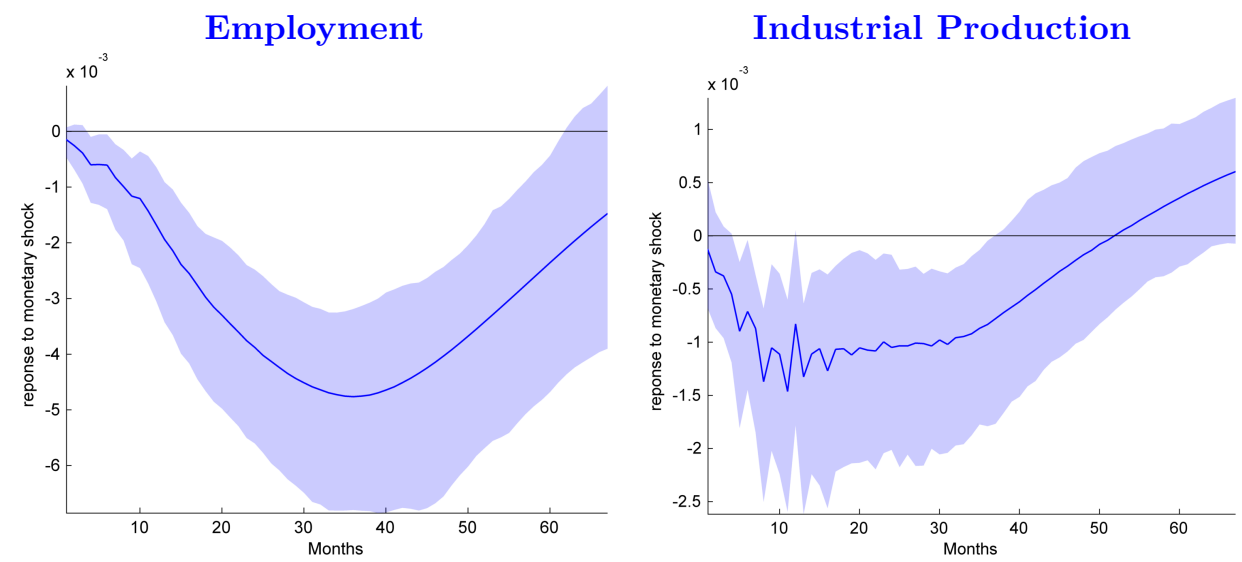

Interest Rate

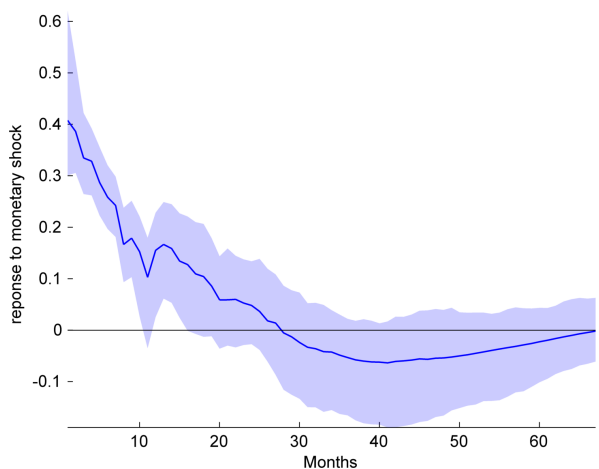

Corporate Spread
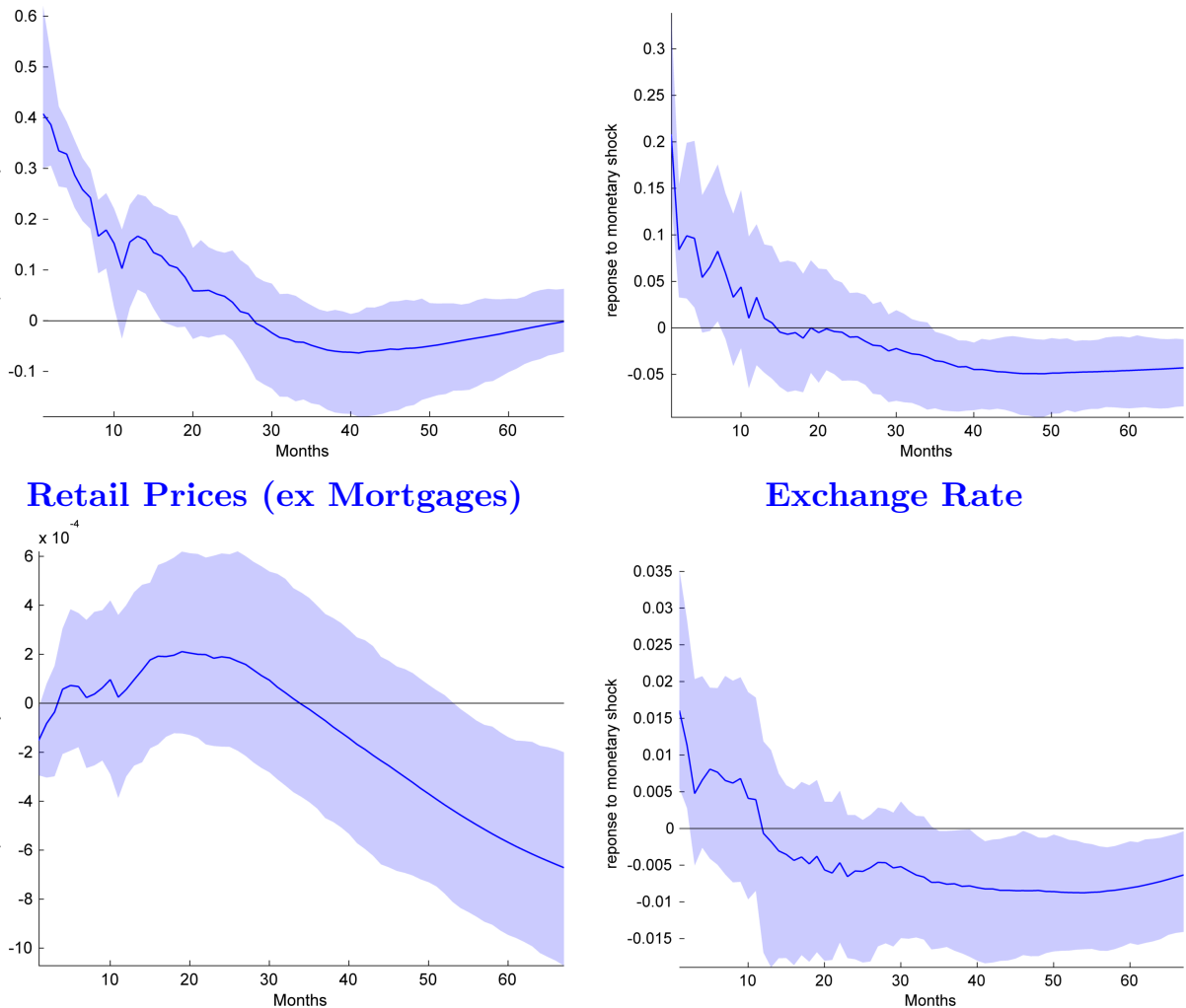

Exchange Rate

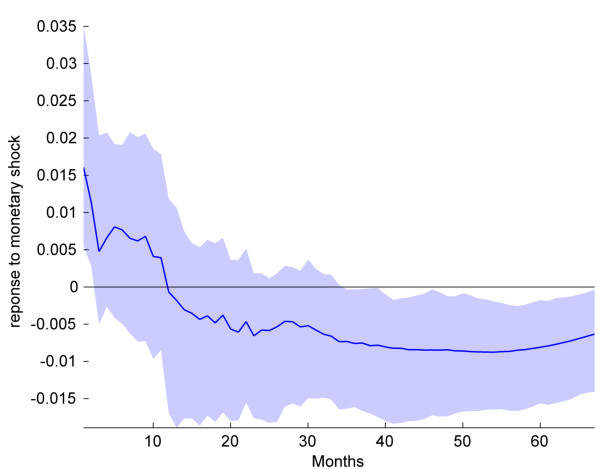

Notes: Estimates are from a proxy SVAR estimated on UK monthly data over the period 1982-2016. Monetary policy shocks are identified using the Gerko-Rey series. The blue solid lines are the point estimates, and the shaded areas are the $90 \%$ confidence intervals constructed from a wild recursive bootstrap.

\section{Theoretical Framework}

The results above suggest that proxies for financial constraints govern the strength of a firm's response to monetary policy shocks. However, such a finding is not necessarily in line with the theory on how firms behave under financial frictions. There are two competing mechanisms. First, ceteribus paribus, a firm facing financial constraints should be less sensitive to shocks 
to the demand for external finance (see Farre-Mensa and Ljungqvist (2016) and Ottonello and Winberry (2018)). The intuition being that constrained firms face a steeper (or potentially vertical) supply curve for funding, and hence any given shift in demand results in a smaller change in quantities. Second, and alternatively, key macroeconomic theories emphasise how financial frictions accelerate the response of activity to monetary policy shocks (Bernanke, Gertler, and Gilchrist (1999)). Expansionary monetary policy raises assets prices, this increases the net worth, or the value of collateral, available to financially constrained firms, alleviating the constraint and allowing a larger expansion.

The goal of this section is to provide a very simple theoretical framework to illustrate this intuition, to fix ideas and to allow us to discipline further analysis of the data so as to disentangle mechanisms. We proceed in a reduced form setting but a fully microfounded general equilibrium model containing similar ideas can be found in Ottonello and Winberry (2018). Imagine a firm $i$ that produces a good using a labour input with production function $Y_{t+1}^{i}=A_{t+1}^{i}\left(N_{t}^{i}\right)^{\alpha}(\alpha \leq 1)$, where $A^{i}$ is an exogenous, stochastic productivity level. The product can be sold at price $p_{t+1}$. Following Catherine, Chaney, Huang, Sraer, and Thesmar (2018), to operate the firm uses a factory which requires a fixed quantity of land $L^{i}$ that has market price $q_{t} L^{i}$. This will serve as a meaningful source of collateral for the firm. The firm keeps no cash in hand (e.g. all profits distributed as dividends at the end of the period), but employees must be hired in the previous period and paid a wage $w_{t}$ in advance of production being brought to market. The firm must therefore borrow $b_{t}=w_{t} N_{i, t+1}$ in order to pay its workers. The risk free interest rate is $r_{t}$, but in addition to it, creditors demand a credit spread $c s^{i}\left(w_{t} N_{t}^{i}, q_{t} L^{i}\right) \geq 0$.

The firm's expected profits are therefore:

$$
\Pi_{t}^{i}\left(N_{t}^{i}\right)=\mathbb{E}\left[p_{t+1} A_{t+1}^{i}\left(N_{t}^{i}\right)^{\alpha}-\left(1+r_{t}+c s_{t}^{i}\right) w_{t} N_{t}^{i}\right]
$$

For convenience, drop $t$ subscripts and let subscripts denote derivatives. We assume that $c s_{1}^{i} \geq 0$ and $c s_{11}^{i} \geq 0$ such that the spread is weakly convex and increasing in the amount borrowed. We also assume that $c s_{2}^{i} \leq 0$ and $c s_{12}^{i} \leq 0$ such that increasing the value of the firm's buildings both weakly lowers the spread and flattens the spread function. Last, the $i$ superscript on $c s$ denotes that there are innate firm level features that govern the ability of the firm to borrow (e.g. opacity). This reduced form way of modelling a financial constraint is similar to ?. In terms of microfoundations, the $c s$ function in the model above is compatible either with models of costly default (e.g. Townsend (1979)) or models of limited commitment/moral hazard (e.g. Kiyotaki and Moore (1997)). The difference with the latter is that the financial friction manifests as a constraint on the quantity of credit available rather than its price (credit rationing), in which case the marginal spread term in the firm's first order condition should be interpreted as the shadow value of a leverage constraint rather than a genuine credit spread. 
Given that the firm acts to maximise profits period by period, the first order condition is:

$$
\mathbb{E}\left[\alpha p A^{i}\right]\left(N^{i}\right)^{\alpha-1}=\left(1+r+c s^{i}+c s_{1}^{i} w N^{i}\right) w .
$$

Taking logarithms yields:

$$
\underbrace{\log \left(M P L^{i}\right)-\log (w)-r}_{\text {unconstrained firm's foc }}=\underbrace{c s^{i}+c s_{1}^{i} w N^{i}}_{\text {wedge due to constraint }},
$$

where $M P L^{i}=\mathbb{E}[\alpha p A]\left(N^{i}\right)^{\alpha-1}$. For simplicity, assume that the aggregate prices and firm specific productivity are uncorrelated. So $\log \left(M P L^{i}\right)=\alpha+\log (\mathbb{E}[p])+\log \left(\mathbb{E}\left[A^{i}\right]\right)+(\alpha-$ 1) $\log (N)$. Define the term $M B^{i}=\log \left(M P L^{i}\right)-\log (w)-r$, such that the efficient level of employment is the level that sets $M B^{i}=0$, and define $M S^{i}=c s^{i}+c s_{1}^{i} w N^{i}$ as the marginal credit spread. Applying the implicit function theorem to 8, we get:

$$
\frac{d N^{i}}{d r}=-\frac{\frac{\partial M B^{i}}{\partial r}-\frac{\partial M S^{i}}{\partial r}}{\frac{(\alpha-1)}{N^{i}}-2 w c s_{1}^{i}-c s_{11}^{i}} .
$$

By construction, $\frac{\partial M B^{i}}{\partial r}$ can be treated as homogeneous among firms and we can drop the $i$ superscript. We assume also that $\frac{\partial M B}{\partial r}=\frac{\partial \log (E(p))}{\partial r}-\frac{\partial \log (w)}{\partial r}-1<0$, which implies that a contractionary monetary policy shock is contractionary for an unconstrained firm. Note that all derivatives with respect to $r$ refer to contractionary shocks:

$$
\frac{d N^{i}}{d r}=-\frac{\frac{\partial M B}{\partial r}-\frac{\partial c s^{i}}{\partial r}-w N^{i} \frac{\partial c s_{1}^{i}}{\partial r}-\frac{\partial w}{\partial r} N^{i} c s_{1}^{i}}{\frac{(\alpha-1)}{N^{i}}-2 w c s_{1}^{i}-c s_{11}^{i}}
$$

Define $\Lambda^{i}=-\left(\frac{(\alpha-1)}{N^{i}}-2 w c s_{1}^{i}-c s_{11}^{i}\right)^{-1}$ and note the following regarding the denominator of 10: (i) it is strictly negative, as we are at an interior maximum, so the sign of $\frac{d N^{i}}{d r}$ is pinned down by the numerator; (ii) consider two firms with different volumes of buildings $L^{i}>L^{j}$ but are otherwise identical. Firm $i$ will hire more workers and will be on a less convex part of the credit spread curve hence the denominator will be smaller for the less constrained firm (this comes from the convexity of the spread). Now consider the numerator. We can write the following:

$$
\frac{\partial M B}{\partial r}-L^{i} \frac{\partial q}{\partial r}\left(c s_{2}^{i}+c s_{12}^{i}\right)-N^{i} \frac{\partial w}{\partial r}\left((1+w) c s_{1}^{i}+c s_{11}^{i}\right) .
$$

The standard assumption in the literature is that wages respond acyclically to monetary policy (see ?) hence we will assume $\frac{\partial w}{\partial r} \approx 0$. A change in the interest rate then has two effects: (i) The first term in 11 captures that it shifts labour demand through its effect on $M B$. Holding prices and wages fixed, a higher interest rate works through the cost channel of monetary policy. 
Even an unconstrained firm needs to pay cash in advance, the higher the interest rate the more expensive that is and the lower the demand for labour. (ii) The second term in 11 captures the effect through the value of the firm's buildings which serve as collateral. Typically, $\frac{\partial q}{\partial r}<0$ and since $c s_{2} \leq 0$ and $c s_{12} \leq 0$, a higher interest rate increases and steepens the credit spread function. This reduces labour demand for constrained firms.

\section{C.1 Constrained versus Unconstrained Firms}

Let $c$ and $u c$ superscripts denote constrained firms and unconstrained firms respectively. An unconstrained firm has the following characteristics: (i) $\Lambda^{u c}=\frac{N^{u c}}{(1-\alpha)}$; (ii) $M S^{u c}=0$; and (iii) $\frac{\partial M S^{u c}}{\partial r}=0$. A constrained firm has $c s^{c}>0, c s_{1}^{c}>0$ and $c s_{2}^{c}>0$; the cross derivatives need only be weakly positive. Now we can write:

$$
\frac{d N^{c}}{d r}-\frac{d N^{u c}}{d r}=\left(\Lambda^{c}-\Lambda^{u c}\right) \frac{\partial M B}{\partial r}-\bar{L} \Lambda^{c} \frac{\partial q}{\partial r}\left(c s_{2}+c s_{12}\right) .
$$

The above is a relative impulse response and hence is an analogue of our empirical analysis in Section ??. If age, leverage and credit score are proxying financial constraints our empirical evidence suggests that $\frac{d N^{c}}{d r}-\frac{d N^{u c}}{d r}<0$. However, note that $\left(\Lambda^{c}-\Lambda^{u c}\right)<0$ so the first term on the right-hand side of equation 12 implies that a shock has a smaller effect on constrained firms due to the fact they are on the upward sloping region of the spread curve. This is the first mechanism highlighted in the first paragraph of this section: constrained firms are less responsive.

The second term on the right-hand side of equation 12 comes from the fact that for the constrained firm, tighter monetary policy, reduces the value of its real estate and therefore tightens the financial constraint. This is the financial accelerator. This makes the constrained firm more sensitive to monetary policy shocks. For constrained firms to respond more, this effect needs to dominate. The relative sensitivity of constrained firms is increasing in $\frac{\partial q}{\partial r}$, i.e. the sensitivity of asset prices to interest rates. In order for constrained firms to respond more, we need the term $\frac{\partial q}{\partial r}$ to be sufficiently large.

We can also say that if $\frac{d N^{c}}{d r}<\frac{d N}{d r}^{u c}$ as $\alpha \rightarrow 1$, then $\frac{d M S^{c}}{d r}>0$. That is to say that a contractionary monetary policy shock must tighten credit spreads for constrained firms in equilibrium. Since unconstrained firms face no credit spreads, the average spread across firms must also tighten. Inspecting Figure 20 in the Appendix, this is exactly what emerges from the aggregate data using our VAR in Section ??.

Curve Shifting Let us illustrate these effects graphically. Consider two interest rates $r^{1}$ and $r^{2}$ with $r^{2}<r^{1}$. Assume that the two firms face two different marginal spread curves: $M S^{u c} \leq M S^{c}$. In Figure 21 we assume that $\frac{\partial q}{\partial r}=0$. This switches off the financial accelerator. 
The constrained firm increases employment by less due to the convexity of the $M S$ curve (which is what $\Lambda^{c}-\Lambda^{u c}$ captures in the expression 12 above). In Figure 22 we relax the assumption

Figure 21: Employment responses: no financial accelerator

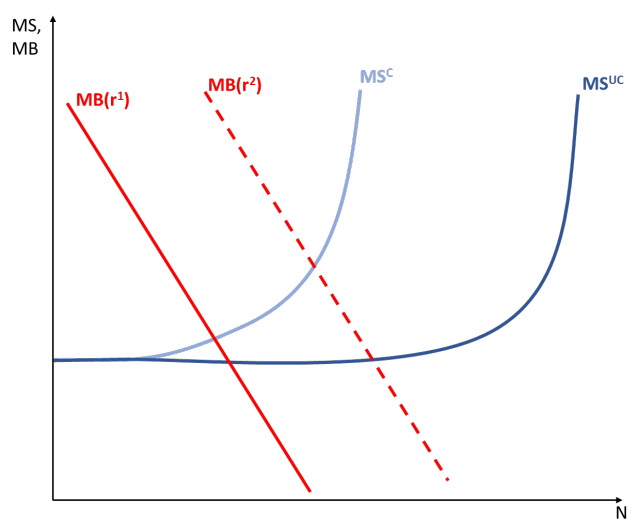

that $\frac{\partial q}{\partial r}=0$. In the left panel we assume that $\frac{\partial q}{\partial r}$ is relatively small. The response of the constrained firm increases but it is still smaller than that of the unconstrained firm. The financial accelerator is weak. Note also that the expansionary monetary policy shock increases the marginal credit spread for the constrained firm. The right panel has a large $\frac{\partial q}{\partial r}$ and thereby a strong financial accelerator. In these circumstances, $M C^{c}$ can shift sufficiently far outward following a fall in interest rates so that the constrained firm would respond more.

Figure 22: Employment responses: with financial accelerator
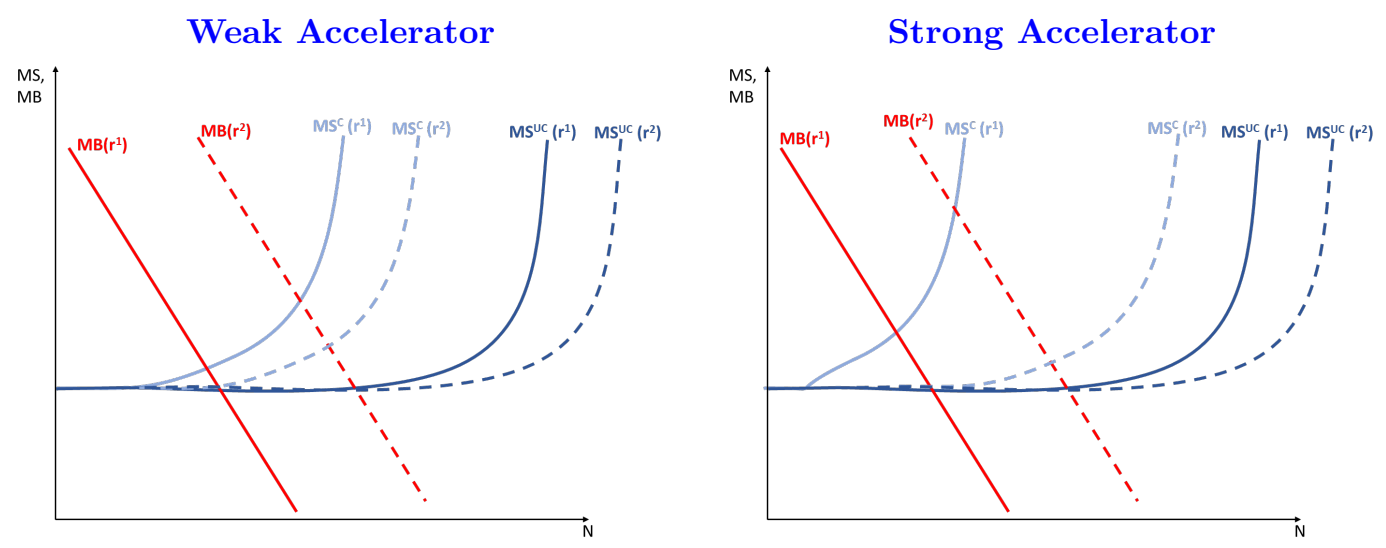


\section{Average Firm-Level Response: Robustness}

\section{D.1 Adding Firm Controls}

Figure 23: Linear Effect of Monetary Policy on Firms: Adding Firm Controls

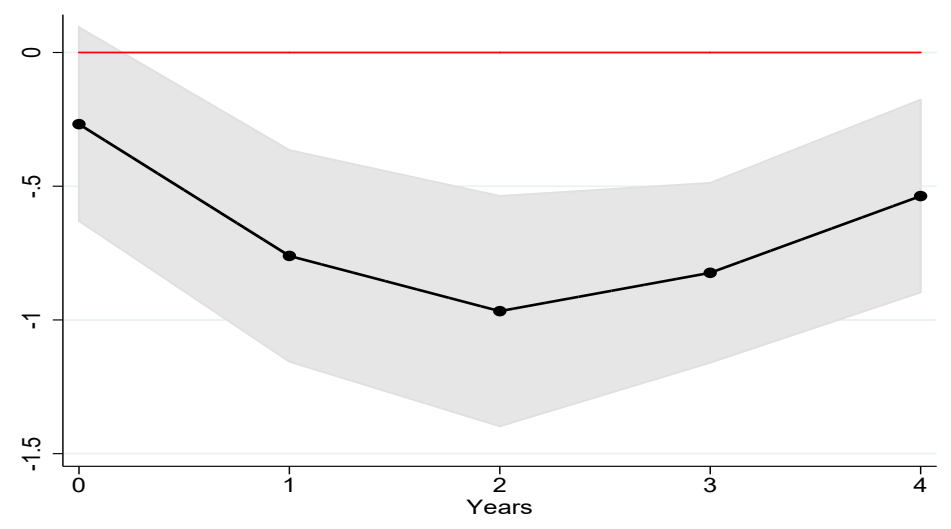

Notes: Firm level responses to a 25bp contractionary monetary policy shock. Black lines are point estimates. Grey shaded area is $90 \%$ confidence interval. The dependent variable is the cumulative growth rate in log points of employment from $t-1$ to $t+h$ where $t$ is the date of the monetary policy shock and $h$ is the x-axis. This regression adds a lag of leverage, a lag of log total assets and the lagged ratio of current to total assets to the baseline regression as controls.

\section{D.2 Adding Firm Fixed Effects}

Figure 24: Linear Effect of Monetary Policy on Firms: Firm Fixed Effect

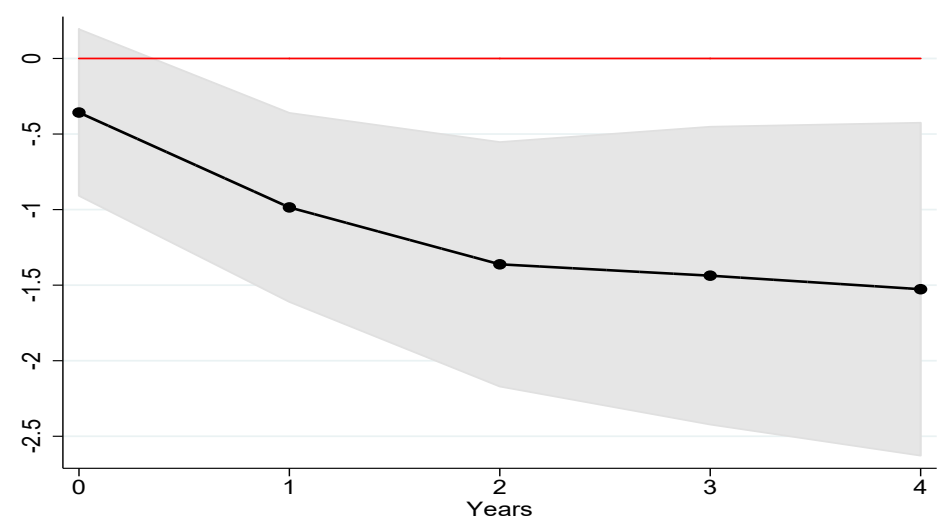

Notes: Firm level responses to a 25bp contractionary monetary policy shock. Black lines are point estimates. Grey shaded area is $90 \%$ confidence interval. The dependent variable is the cumulative growth rate in log points of employment from $t-1$ to $t+h$ where $t$ is the date of the monetary policy shock and $h$ is the x-axis. This regression adds firm fixed effects. 


\section{E Further Results on Firm-Level Heterogeneity}

\section{E.1 Alternative Firm Age Cuts}

Figure 25: Level Effects on Employment by Firm Age Groups
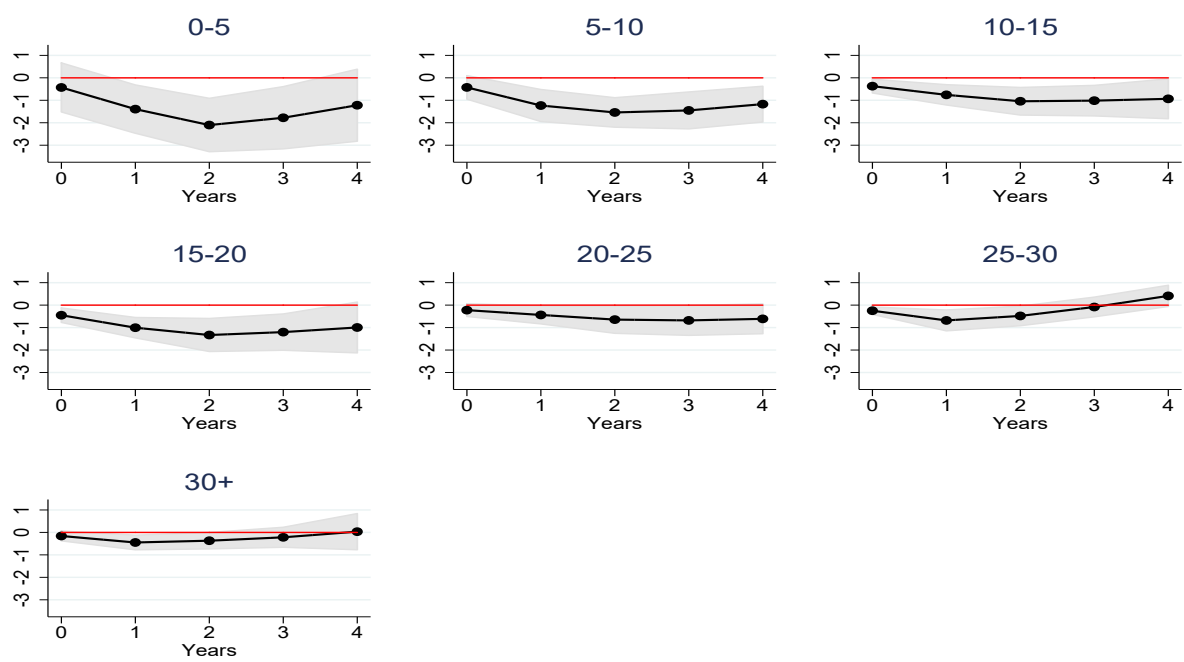

Notes: Firm level responses to a 25bp contractionary monetary policy shock for different firm age groups. Firm Age is measured in years. Black lines are point estimates. Grey shaded area is $90 \%$ confidence interval. The dependent variable is the cumulative growth rate in $\log$ points of Employment from $t-1$ to $t+h$ where $t$ is the date of the monetary policy shock and $h$ is the x-axis see specification 1 . 


\section{E.2 Alternative Firm Leverage Cuts}

Figure 26: Level Effects on Employment by Firm Leverage Groups
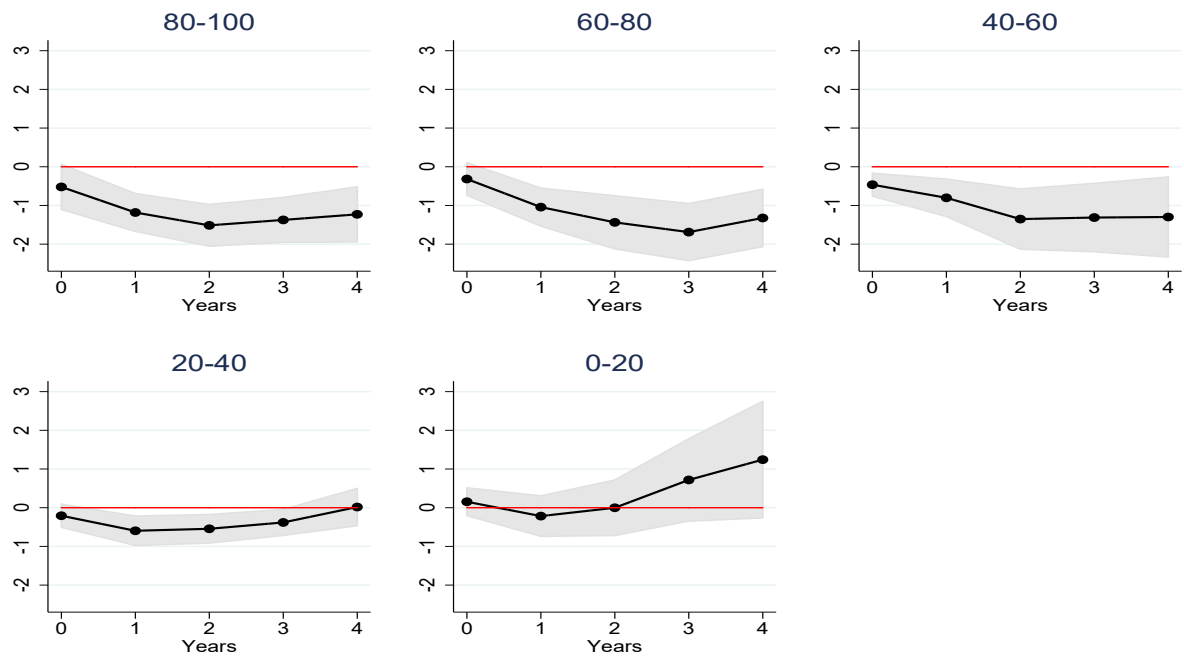

Notes: Firm level responses to a 25bp contractionary monetary policy shock for different firm leverage groups. Firm leverage is measured as the ratio of the balance sheet items "Total Liabilities" to "Total Assets". Black lines are point estimates. Grey shaded area is $90 \%$ confidence interval. The dependent variable is the cumulative growth rate in $\log$ points of Employment from $t-1$ to $t+h$ where $t$ is the date of the monetary policy shock and $h$ is the x-axis - see specification 1 .

\section{E.3 Alternative Firm Size Cuts}

Figure 27: Level Effects on Employment by Firm Size Groups
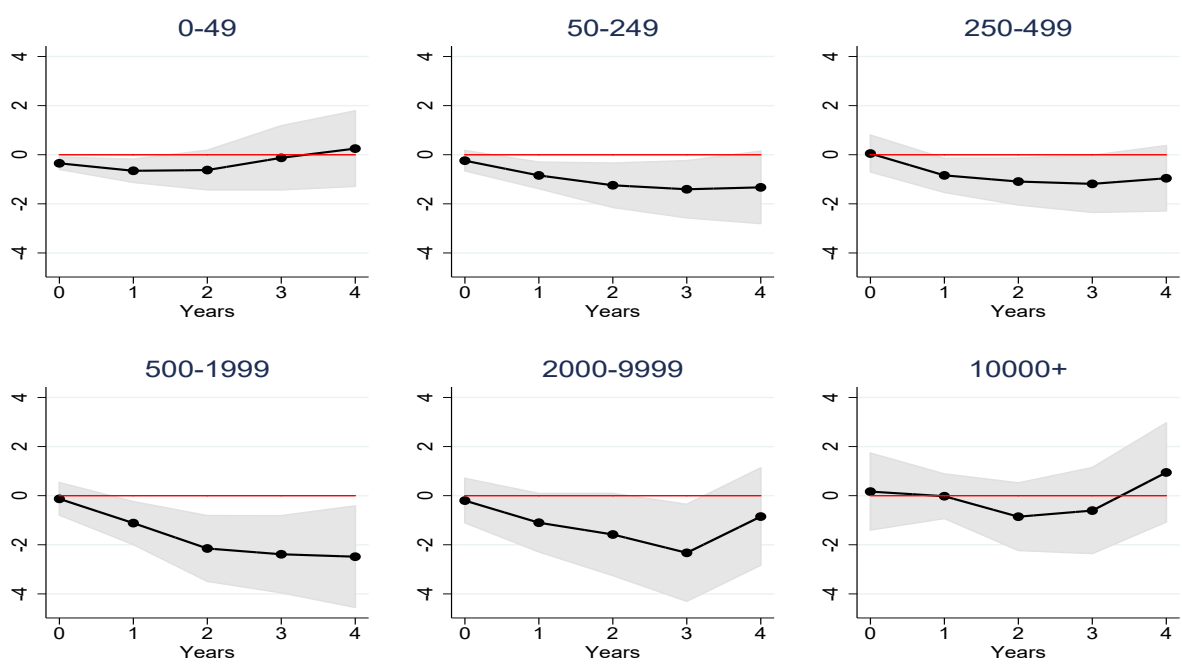

Notes: Firm level responses to a 25bp contractionary monetary policy shock for different firm size groups. Firm size is measured as the "Number of Employees". Black lines are point estimates. Grey shaded area is $90 \%$ confidence interval. The dependent variable is the cumulative growth rate in log points of Employment from $t-1$ to $t+h$ where $t$ is the date of the monetary policy shock and $h$ is the $\mathrm{x}$-axis - see specification 1 . 


\section{F Robustness: Identification}

\section{F.1 Adding Region-Year Fixed Effects}

Figure 28: Relative Effects on Employment by Age, Leverage and Director Beta, Triple Sorted
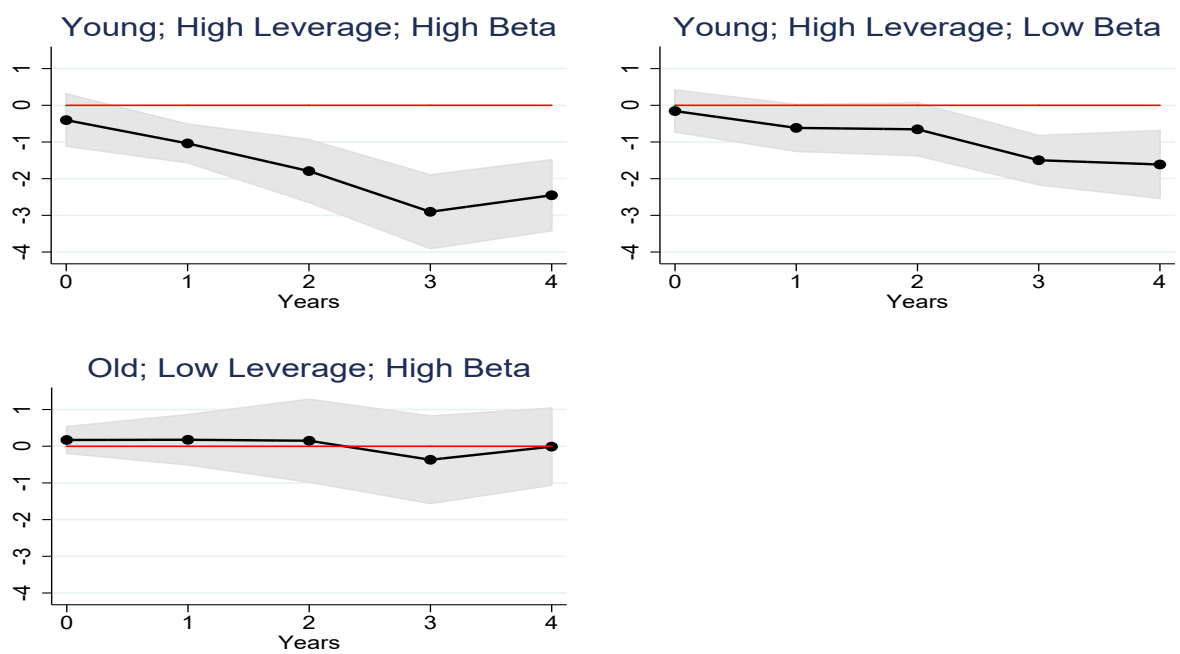

Notes: Firm level responses to a 25bp contractionary monetary policy shock. Black lines are point estimates. Grey shaded area is $90 \%$ confidence interval. The dependent variable is the cumulative growth rate in log points of Employment from $t-1$ to $t+h$ where $t$ is the date of the monetary policy shock and $h$ is the x-axis. All the responses are relative to the group of older and more levered firms in low- $\beta$ region (omitted given the inclusion of industry-month and region-year fixed effects - see specification 2 ). 


\section{F.2 Directors Who Live 30 Miles Away}

\section{F.2.1 All Directors}

Figure 29: Level Effects on Employment by Age, Leverage and Director Beta, Triple Sorted
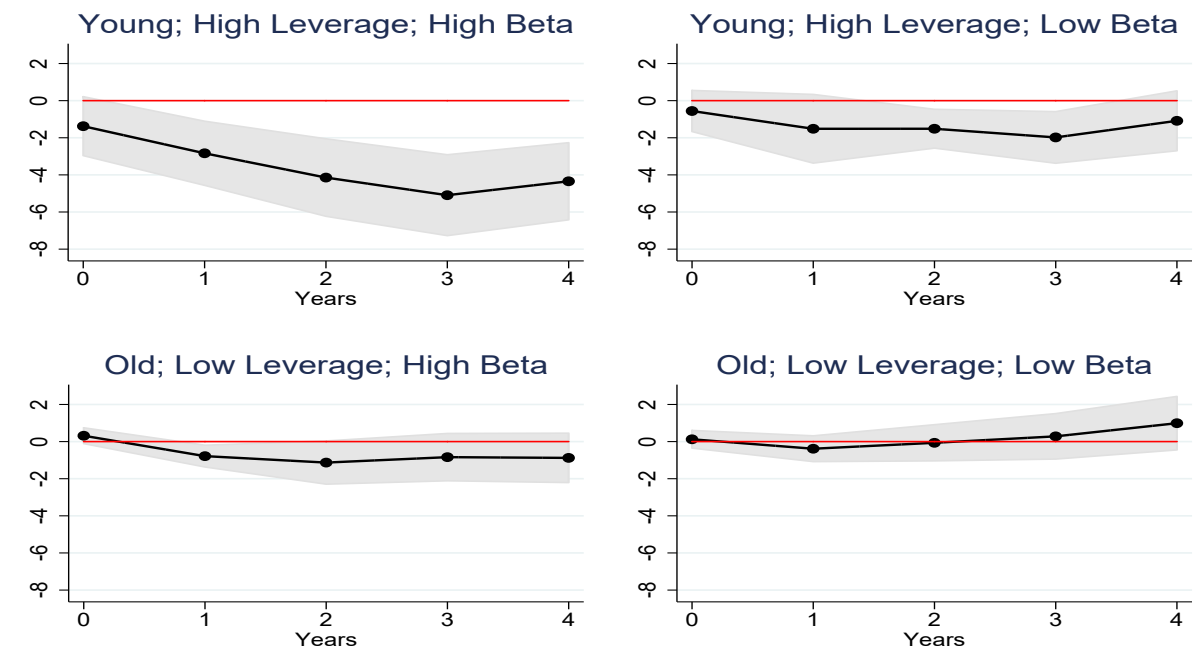

Notes: Firm level responses to a 25bp contractionary monetary policy shock. Black lines are point estimates. Grey shaded area is $90 \%$ confidence interval. The dependent variable is the cumulative growth rate in log points of Employment from $t-1$ to $t+h$ where $t$ is the date of the monetary policy shock and $h$ is the x-axis - see specification 1 . All the responses are \%-deviations.

Figure 30: Relative Effects on Employment by Age, Leverage and Director Beta, Triple Sorted
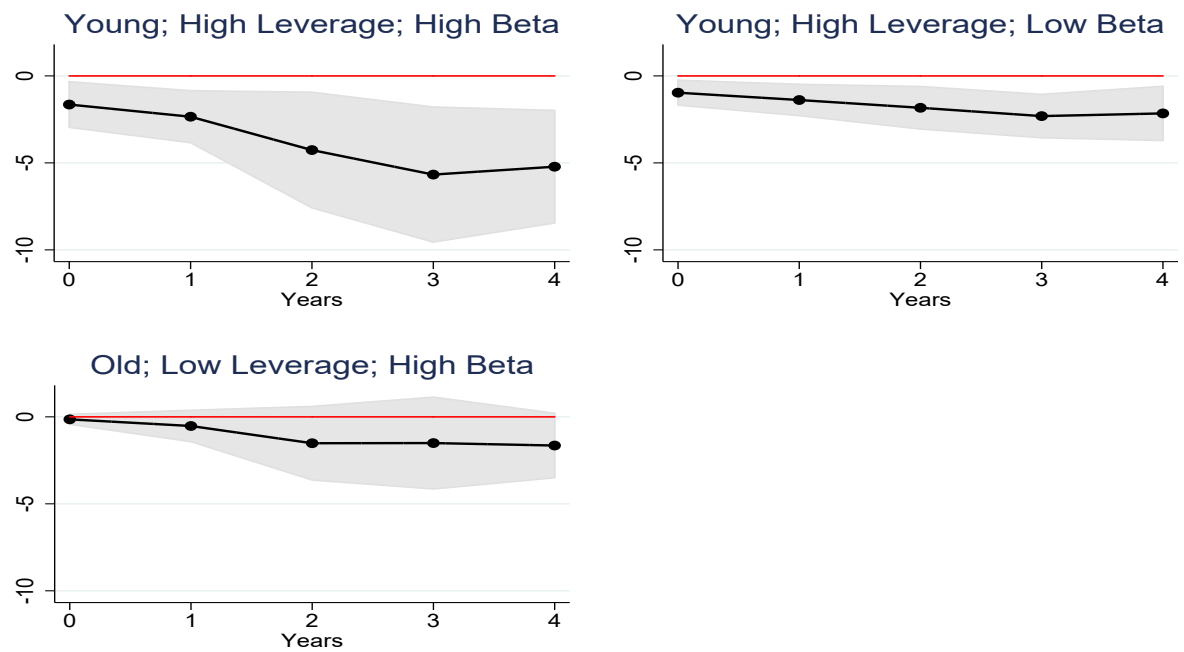

Notes: Firm level responses to a 25bp contractionary monetary policy shock. Black lines are point estimates. Grey shaded area is $90 \%$ confidence interval. The dependent variable is the cumulative growth rate in log points of Employment from $t-1$ to $t+h$ where $t$ is the date of the monetary policy shock and $h$ is the x-axis. All the responses are relative to the group of older and more levered firms in low- $\beta$ region (omitted given the inclusion of industry-month and NUTS1-month fixed effects - see specification 2). 


\section{F.2.2 Shareholder Directors}

Figure 31: Level Effects on Employment by Age, Leverage and Director Beta, Triple Sorted
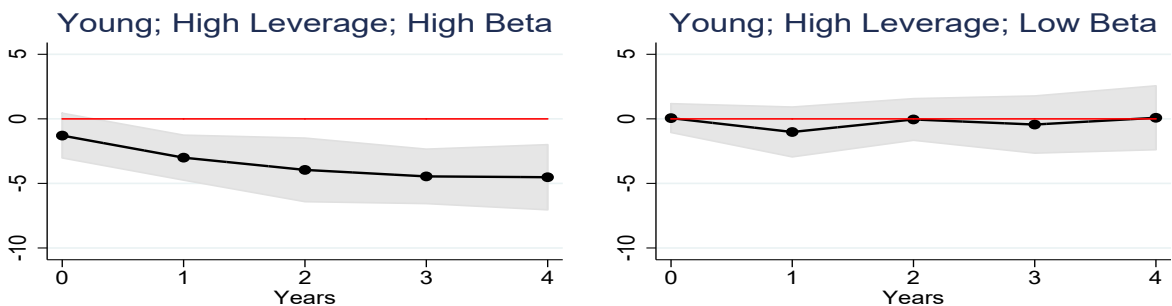

Old; Low Leverage; High Beta
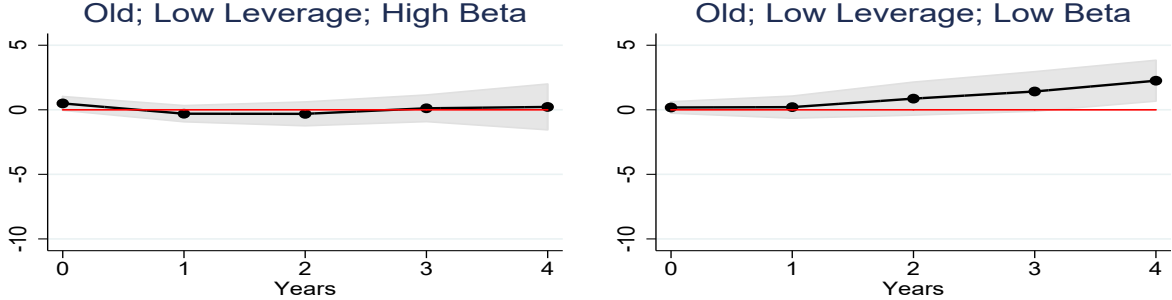

Notes: Firm level responses to a 25bp contractionary monetary policy shock. Black lines are point estimates. Grey shaded area is $90 \%$ confidence interval. The dependent variable is the cumulative growth rate in log points of Employment from $t-1$ to $t+h$ where $t$ is the date of the monetary policy shock and $h$ is the x-axis - see specification 1 . All the responses are \%-deviations.

Figure 32: Relative Effects on Employment by Age, Leverage and Director Beta, Triple Sorted
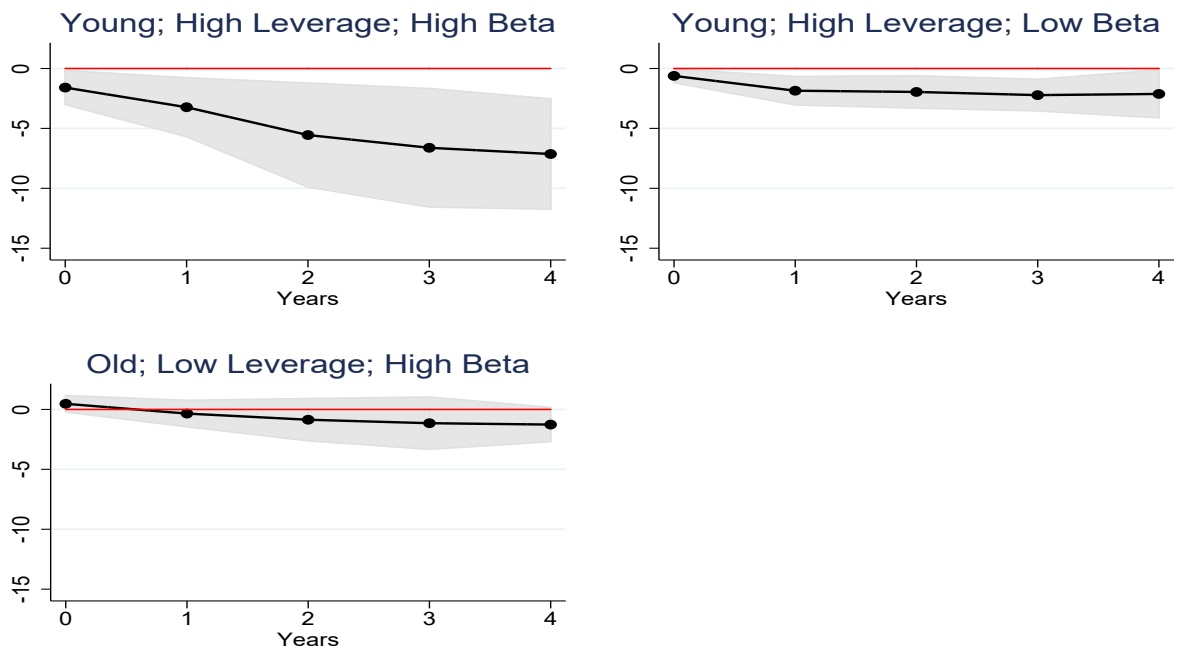

Notes: Firm level responses to a 25bp contractionary monetary policy shock. Black lines are point estimates. Grey shaded area is $90 \%$ confidence interval. The dependent variable is the cumulative growth rate in log points of Employment from $t-1$ to $t+h$ where $t$ is the date of the monetary policy shock and $h$ is the x-axis. All the responses are relative to the group of older and more levered firms in low- $\beta$ region (omitted given the inclusion of industry-month and NUTS1-month fixed effects - see specification 2). 


\section{F.2.3 Non-Shareholder Directors}

Figure 33: Level Effects on Employment by Age, Leverage and Director Beta, Triple Sorted
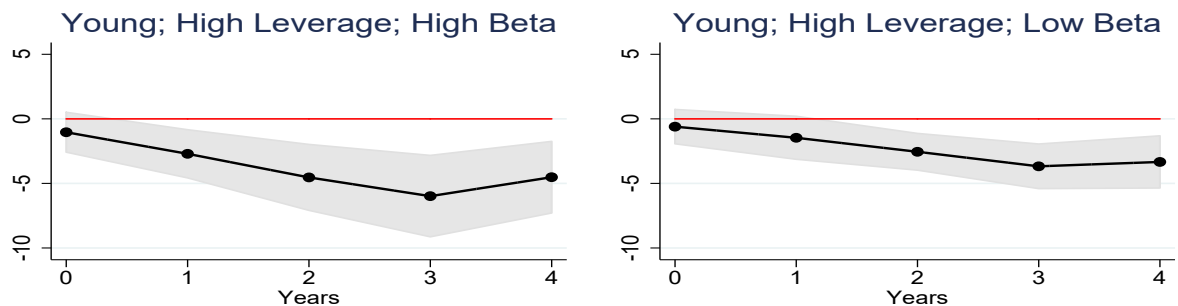

Old; Low Leverage; High Beta
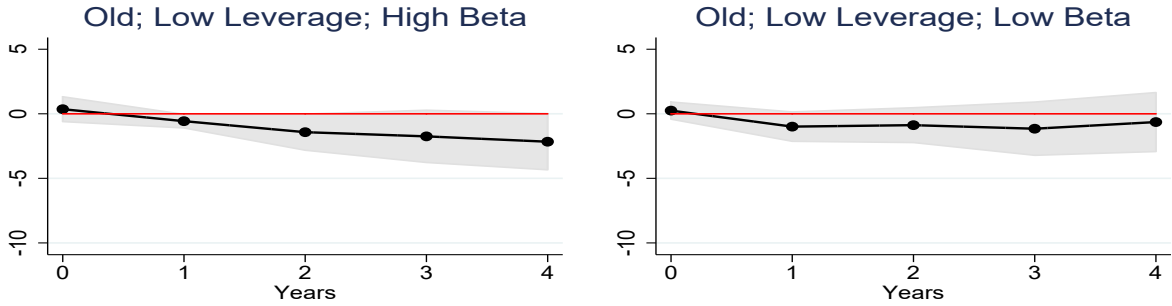

Notes: Firm level responses to a 25bp contractionary monetary policy shock. Black lines are point estimates. Grey shaded area is $90 \%$ confidence interval. The dependent variable is the cumulative growth rate in log points of Employment from $t-1$ to $t+h$ where $t$ is the date of the monetary policy shock and $h$ is the x-axis - see specification 1 . All the responses are \%-deviations.

Figure 34: Relative Effects on Employment by Age, Leverage and Director Beta, Triple Sorted
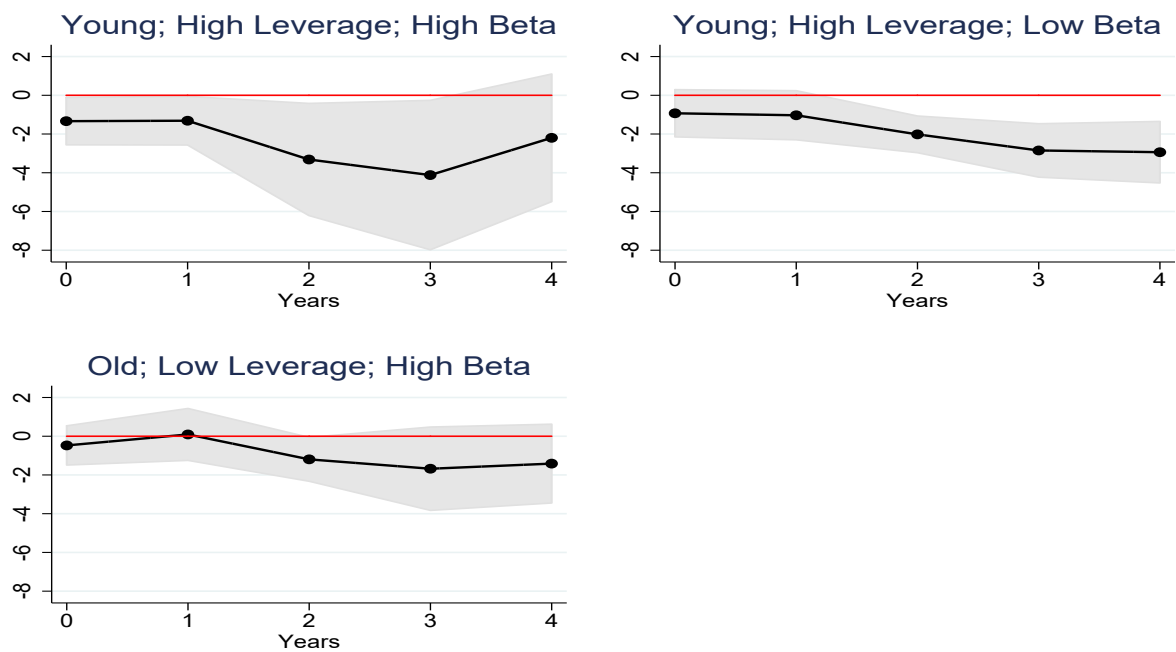

Notes: Firm level responses to a 25bp contractionary monetary policy shock. Black lines are point estimates. Grey shaded area is $90 \%$ confidence interval. The dependent variable is the cumulative growth rate in log points of Employment from $t-1$ to $t+h$ where $t$ is the date of the monetary policy shock and $h$ is the x-axis. All the responses are relative to the group of older and more levered firms in low- $\beta$ region (omitted given the inclusion of industry-month and NUTS1-month fixed effects - see specification 2). 


\section{F.3 Excluding Non-Tradeable Sectors}

Figure 35: Level Effects on Employment by Age, Leverage and Director Beta, Triple Sorted
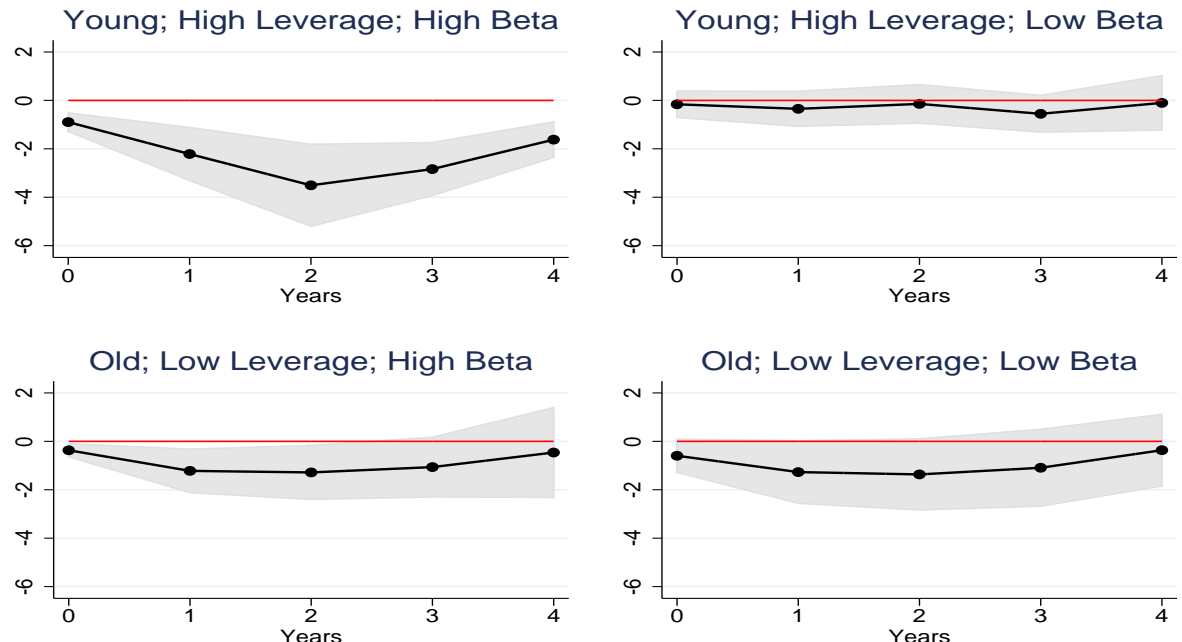

Notes: Firm level responses to a 25bp contractionary monetary policy shock. Black lines are point estimates. Grey shaded area is $90 \%$ confidence interval. The dependent variable is the cumulative growth rate in log points of Employment from $t-1$ to $t+h$ where $t$ is the date of the monetary policy shock and $h$ is the x-axis - see specification 1 . All the responses are \%-deviations. The sample only includes firm operating in the tradeable goods sector.

Figure 36: Relative Effects on Employment on by Age, Leverage and Director Beta, Triple Sorted
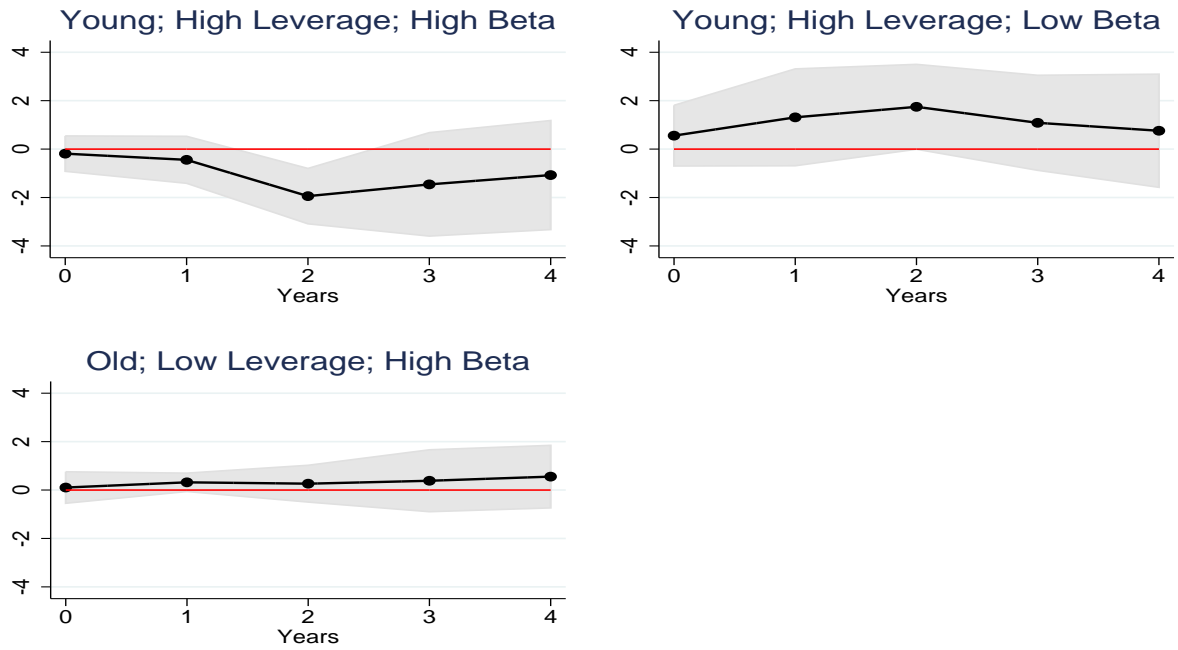

Notes: Firm level responses to a 25bp contractionary monetary policy shock. Black lines are point estimates. Grey shaded area is $90 \%$ confidence interval. The dependent variable is the cumulative growth rate in log points of Employment from $t-1$ to $t+h$ where $t$ is the date of the monetary policy shock and $h$ is the x-axis. All the responses are relative to the group of older and more levered firms in low- $\beta$ region (omitted given the inclusion of industry-month and NUTS1-month fixed effects - see specification 2). The sample only includes firm operating in the tradeable goods sector. 


\section{F.4 Adding Firm Fixed Effects}

Figure 37: Level Effects on Employment by Age, Leverage and Director Beta, Triple Sorted
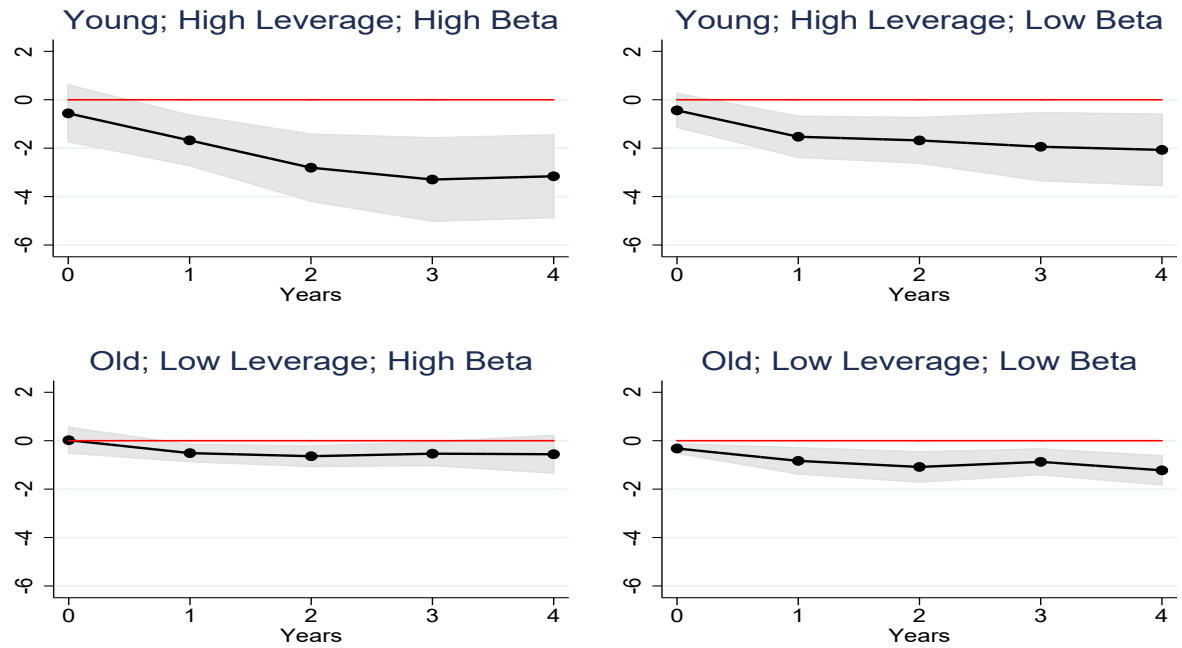

Notes: Firm level responses to a 25bp contractionary monetary policy shock. Black lines are point estimates. Grey shaded area is $90 \%$ confidence interval. The dependent variable is the cumulative growth rate in log points of Employment from $t-1$ to $t+h$ where $t$ is the date of the monetary policy shock and $h$ is the x-axis - see specification 1. All the responses are \%-deviations. All regressions include firm fixed effects. 
Figure 38: Relative Effects on Employment by Age, Leverage and Director Beta, Triple Sorted
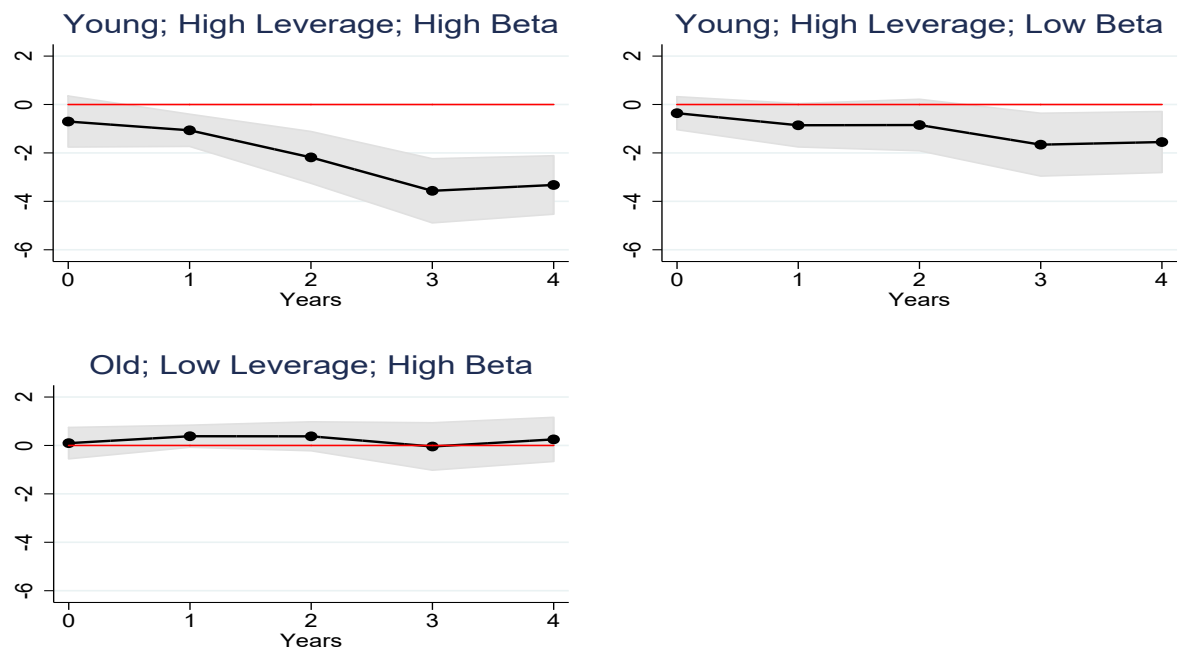

Notes: Firm level responses to a 25bp contractionary monetary policy shock. Black lines are point estimates. Grey shaded area is $90 \%$ confidence interval. The dependent variable is the cumulative growth rate in log points of Employment from $t-1$ to $t+h$ where $t$ is the date of the monetary policy shock and $h$ is the x-axis. All the responses are relative to the group of older and more levered firms in low- $\beta$ region (omitted given the inclusion of industry-month and NUTS1-month fixed effects - see specification 2). All regressions include firm fixed effects.

\section{F.5 Adding Firm Controls}

Figure 39: Level Effects on Employment by Age, Leverage and Director Beta, Triple Sorted
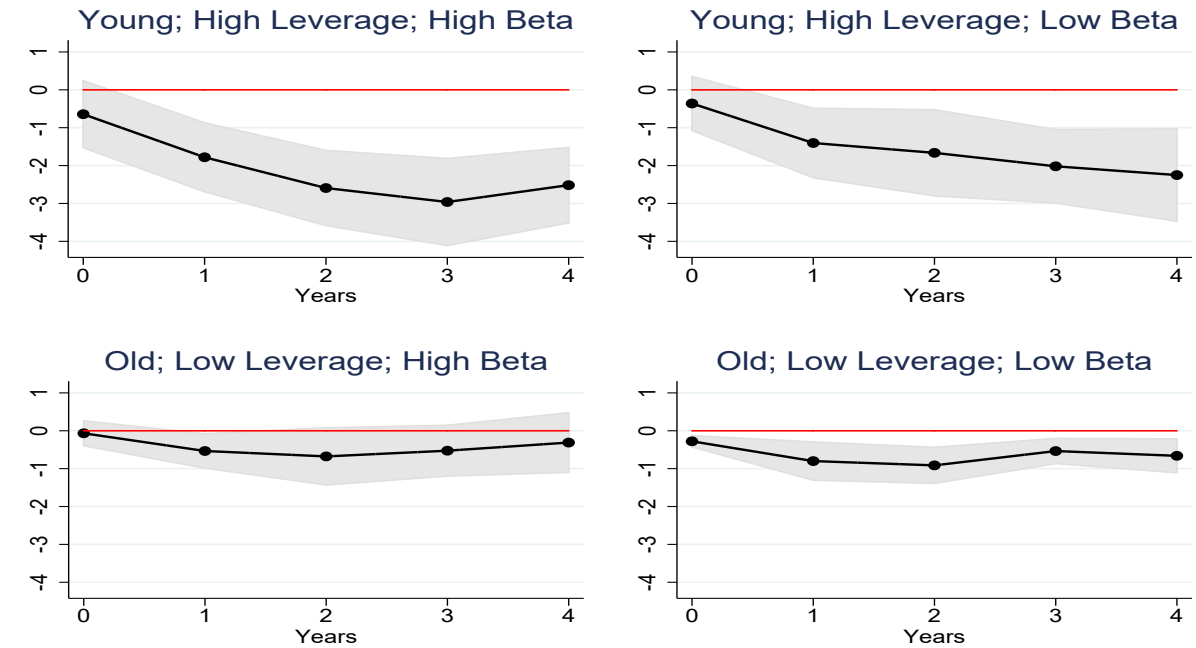

Notes: Firm level responses to a 25bp contractionary monetary policy shock. Black lines are point estimates. Grey shaded area is $90 \%$ confidence interval. The dependent variable is the cumulative growth rate in log points of Employment from $t-1$ to $t+h$ where $t$ is the date of the monetary policy shock and $h$ is the $\mathrm{x}$-axis - see specification 1 . All the responses are \%-deviations. This regression adds a lag of leverage, a lag of log total assets and the lagged ratio of current to total assets to the baseline regression as controls. 
Figure 40: Relative Effects on Employment by Age, Leverage and Director Beta, Triple Sorted
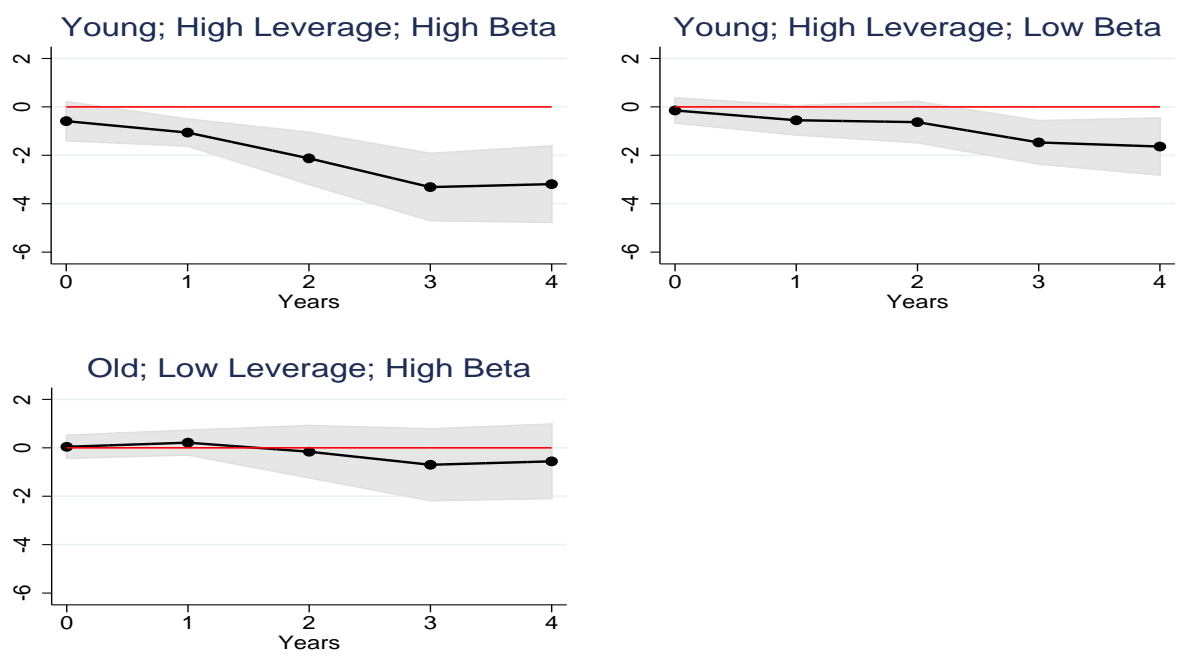

Notes: Firm level responses to a 25bp contractionary monetary policy shock. Black lines are point estimates. Grey shaded area is 90\% confidence interval. The dependent variable is the cumulative growth rate in log points of Employment from $t-1$ to $t+h$ where $t$ is the date of the monetary policy shock and $h$ is the x-axis. All the responses are relative to the group of older and more levered firms in low- $\beta$ region (omitted given the inclusion of industry-month and NUTS1-month fixed effects - see specification 2 ). This regression adds a lag of leverage, a lag of log total assets and the lagged ratio of current to total assets to the baseline regression as controls. 


\section{F.6 Excluding Directors Living In London}

Figure 41: Level Effects on Employment by Age, Leverage and Firm Real Estate Beta, Triple Sorted
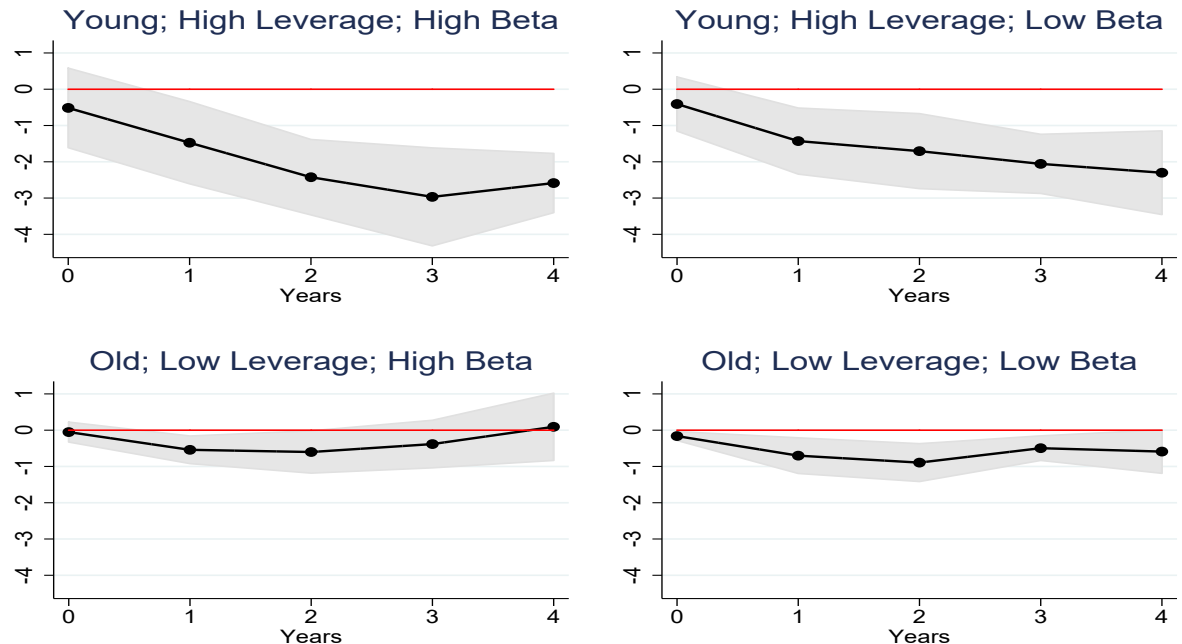

Notes: Firm level responses to a 25bp contractionary monetary policy shock. Black lines are point estimates. Grey shaded area is $90 \%$ confidence interval. The dependent variable is the cumulative growth rate in log points of Employment from $t-1$ to $t+h$ where $t$ is the date of the monetary policy shock and $h$ is the x-axis - see specification 1 . This sample excludes directors living in the 32 boroughs of London when constructing the firm-average of director betas.

Figure 42: Relative Effects on Employment by Age, Leverage and Firm Real Estate Beta, Triple Sorted
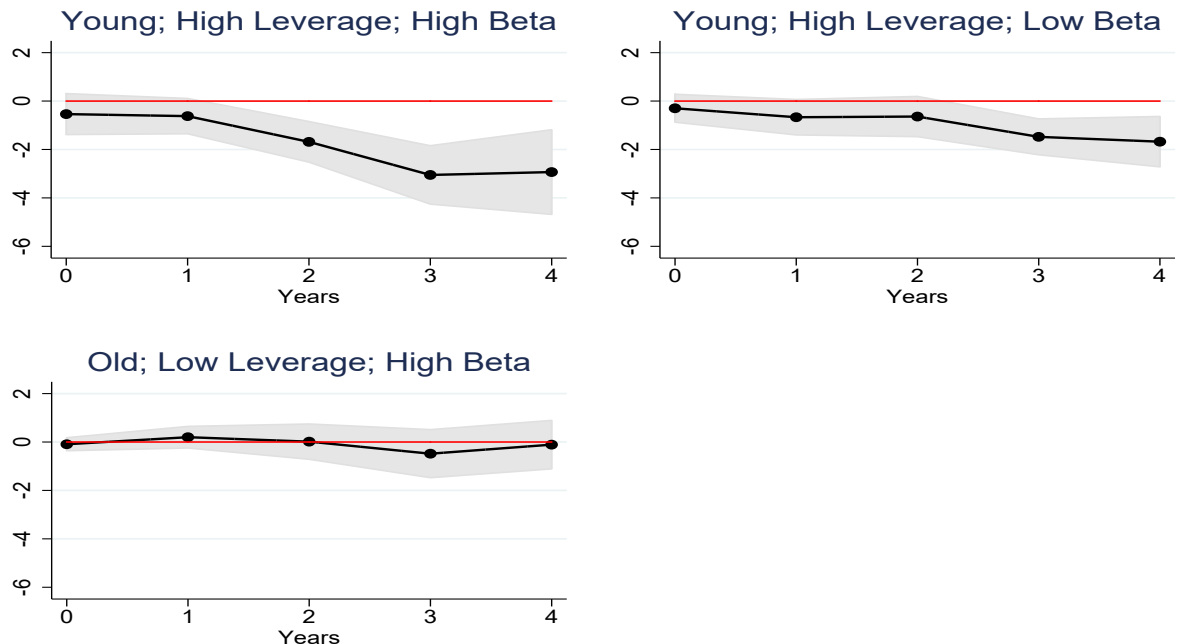

Notes: Firm level responses to a 25bp contractionary monetary policy shock. Black lines are point estimates. Grey shaded area is $90 \%$ confidence interval. The dependent variable is the cumulative growth rate in log points of Employment from $t-1$ to $t+h$ where $t$ is the date of the monetary policy shock and $h$ is the x-axis. All the responses are relative to the group of older and more levered firms in low- $\beta$ region (omitted given the inclusion of industry-month and NUTS1-month fixed effects - see specification 2). This sample excludes directors living in the 32 boroughs of London when constructing the firm-average of director betas. 


\section{F.7 Adding Bank-Year Fixed Effects}

Figure 43: Relative Effects on Employment by Age, Leverage and Director Beta, Triple Sorted
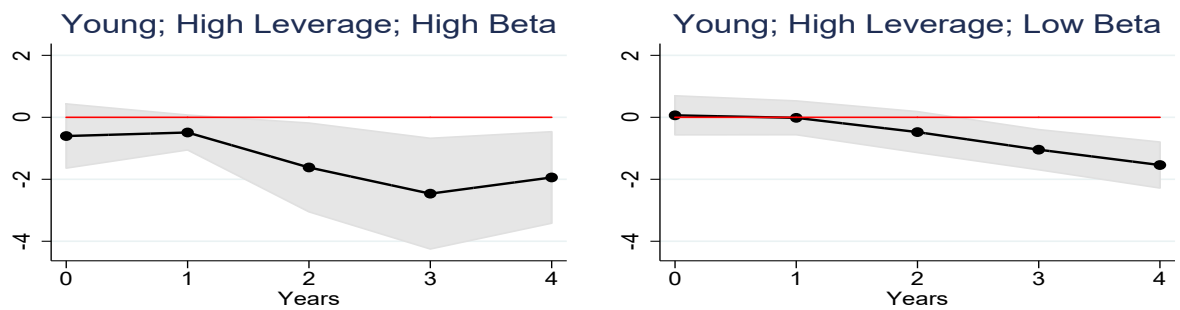

Old; Low Leverage; High Beta

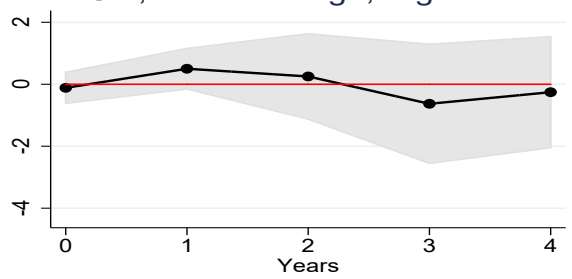

Notes: Firm level responses to a 25bp contractionary monetary policy shock. Black lines are point estimates. Grey shaded area is $90 \%$ confidence interval. The dependent variable is the cumulative growth rate in log points of Employment from $t-1$ to $t+h$ where $t$ is the date of the monetary policy shock and $h$ is the x-axis. All the responses are relative to the group of older and more levered firms in low- $\beta$ region (omitted given the inclusion of industry-month and NUTS1-month and bank-year fixed effects - see specification 2). 


\section{G Robustness: Measurement and Selection}

\section{G.1 Using Refusal Rates}

Figure 44: Level Employment Effects by Age, Leverage and Director Region Refusal Rates, Triple Sorted
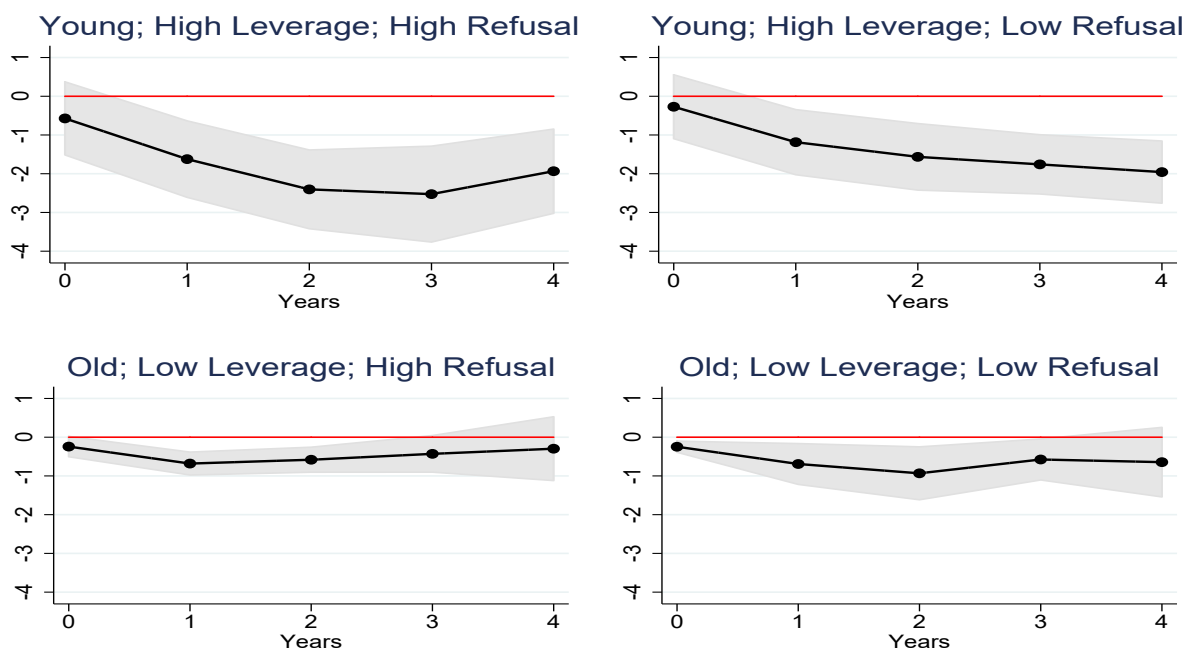

Notes: Firm level responses to a 25bp contractionary monetary policy shock. Black lines are point estimates. Grey shaded area is $90 \%$ confidence interval. The dependent variable is the cumulative growth rate in log points of Employment from $t-1$ to $t+h$ where $t$ is the date of the monetary policy shock and $h$ is the x-axis - see specification 1 . All the responses are \%-deviations. 
Figure 45: Relative Employment Effects by Age, Leverage and Director Region Refusal Rate, Triple Sorted
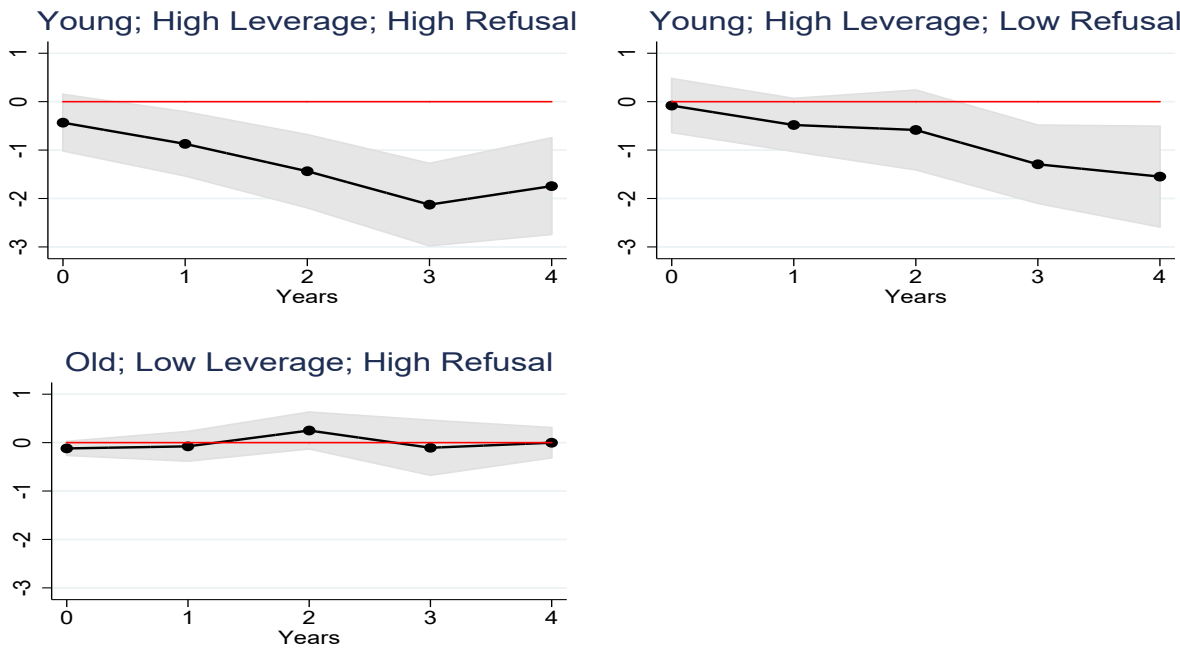

Notes: Firm level responses to a 25bp contractionary monetary policy shock. Black lines are point estimates. Grey shaded area is $90 \%$ confidence interval. The dependent variable is the cumulative growth rate in log points of Employment from $t-1$ to $t+h$ where $t$ is the date of the monetary policy shock and $h$ is the x-axis. All the responses are relative to the group of older and more levered firms in low refusal rate region (omitted given the inclusion of industry-month and NUTS1-month fixed effects - see specification 2).

\section{G.2 Exposure}

Figure 46: Level Effects on Employment by Age, Leverage and Director Housing Exposure, Triple Sorted
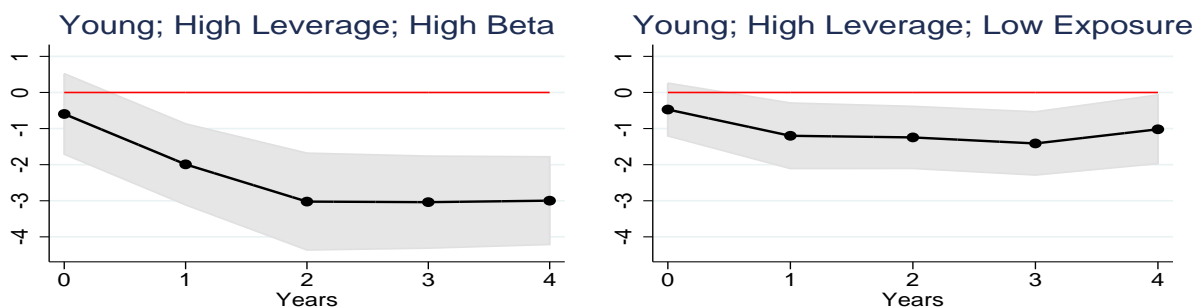

Old; Low Leverage; High Exposure
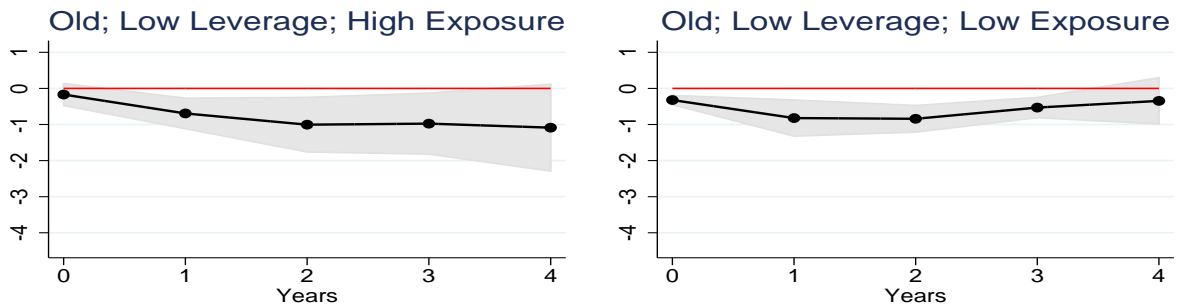

Notes: Firm level responses to a 25bp contractionary monetary policy shock. Black lines are point estimates. Grey shaded area is $90 \%$ confidence interval. The dependent variable is the cumulative growth rate in log points of Employment from $t-1$ to $t+h$ where $t$ is the date of the monetary policy shock and $h$ is the x-axis - see specification 1 . All the responses are \%-deviations. 
Figure 47: Relative Effects on Employment by Age, Leverage and Director Housing Exposure, Triple Sorted
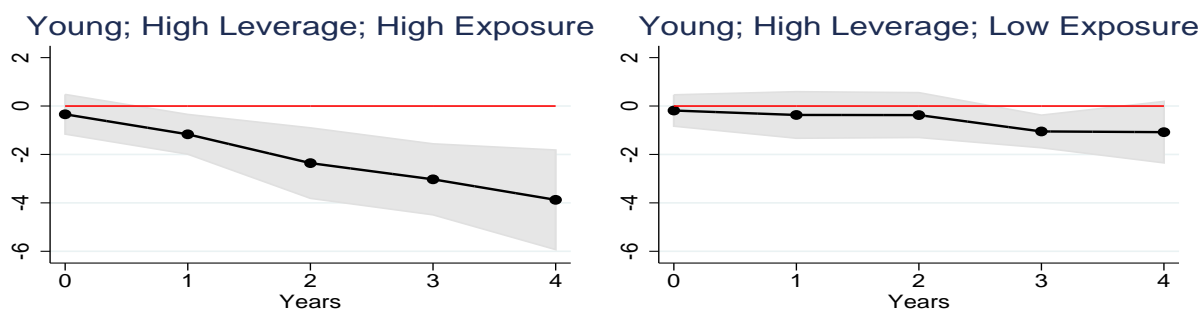

Old; Low Leverage; High Exposure

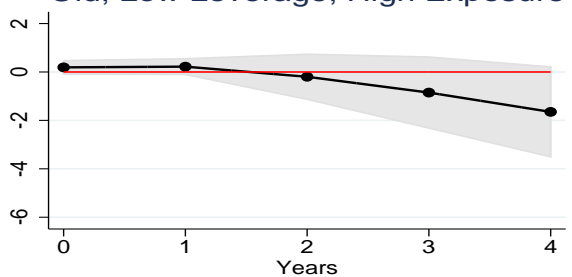

Notes: Firm level responses to a 25bp contractionary monetary policy shock. Black lines are point estimates. Grey shaded area is $90 \%$ confidence interval. The dependent variable is the cumulative growth rate in log points of Employment from $t-1$ to $t+h$ where $t$ is the date of the monetary policy shock and $h$ is the x-axis. All the responses are relative to the group of older and more levered firms in low housing exposure region (omitted given the inclusion of industry-month and NUTS1-month fixed effects - see specification 2). 


\section{G.3 Firm Region Responsiveness}

Figure 48: Level Effects on Employment by Age, Leverage and Firm Real Estate Beta, Triple Sorted
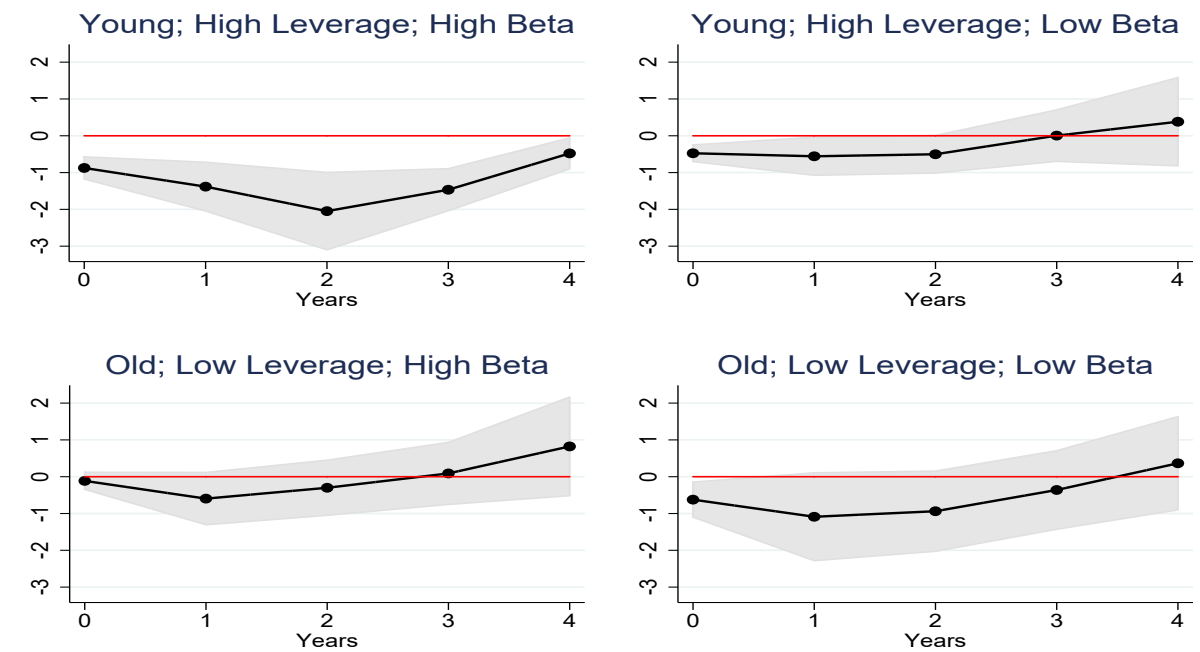

Notes: Firm level responses to a 25bp contractionary monetary policy shock. Black lines are point estimates. Grey shaded area is $90 \%$ confidence interval. The dependent variable is the cumulative growth rate in log points of Employment from $t-1$ to $t+h$ where $t$ is the date of the monetary policy shock and $h$ is the x-axis - see specification 1 . All the responses are \%-deviations. The sample is restricted to firms in the tradeables sector, and $\beta$ s are measured based on the firm location (instead of the firm's directors' location. 
Figure 49: Relative Effects on Employment by Age, Leverage and Firm Real Estate Beta, Triple Sorted
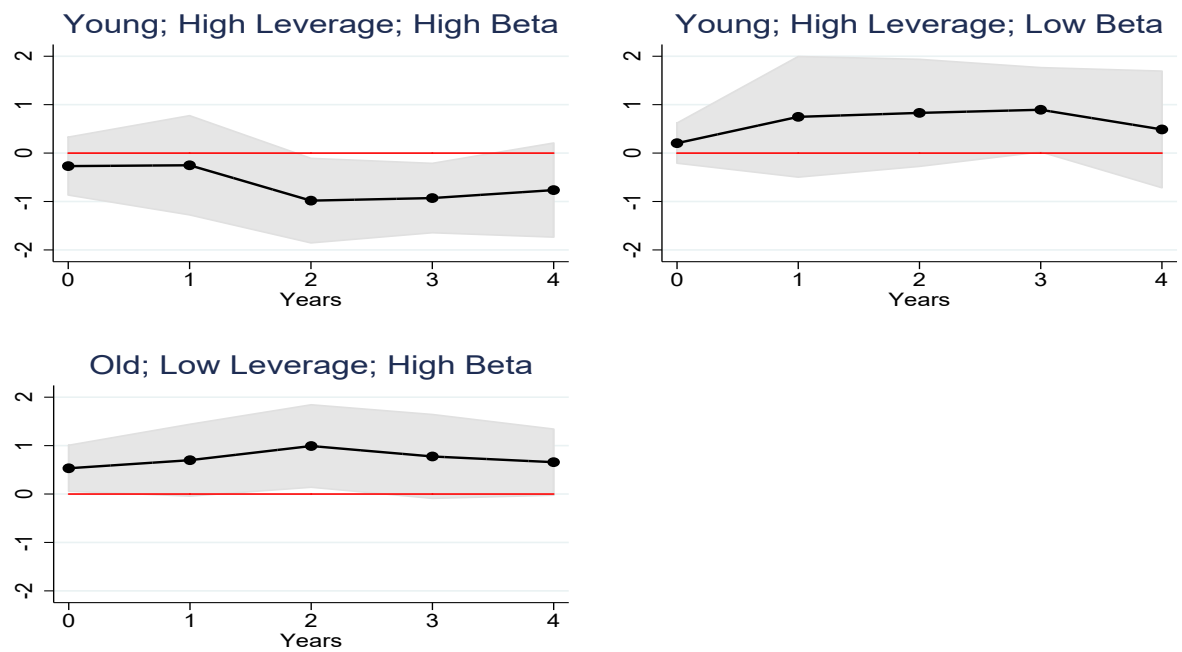

Notes: Firm level responses to a 25bp contractionary monetary policy shock. Black lines are point estimates. Grey shaded area is $90 \%$ confidence interval. The dependent variable is the cumulative growth rate in log points of Employment from $t-1$ to $t+h$ where $t$ is the date of the monetary policy shock and $h$ is the x-axis. All the responses are relative to the group of older and more levered firms in low- $\beta$ region (omitted given the inclusion of industry-month and NUTS1-month fixed effects - see specification 2). The sample is restricted to firms in the tradeables sector, and $\beta \mathrm{s}$ are measured based on the firm location (instead of the firm's directors' location).

\section{G.4 Excluding Zero Lower Bound Period}

Figure 50: Level Effects on Employment by Age, Leverage and Director Beta, Triple Sorted
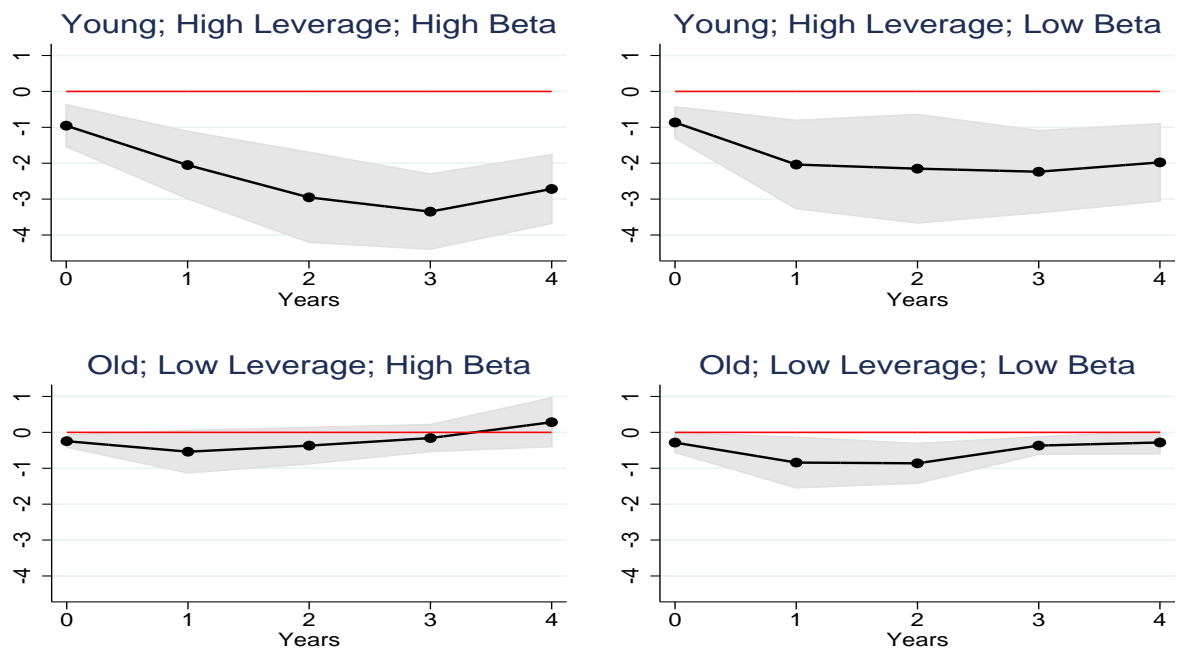

Notes: Firm level responses to a 25bp contractionary monetary policy shock. Black lines are point estimates. Grey shaded area is $90 \%$ confidence interval. The dependent variable is the cumulative growth rate in log points of Employment from $t-1$ to $t+h$ where $t$ is the date of the monetary policy shock and $h$ is the x-axis - see specification 1 . All the responses are \%-deviations. The estimation excludes the period post-2008. 
Figure 51: Relative Effects on Employment by Age, Leverage and Director Beta, Triple Sorted
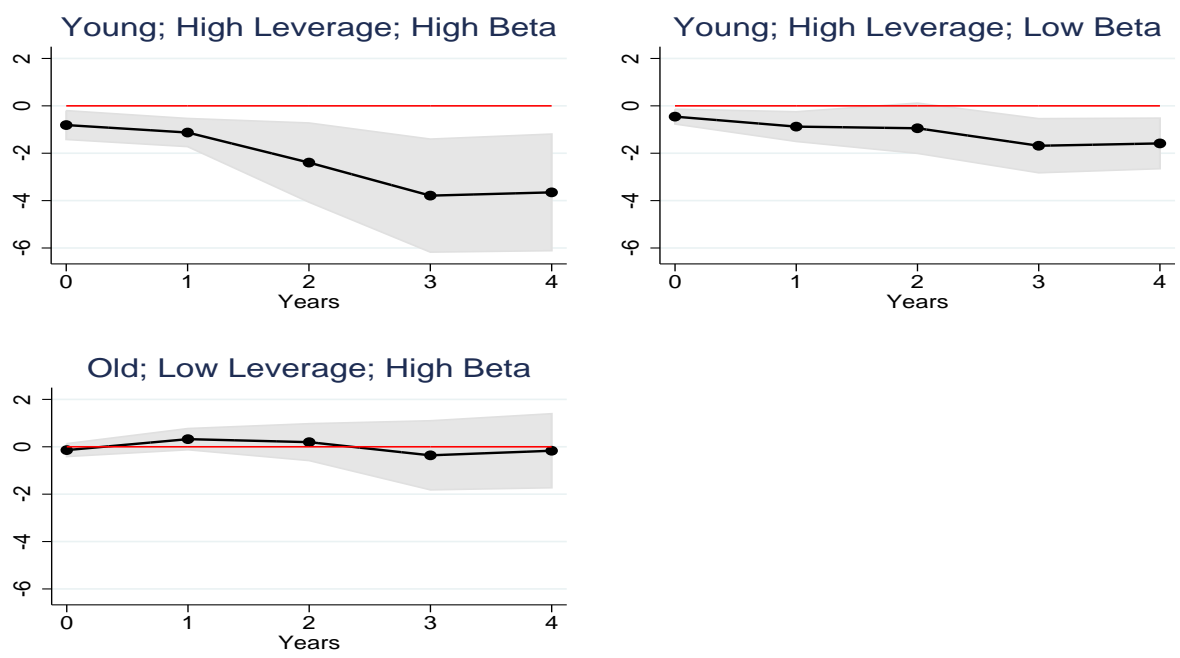

Notes: Firm level responses to a 25bp contractionary monetary policy shock. Black lines are point estimates. Grey shaded area is $90 \%$ confidence interval. The dependent variable is the cumulative growth rate in log points of Employment from $t-1$ to $t+h$ where $t$ is the date of the monetary policy shock and $h$ is the x-axis. All the responses are relative to the group of older and more levered firms in low- $\beta$ region (omitted given the inclusion of industry-month and NUTS1-month fixed effects - see specification 2). The estimation excludes the period post-2008. 


\section{G.5 Using Credit Score As Alternative To Leverage}

Figure 52: Level Effects on Employment by Age, Credit Score and Director Beta, Triple Sorted
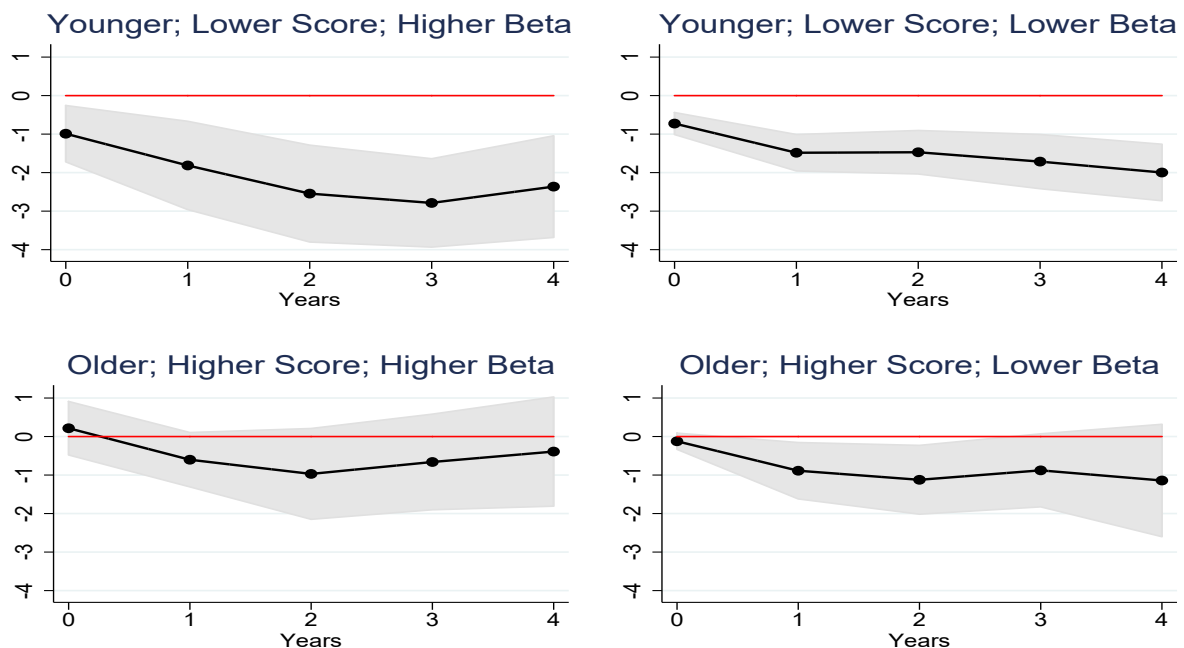

Notes: Firm level responses to a 25bp contractionary monetary policy shock. Black lines are point estimates. Grey shaded area is $90 \%$ confidence interval. The dependent variable is the cumulative growth rate in log points of Employment from $t-1$ to $t+h$ where $t$ is the date of the monetary policy shock and $h$ is the x-axis - see specification 1. All the responses are \%-deviations. Younger is defined as less than 15 years old, and higher score is defined as credit score above 60.

Figure 53: Relative Effects on Employment by Age, Credit Score and Director Beta, Triple Sorted
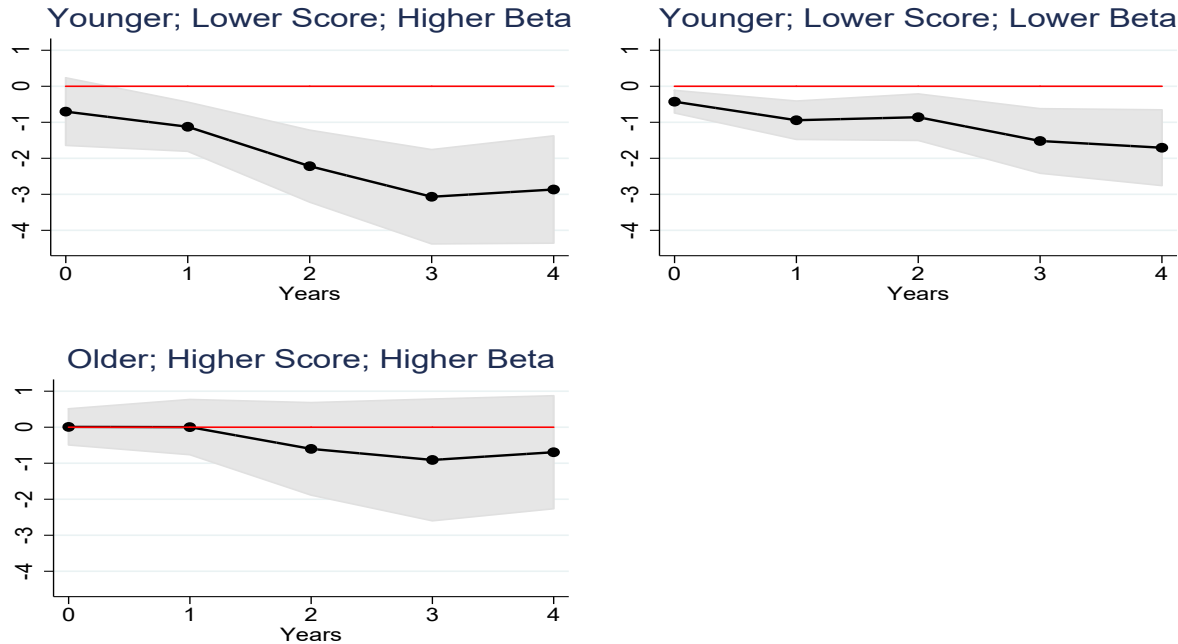

Notes: Firm level responses to a 25bp contractionary monetary policy shock. Black lines are point estimates. Grey shaded area is $90 \%$ confidence interval. The dependent variable is the cumulative growth rate in log points of Employment from $t-1$ to $t+h$ where $t$ is the date of the monetary policy shock and $h$ is the x-axis. All the responses are relative to the group of older and higher credit score firms in low- $\beta$ region (omitted given the inclusion of industry-month and NUTS1-month fixed effects - see specification 2 ). Younger is defined as less than 15 years old, and higher score is defined as credit score above 60. 


\section{G.6 Alternative Firm Age Cut at 5 Years Old}

Figure 54: Level Effects on Employment by Age, Leverage and Director Beta, Triple Sorted
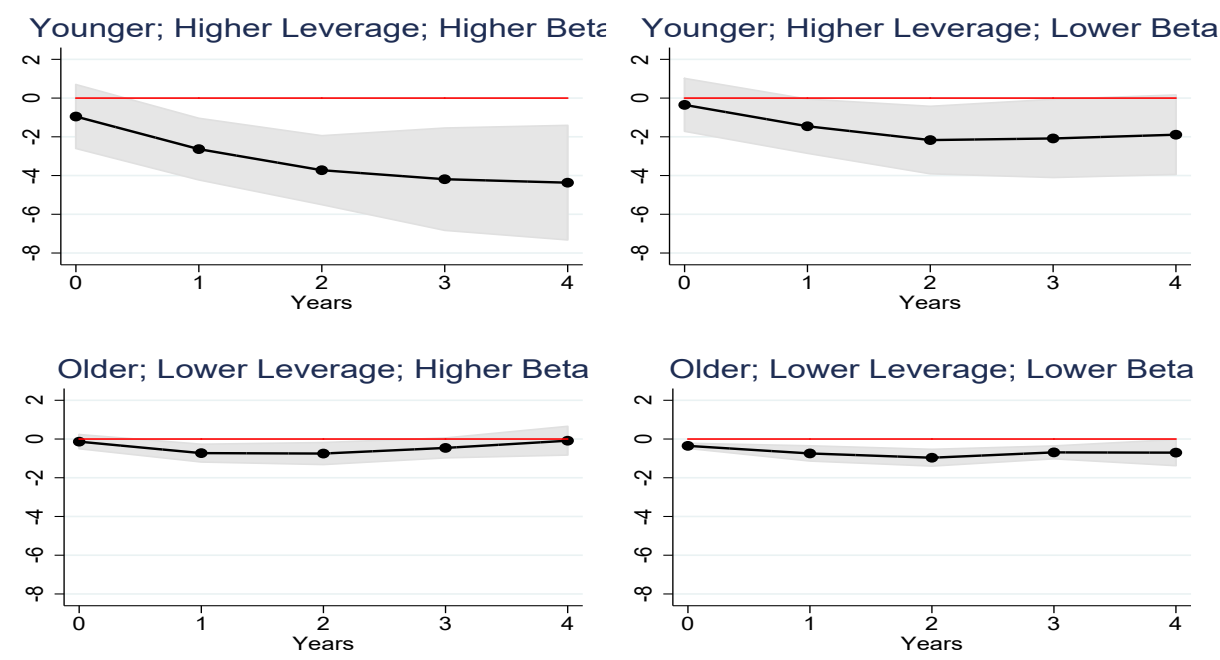

Notes: Firm level responses to a 25bp contractionary monetary policy shock. Black lines are point estimates. Grey shaded area is $90 \%$ confidence interval. The dependent variable is the cumulative growth rate in log points of Employment from $t-1$ to $t+h$ where $t$ is the date of the monetary policy shock and $h$ is the x-axis - see specification 1 . All the responses are \%-deviations. Younger is defined as less than 5 years old, and higher leverage is defined as above the median firm leverage by year. 

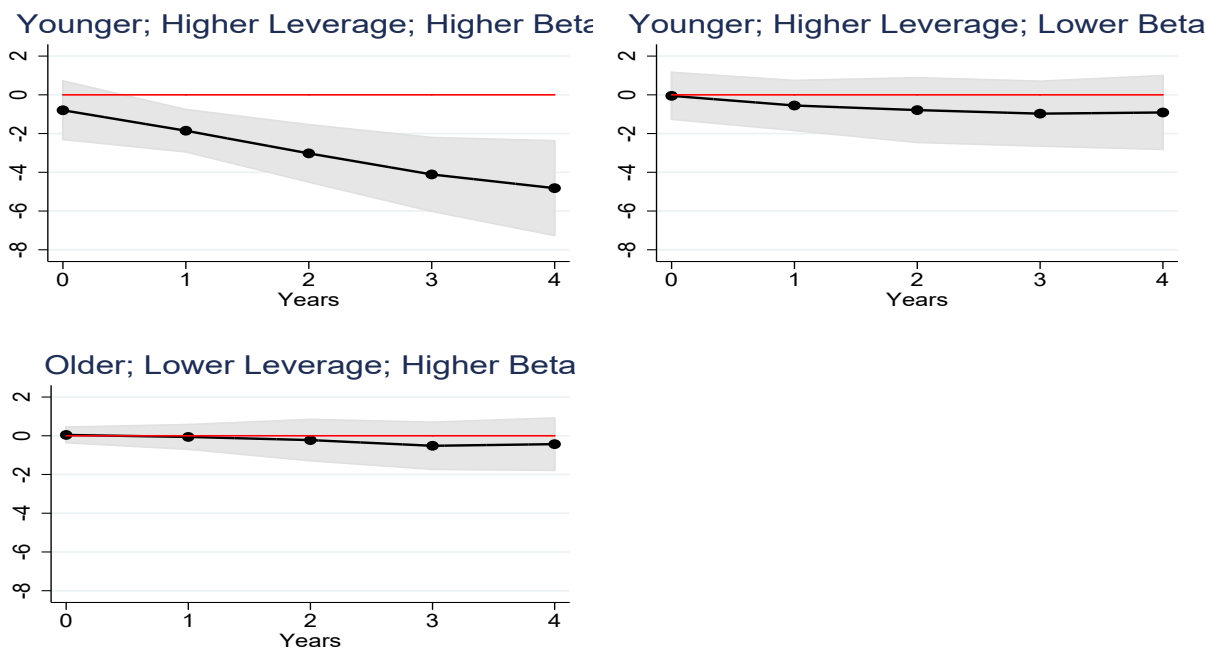

Notes: Firm level responses to a 25bp contractionary monetary policy shock. Black lines are point estimates. Grey shaded area is $90 \%$ confidence interval. The dependent variable is the cumulative growth rate in log points of Employment from $t-1$ to $t+h$ where $t$ is the date of the monetary policy shock and $h$ is the x-axis. All the responses are relative to the group of older and more levered firms in low- $\beta$ region (omitted given the inclusion of industry-month and NUTS1-month fixed effects - see specification 2). Younger is defined as less than 5 years old, and higher leverage is defined as above the median firm leverage by year.

\section{G.7 Restricting to SMEs}

Figure 56: Level Effects on Employment by Age, Leverage and Director Beta, Triple Sorted
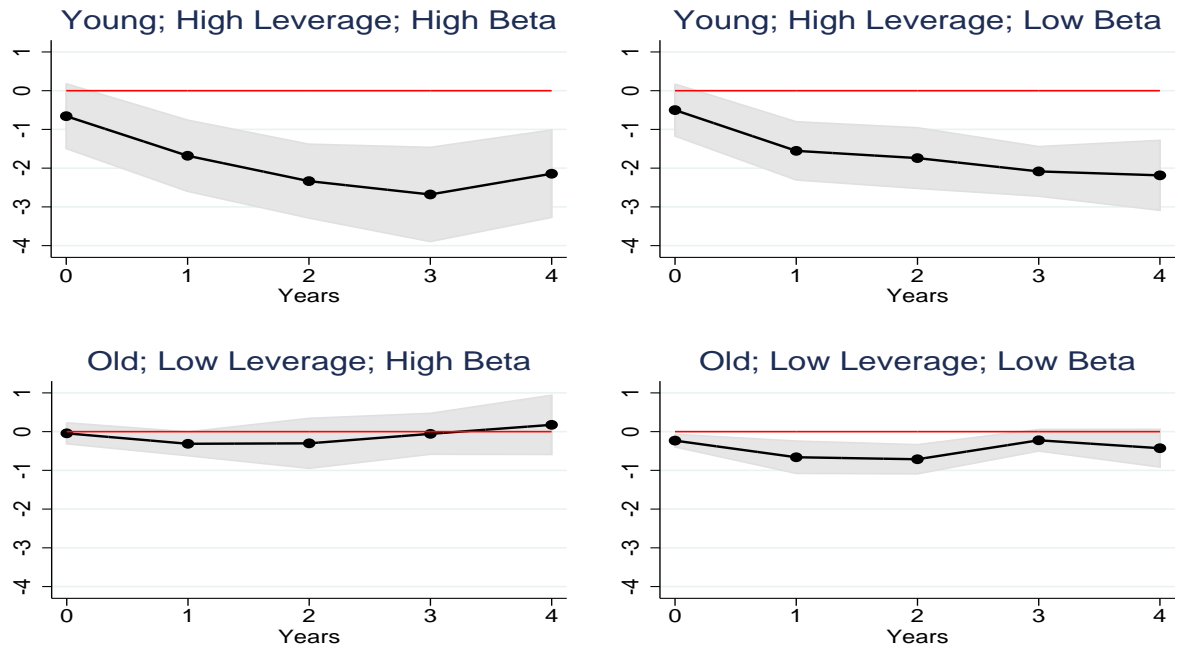

Notes: Firm level responses to a 25bp contractionary monetary policy shock. Black lines are point estimates. Grey shaded area is $90 \%$ confidence interval. The dependent variable is the cumulative growth rate in log points of Employment from $t-1$ to $t+h$ where $t$ is the date of the monetary policy shock and $h$ is the x-axis - see specification 1 . All the responses are \%-deviations. The sample excludes firms with more than 250 employees. 
Figure 57: Relative Effects on Employment by Age, Leverage and Director Beta, Triple Sorted
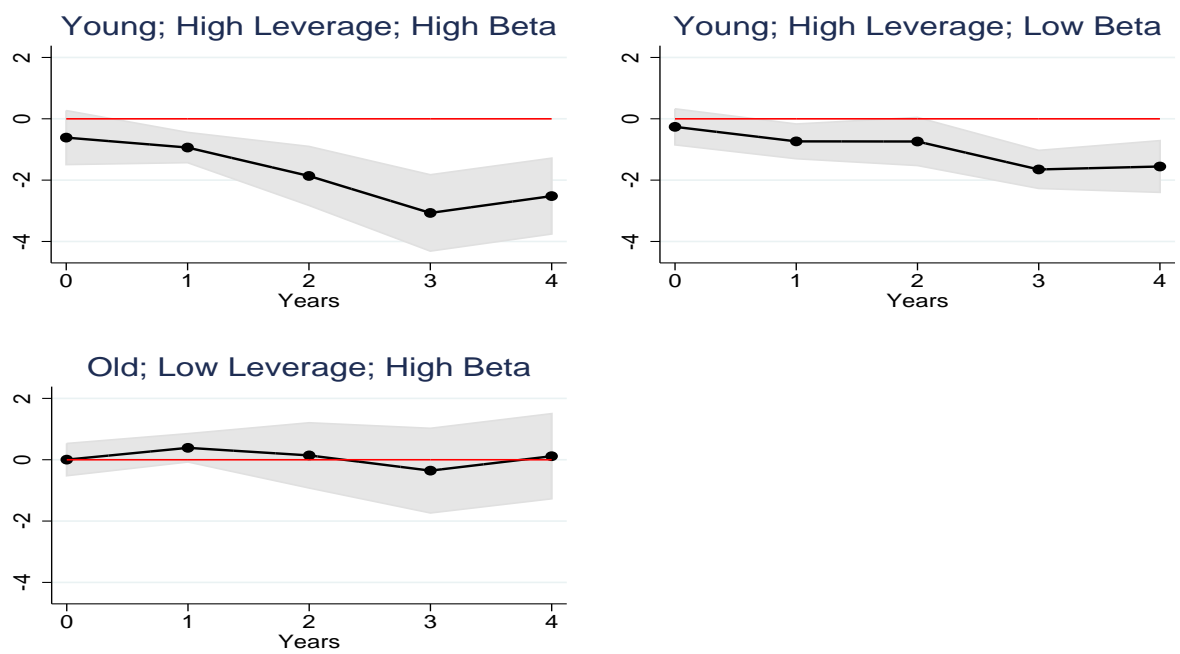

Notes: Firm level responses to a 25bp contractionary monetary policy shock. Black lines are point estimates. Grey shaded area is $90 \%$ confidence interval. The dependent variable is the cumulative growth rate in log points of Employment from $t-1$ to $t+h$ where $t$ is the date of the monetary policy shock and $h$ is the x-axis. All the responses are relative to the group of older and more levered firms in low- $\beta$ region (omitted given the inclusion of industry-month and NUTS1-month fixed effects - see specification 2). The sample excludes firms with more than 250 employees. 


\section{H Alternative Dependent Variables}

\section{H.1 Total Debt}

Figure 58: Relative Effect on Total Debt by Age, Leverage and Director Beta, Triple Sorted
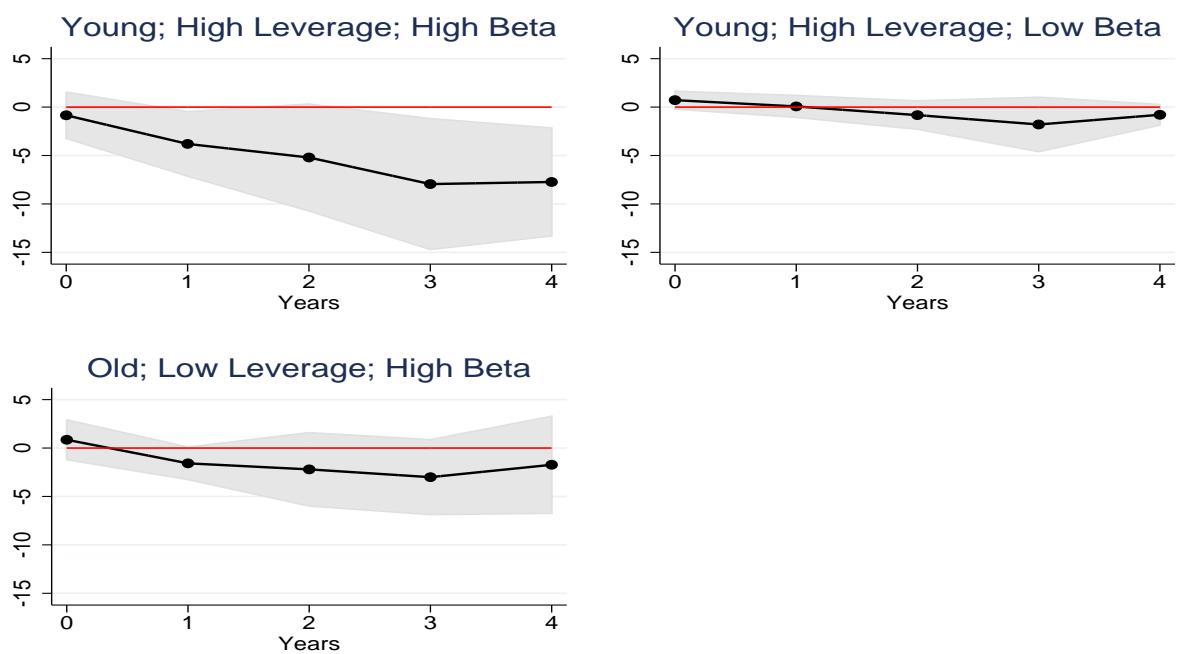

Notes: Firm level responses to a 25bp contractionary monetary policy shock. Black lines are point estimates. Grey shaded area is $90 \%$ confidence interval. The dependent variable is the cumulative growth rate in log points of Total Debt from $t-1$ to $t+h$ where $t$ is the date of the monetary policy shock and $h$ is the x-axis. All the responses are relative to the group of older and more levered firms in low- $\beta$ region (omitted given the inclusion of industry-month and NUTS1-month fixed effects - see specification 2). 


\section{H.2 Current Assets}

Figure 59: Relative Effect on Current Assets by Age, Leverage and Director Beta, Triple Sorted
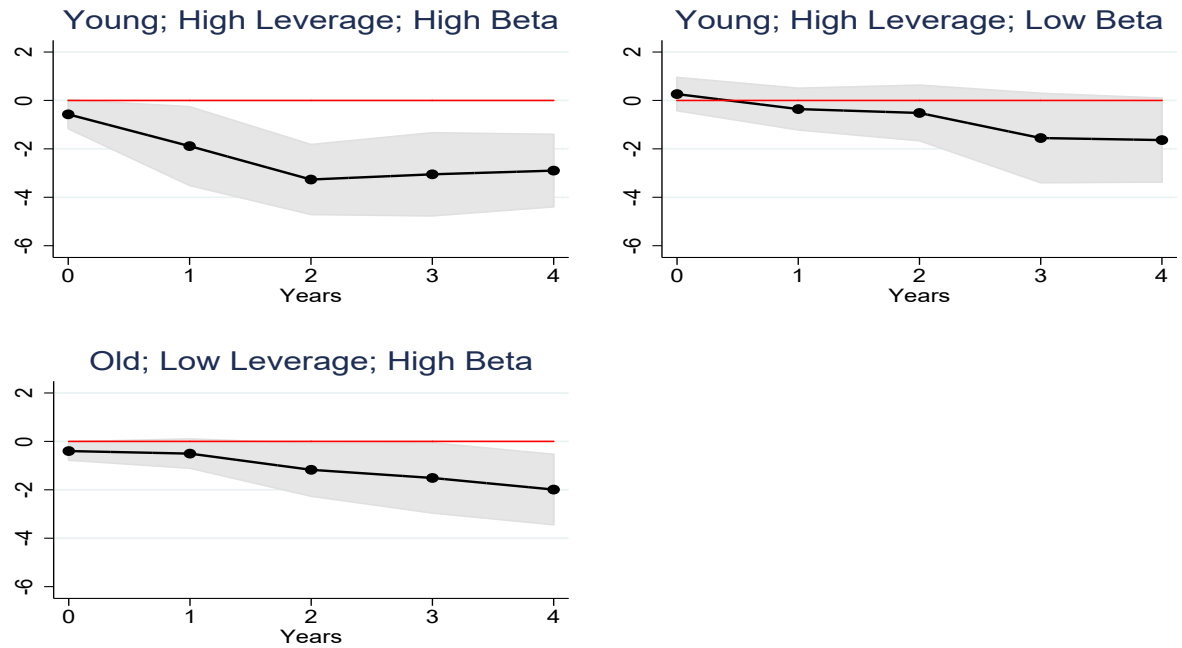

Notes: Firm level responses to a 25bp contractionary monetary policy shock. Black lines are point estimates. Grey shaded area is $90 \%$ confidence interval. The dependent variable is the cumulative growth rate in log points of Current Assets from $t-1$ to $t+h$ where $t$ is the date of the monetary policy shock and $h$ is the x-axis. All the responses are relative to the group of older and more levered firms in low- $\beta$ region (omitted given the inclusion of industry-month and NUTS1-month fixed effects - see specification 2).

\section{H.3 Fixed Assets}

Figure 60: Relative Effect on Fixed Assets by Age, Leverage and Director Beta, Triple Sorted
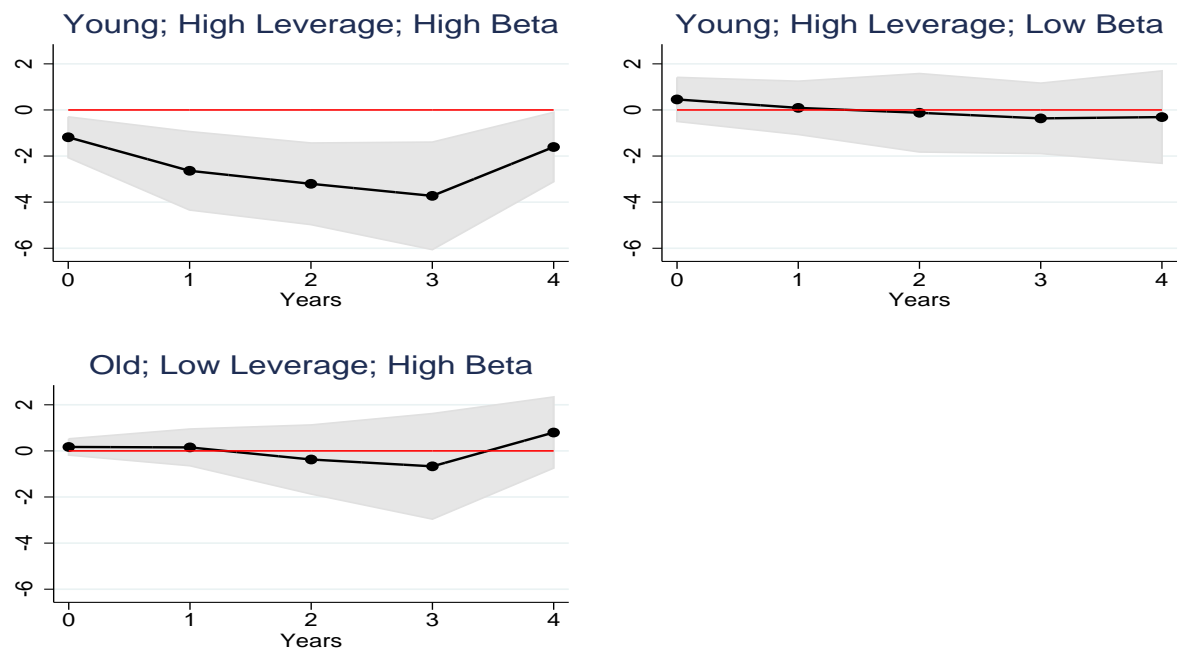

Notes: Firm level responses to a 25bp contractionary monetary policy shock. Black lines are point estimates. Grey shaded area is $90 \%$ confidence interval. The dependent variable is the cumulative growth rate in log points of Fixed Assets from $t-1$ to $t+h$ where $t$ is the date of the monetary policy shock and $h$ is the x-axis. All the responses are relative to the group of older and more levered firms in low- $\beta$ region (omitted given the inclusion of industry-month and NUTS1-month fixed effects - see specification 2). 


\section{H.4 Turnover}

Figure 61: Relative Effect on Turnover by Age, Leverage and Director Beta, Triple Sorted
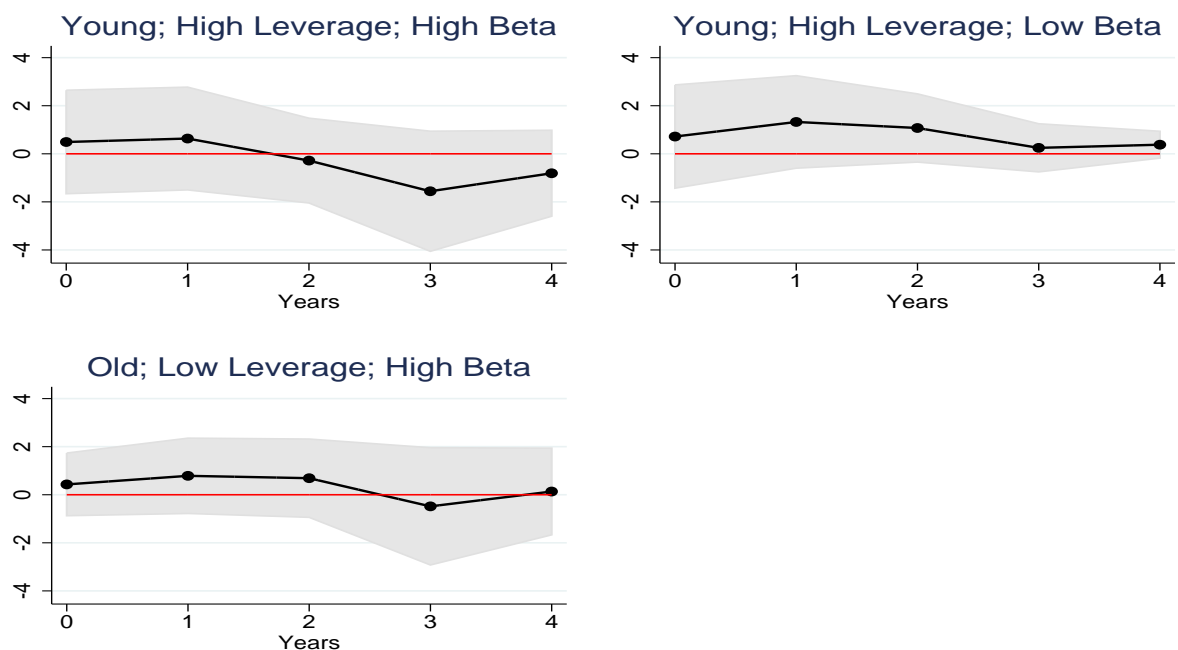

Notes: Firm level responses to a 25bp contractionary monetary policy shock. Black lines are point estimates. Grey shaded area is $90 \%$ confidence interval. The dependent variable is the cumulative growth rate in log points of Turnover from $t-1$ to $t+h$ where $t$ is the date of the monetary policy shock and $h$ is the x-axis. All the responses are relative to the group of older and more levered firms in low- $\beta$ region (omitted given the inclusion of industry-month and NUTS1-month fixed effects - see specification 2). 